\title{
Essays on financial decision making
}

Citation for published version (APA):

Gerhard, P. (2019). Essays on financial decision making: how households save, invest, and dissave.

[Doctoral Thesis, Maastricht University]. Maastricht University. https://doi.org/10.26481/dis.20190606pg

Document status and date:

Published: 01/01/2019

DOI:

10.26481/dis.20190606pg

Document Version:

Publisher's PDF, also known as Version of record

\section{Please check the document version of this publication:}

- A submitted manuscript is the version of the article upon submission and before peer-review. There can be important differences between the submitted version and the official published version of record.

People interested in the research are advised to contact the author for the final version of the publication, or visit the DOI to the publisher's website.

- The final author version and the galley proof are versions of the publication after peer review.

- The final published version features the final layout of the paper including the volume, issue and page numbers.

Link to publication

\footnotetext{
General rights rights.

- You may freely distribute the URL identifying the publication in the public portal. please follow below link for the End User Agreement:

www.umlib.nl/taverne-license

Take down policy

If you believe that this document breaches copyright please contact us at:

repository@maastrichtuniversity.nl

providing details and we will investigate your claim.
}

Copyright and moral rights for the publications made accessible in the public portal are retained by the authors and/or other copyright owners and it is a condition of accessing publications that users recognise and abide by the legal requirements associated with these

- Users may download and print one copy of any publication from the public portal for the purpose of private study or research.

- You may not further distribute the material or use it for any profit-making activity or commercial gain

If the publication is distributed under the terms of Article $25 \mathrm{fa}$ of the Dutch Copyright Act, indicated by the "Taverne" license above, 
Essays on Financial Decision Making:

How Households Save, Invest, and Dissave

Patrick Gerhard 
Essays on Financial Decision Making: How Households Save, Invest, and Dissave

(C) Patrick Gerhard, Maastricht 2019

All rights reserved. No part of this publication may be reproduced, stored in a retrieval system or transmitted, in any form, or by any means, electronic, mechanical, photocopying, recording or otherwise, without the prior permission in writing by the author.

ISBN: 978-90-829801-9-6

Cover design by: J. Bukovski

Printed by: Impress OOD, Varna, Bulgaria 


\title{
Essays on Financial Decision Making: How Households Save, Invest, and Dissave
}

\author{
Dissertation
}

To obtain the degree of Doctor at Maastricht University, on the authority of the Rector Magnificus Prof. dr. Rianne M. Letschert

in accordance with the decision of the Board of Deans, to be defended in public

on Thursday 06 June 2019, at 10.00 hours

by

Patrick Gerhard 
Supervisors:

Prof. Dr. Piet Eichholtz

Prof. Dr. Arvid Hoffmann (University of Adelaide)

Dr. Thomas Post

Assessment Committee:

Prof. Dr. Joost Pennings, Chair

Prof. Dr. Elisabeth Brüggen

Prof. Dr. Martijn van den Assem (Vrije Universiteit Amsterdam)

Dr. Caezilia Loibl (Ohio State University) 
Let's start with a plan.

- To my dad. 



\section{Contents}

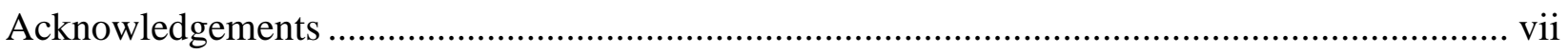

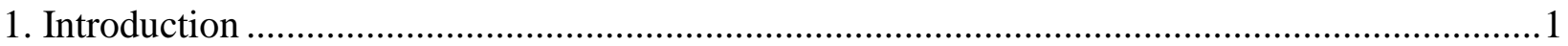

2. Psychological Characteristics and Household Savings Behavior ...............................................

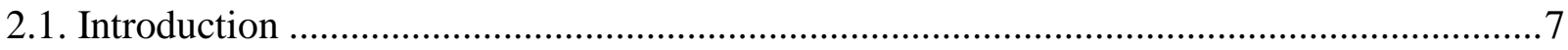

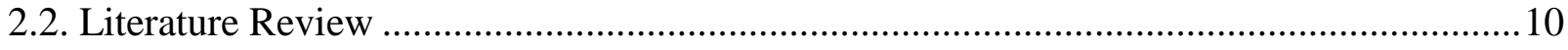

2.2.1. Interactions between Psychological Characteristics and Demographics ......................10

2.2.2. Household Characteristics: Financial Literacy ............................................................12

2.2.3. Personality Traits: The 'Big Five' ...............................................................................12

2.2.4. Personality Traits: Self-Control ............................................................................

2.2.5. Personality Traits: Optimism ...............................................................................

2.2.6. Personality Traits: Attitude towards Savings ............................................................15

2.2.7. Saving motives: Promotion versus Prevention Regulatory Focus .................................15

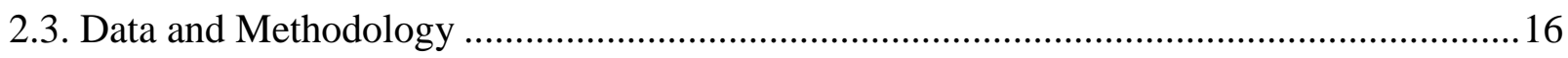

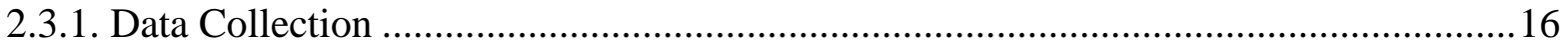

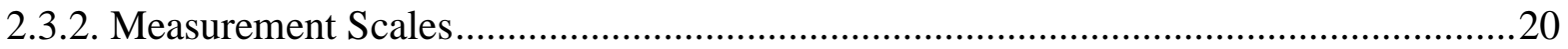

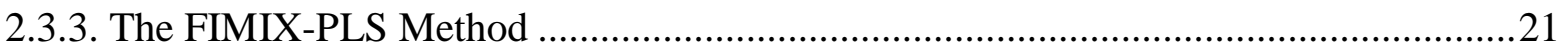

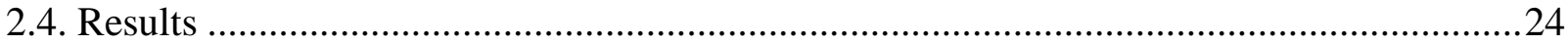

2.4.1. Latent Heterogeneity and Total Household Savings...................................................24

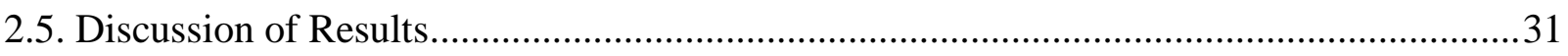

2.6. Implications and Conclusion ..........................................................................................

3. Past Performance Framing and Investors' Belief Updating ............................................................

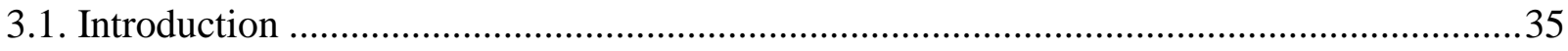

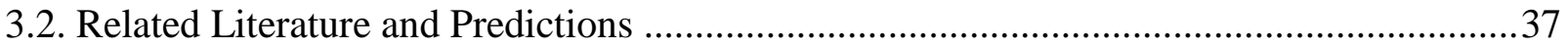

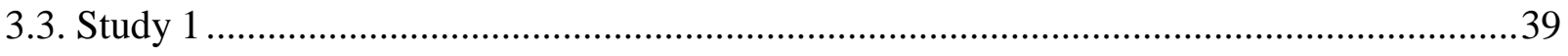

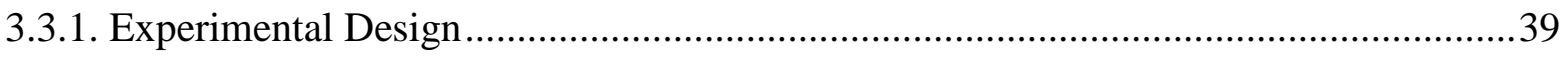

3.3.2. Descriptive Statistics and Data Quality ………..........................................................

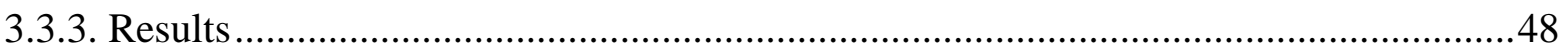




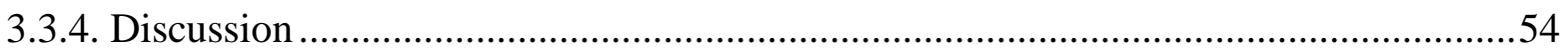

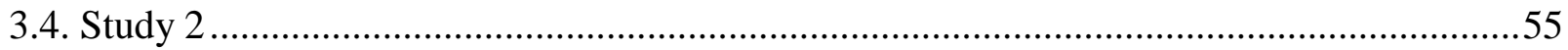

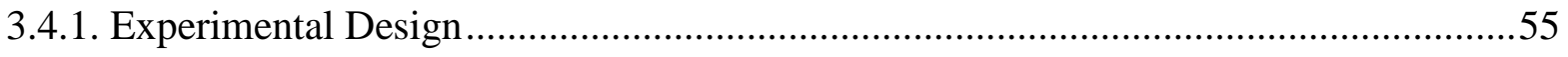

3.4.2. Descriptive Statistics and Data Quality ………………..........................................56

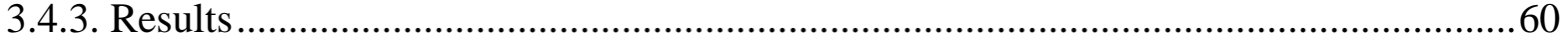

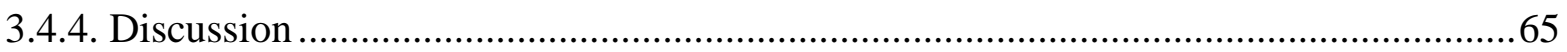

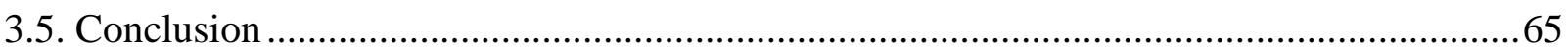

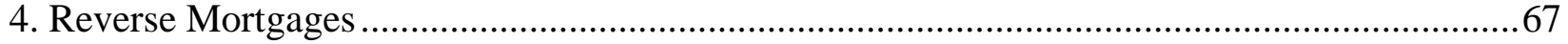

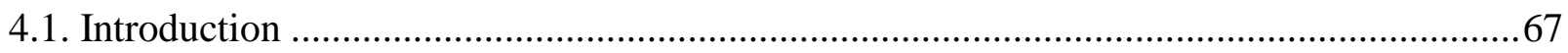

4.2. Reverse Mortgages and the U.S. HECM Program …………...........................................70

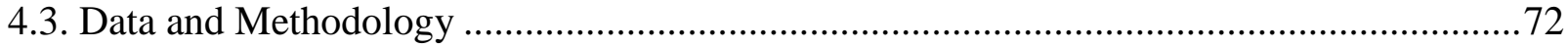

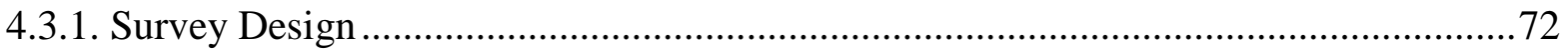

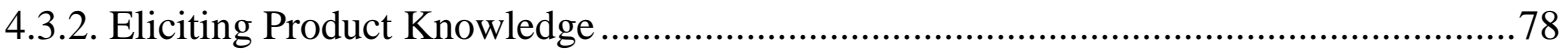

4.3.3. Survey Data Quality and Additional Data Sources.......................................................79

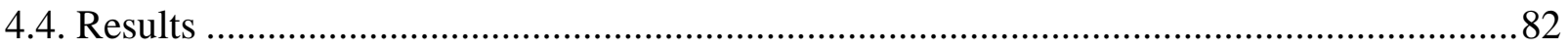

4.4.1. What Do Elderly Homeowners Know about Reverse Mortgages?...............................8 82

4.4.2. Reverse Mortgage Product Knowledge and Respondent Characteristics ......................86

4.4.3. Reverse Mortgage Knowledge and Intention to use a Reverse Mortgage .....................8 89

4.4.4. The Impact of Information Transfer on the Intention to Use a Reverse Mortgage ......96

4.5. Conclusion ..................................................................................................................

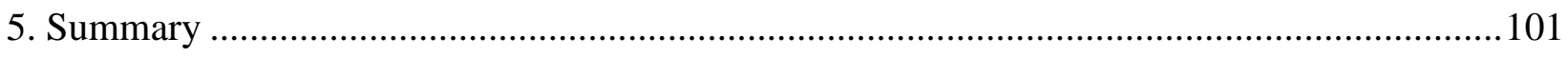

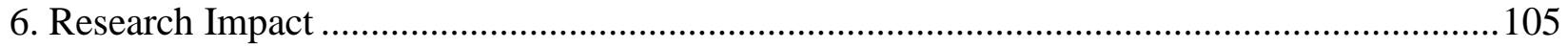

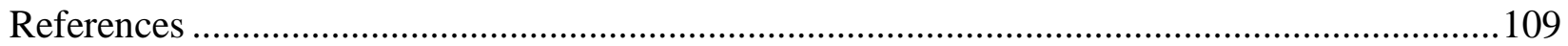

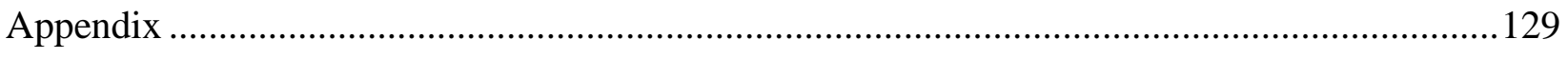

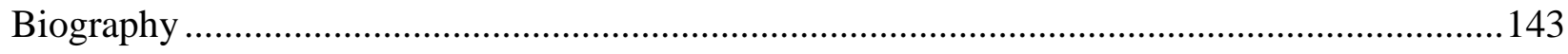




\section{Tables}

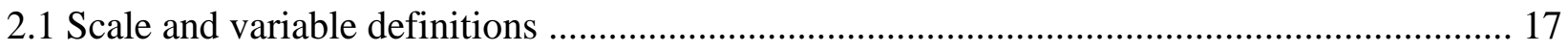

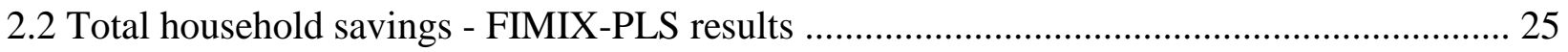

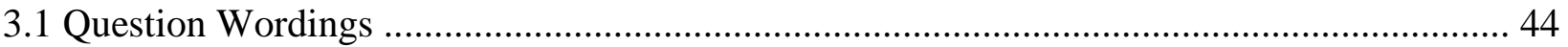

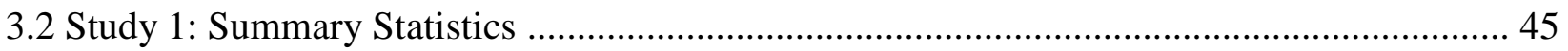

3.3 Study 1: Impact of Returns and Clicking Behavior on Belief Updating ............................... 46

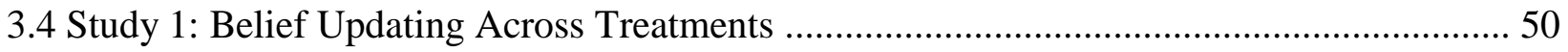

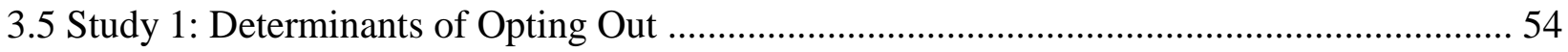

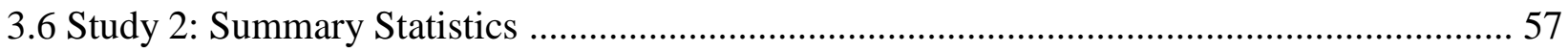

3.7 Study 2: Returns and Clicking Behavior ……....................................................................... 58

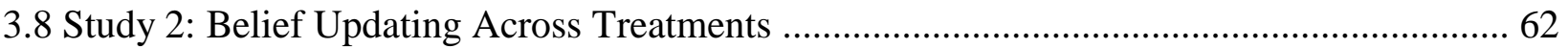

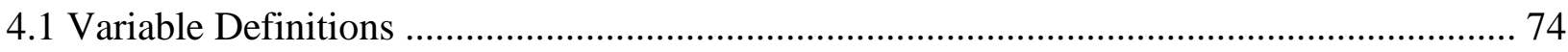

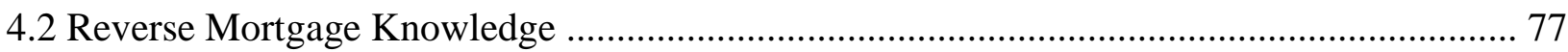

4.3 Comparison of Survey Respondents' Characteristics with the SCF ………………............. 80

4.4 Explaining Reverse Mortgage Product Knowledge ……………………………................ 87

4.5 Explaining the Intention to Use a Reverse Mortgage ………………………………........... 91

A2.1 Classification of saving motives as promotion and prevention ........................................ 130

A4.6 Factor Loadings of the Reverse Mortgage Knowledge Index .......................................... 138

A4.7 Explaining RM Product Knowledge using a Factor Weighted Index and IRT scores ...... 139 



\section{Figures}

3.1 Examples of Returns Presented in Different Treatments ..................................................... 41

3.2 Example of a Typical Brokerage Interface ………............................................................... 42

3.3 Study 1: Return Expectations and Risk Perceptions ............................................................ 47

3.4 Study 1: Belief Updating Across Treatments ........................................................................... 48

3.5 Study 1: Opting Out of the Default Information Horizon ...................................................... 52

3.6.A Study 2: Opting Out Possible: Return Expectations and Risk Perceptions ......................... 59

3.6.B Study 2: Opting Out Not Possible: Return Expectations and Risk Perceptions .................. 60

3.7 Study 2: Opting Out Possible: Belief Updating Across Treatments ........................................ 61

3.8 Study 2: Opting Out of the Default Information Horizon ....................................................... 63

3.9 Study 2: Opting Out Not Possible: Belief Updating Across Treatments ................................ 64

4.1 Distribution of the Reverse Mortgage Product Knowledge Score ……………………….... 85

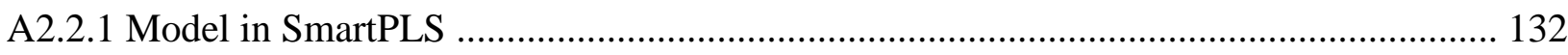

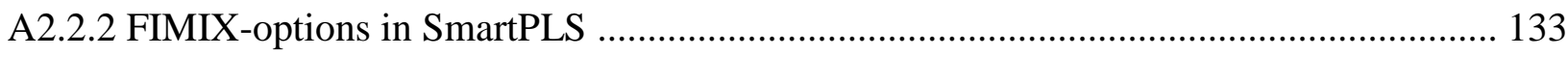

A2.2.3 SmartPLS algorithm options …………………………....................................... 134

A2.2.4 Bootstrapping options in SmartPLS ……………………………………………... 135

A2.3.1 Total household savings - segment membership probabilities ...................................... 136

A4.2 Item Characteristic Curves for Reverse Mortgage Knowledge Questions ........................ 141 



\section{Acknowledgements}

It took a while to reach this point, most likely it took me a bit longer than most of my fellow $\mathrm{PhD}$ students, but I am more than happy to have finally made it this far. I would not have been able to pull this one through without the help and support of several people. Thus, I would like to use the opportunity to acknowledge all the help and support I have received and to say "Thanks" to everyone who has accompanied me through this journey.

I would like to start with my supervisors - not only because they had the most impact on my dissertation, but also because I just happen to have the best ones! There is no possible combination of supervisors I could have wished for other than the amazing trio that Piet, Arvid, and Thomas are. I consider myself extremely lucky to have been supervised by them, and I hope to not have caused them to grow too much grey hair because of me...

If it would not have been for Thomas, I would not even have started the "project PhD". As my supervisor during my master thesis, he was the one who introduced me to the idea of pursuing a $\mathrm{PhD}$. Sometimes, you just have to be with the right person at the right place to the right time. There are only a few such opportunities in life, and thus I did not need much deliberation to decide in favor of it. Reflecting back, I can say that it was the right decision. Pursuing a PhD has helped me to further develop myself and to shape and evolve my personality and character in a much broader way than just "research" or "academic writing".

Arvid and Thomas are just amazing daily supervisors. Any upcoming $\mathrm{PhD}$ student can consider him- or herself lucky to be supervised by any one of them. They were always available for support, if needed. In case I had to write quicker or get some robustness test faster, they might spontaneously drop by to deliver some (digital) whiplashes from their whipping apps. Thanks to both of you for all your help, discussions, the occasionally needed kicks in my ass, mutual travels, conference attendances, and drinks we had over the past years. 
Though Arvid and Thomas were my daily supervisors, Piet is my main promoter. I admire his attitude and wisdom. His charismatic and positive character makes him a great source of advice. No matter how seemingly stuck you might be, go and have a talk with Piet, because he has that talent to always find the right words needed in any given situation to get you back on track.

I am highly grateful to have you as my supervisors.

However, it was not only my supervisors whom I am grateful for. The whole department is a great place to work with amazing colleagues. I did benefit a lot from the various hallway or coffee machine talks I have had which helped me to broaden and expand my horizon. The atmosphere and collegiality among all members of the department is just great. No matter whether it is a full professor or another PhD student you are talking to, you will always have an open dialogue on eye level. Thanks a lot to our entire department's senior and junior faculty members - I owe a lot to your various comments and suggestions. Your tough questions and critical remarks make our department and $\mathrm{PhD}$ seminars some of the most demanding presentations I have come to experience. It is a great experience though, as once you have made it there, you are well prepared and most conference presentations will be easy game. Thanks a lot to Dennis, Jaap, Jeroen, Joost, Nils, Paul, Paulo, Peter, Rachel, Rob, Roger, Stefan and Stefanie.

I am also indebted to my fellow PhD students. Gaby and Omar - as my first office mates you helped me a lot to a great start and it was always a pleasure to share an office with you. Ehsan and Wiebke, thanks a lot for supporting me and being my paranymphs. Not only they, but all of you have helped me out in so many different ways. I can just say thanks to every single one of you - Addy, Aleksandar, Alessandro, Andrea, Anna, Clarissa, Gildas, Han, Iman, Inka, Judy, Leonard, Marina, Matteo, Michael, Mike, Mukul, Nora, Oana, Pieter, Pomme, Rogier and Rogier, Sally, Simone, and Tobias.

I also owe a lot of gratitude to our awesome secretariat - Carina, Cécile, Els, and Francien. Thank you so much for all your support on such a variety of different topics - be it travel planning, vacation tips, website updates, and more recently, my sheer endless amount of questions related to defense planning. You are the ones who keep everything in motion and I hope that the secretariat will continue to be the place to celebrate accomplishments and have the traditional piece of "birthday vlaai". 
To everyone I might have forgotten above: Please forgive me. Rest assured that this was in no way with bad intention. Instead, please feel free to correct my mistake and just include yourself here:

I am very grateful for the co-authors of my papers. Tom and Joe, it was a pleasure working with you. I benefited a lot from our cooperation and I highly appreciate all the additional insights your input and feedback has provided me with.

Furthermore, there always has been a whole lot of support for me outside of the academic world and university. Ina, I know that sometimes it can be tough to live with me. Acknowledging this, I am even more grateful for the fact that you are constantly with me. You are the person who has experienced all highs and lows of the PhD track with me and has constantly supported me the most - initially as my girlfriend, now as my wife. It is an invaluable support to know that no matter what, you are there for me. Обичам те!

I consider myself fortunate to have such a loving and caring family - both in Germany and Bulgaria. My mom, who has been, is, and always will be there for me. I admire your strength and optimism and view on the world in general. Thanks a lot for your unconditional support - even if it's about moving abroad.

David, even though you are my younger brother - and to some extent I have the feeling it should be the opposite way around - you give me a lot of reasons to look up to you (physical height asides). Brothers will always be in some kind of competition and thus, I am happy to still have finished my dissertation before you are done with yours. ;)

Opilein, you are anytime there to discuss all the world and his wife. In regards to my dissertation, it was great to be able to discuss real-life applications of reverse mortgages and design a similar product in reality. No matter what, I won't forget to calm down and just take "three bullets, coming slowly".

Miro, Ivelina, and Baba, thanks a lot for having me welcomed with open arms and like a member of your own family right from the beginning. Not sure how our start in Bulgaria would have been without your support. Благодаря много. 
Unfortunately, there are some people who will not be able to read the final version of my dissertation: most notably my dad and grandma. However, they gave me so much in life and helped me to become the person I am today. Their positive influence on me is still there and I know that somehow, they are still with us.

Lastly, I would like to thank my friends - for being with me, supporting, laughing, drinking, talking, discussing everything but this thesis, which is sometimes exactly what's needed to get a fresh mind and be able to get back to it the next day.

Once again, thanks to every single one who has crossed my path and has accompanied me on (part of) my way.

Varna, April 2019

Patrick Gerhard 


\section{Introduction}

Individuals invest more time contemplating about each car purchase than they do in their entire life thinking about retirement planning. A market research agency found that Germans spend 21 hours of their life thinking about retirement planning. They spend, however, 37 hours for each car purchase (Mühlbauer, 2013). These numbers are worrisome, given that bad retirement planning can have severe and long-lasting financial consequences. A single faulty decision can make the difference between living in modesty or comfort during retirement. Self-responsibility of managing retirement wealth is increasing, and thus, we need better insights into how households save, invest, and dissave. Why do individuals and households not plan more and better for their retirement? Why do they not invest more time into such important decisions? Why do they instead dedicate more time to a car purchase, which has fewer financial consequences?

Potential reasons are manifold. Households might simply not be aware of the importance of retirement planning. Or they might postpone retirement planning since they do not perceive the urgency of the topic due to the large temporal distance to retirement age. Retirement planning is, despite its importance, a complex decision, which might scare households away from confronting the topic. Furthermore, it might be uncomfortable to think about oneself at elderly ages, which can result in the tendency to neglect such topics and avoid such confrontation.

How do households actually form their decisions? What does their decision making processes look like? Households' decision making processes are complex. Due to their complexity, no single theory is likely to be able to explain or predict households' decision making sufficiently. Research on individual investors has shown many instances in which the investors deviate from "rational" decision making benchmarks. Academic research has recognized that individuals do not act like the homo economics, which is the stylized version of a rational agent, free of emotions, exhibiting consistent decision making as a financial utility maximizer. From a rational point of view (depending on the underlying type of rationality assumed, such as being a strict 
financial utility maximizer), households or individuals should decide in a certain way in a certain situation, but they do not display rational behavior in a financial utility maximizing sense. Their decision making processes might reflect more dimensions besides financial utility. Households might maximize based on emotional or social utility. Emotional and social utility are derived from decisions that "feel good" or that are consistent with the expectations of relevant others (see Hoffmann and Broekhuizen (2009) for how social factors drive investment choices and Aspara et al. (2015) for how emotional utility is traded off against financial utility in investment choices). Examples of important reference groups in this regard are family, friends, and colleagues. Thus, households might maximize one or a combination of different utilities, but the definition of utility is different than in traditional economics. Those deviations from rational behavior are oftentimes coined as "biases", because they do not coincide with the underlying economic theory of choice.

This thesis expands our knowledge on household financial decision making. We take a positive research approach. That is, across three studies, we observe financial decision making of households and aim to explain them alongside a wide array of different factors. We do not engage in discussions on rationality, and for the sake of this thesis, assume each decision made by a household can be interpreted as being rational, in a sense that it is arguably made to achieve progress towards a desired individual goal of life, which might not even be visible to the observer. Existing economic theories of financial decision making provide a good benchmark for explaining decision making, and have simplicity as their advantage. However, their disadvantage is that they oftentimes fail to explain real-world behavior. Those are the instances when "biases" are found.

Existing theory is not comprehensive enough to sufficiently reflect the complexity of human decision making. More factors need to be incorporated until observed outcomes can be explained and aligned with the theoretical predictions of such theories. We believe that a positive research approach will better be able to shed light onto household decision making. Insights gained from those attempts could then be incorporated into normative research, to figure out whether actual behavior is predictable and whether existing theory is enriched by these new insights and results from positive research approaches. Any newly identified deviations from strict utility maximization can then serve as input for positive research approaches and will deliver new insights into decision making processes. Thus, both research approaches need each other's input to develop the field of household finance. 
Current normative models reach their boundaries due to the complexity of human nature and households' decision making processes. Rational utility models, for example, aim to incorporate and price non-pecuniary benefits, but this is hard to achieve given that many factors influence and contribute to utility or value derived from a decision's outcome. A few examples are: enjoyment, satisfaction, thrill, excitement, herding behavior borne by a desire for safety and ability to shift responsibility, misperception of a given choice (or financial product) due to marketing efforts, false promises, lack of literacy or miscomprehension of financial products.

The aforementioned examples highlight why academic research needs to reconsider thinking in terms of strict research areas. Times where research in economics, finance, marketing, psychology, et cetera could be seen as separated research fields are already over. Modern theories of choice are and will even extend to be multidisciplinary (cf. Lynch and Wood, 2006). The reason for this multidisciplinarity touches again on the point of the complexity of human nature. Combining different disciplines and their methods allows for a better, more detailed, and finer grained understanding of decision making processes. By combining insights from several research streams, this thesis aims to contribute to the academic literature in the area of behavioral and experimental finance, consumer behavior, and economic psychology.

The following three chapters employ such a multidisciplinary approach. They can be seen as individual essays, each with a different focus to provide additional insights into household decision making. In those essays, we study households under various circumstances and in different stages of their (financial) life cycle. We focus on specific examples of two of these stages: one is the accumulation phase, during which households are part of the labor force and their income typically exceeds their spending level. The other phase is retirement, where households' income stream is reduced and they typically start to consume out of their savings.

Chapter 2 examines household decision making proxied by savings behavior and its link to psychological characteristics. Savings behavior is influenced by psychological characteristics such as personality traits, a tendency to set goals, and financial experience. However, the influence of these characteristics is likely to vary across different (demographic) groups within a population: characteristics which motivate savings behavior in one group may not do so in another. To understand these complex relationships, we analyze latent heterogeneity in the relationship between household characteristics (financial literacy), personality traits (the Big 
Five, self-control, optimism, and attitude towards savings), saving motives (the self-regulation systems promotion and prevention), and savings behavior (total household savings). We simultaneously segment individuals and estimate segment-specific path coefficients, to test whether psychological characteristics predict savings behavior differently across groups. This approach is applied to a representative sample of UK households.

Our results suggest that the relationship between psychological traits and savings behavior is indeed heterogeneous. For example, while lower extraversion and higher self-control are associated with increased total household savings in a more affluent subgroup, no similar effects can be found in a less affluent subgroup. These and other differences demonstrate the importance of accounting for latent heterogeneity when studying the psychological determinants of savings behavior. Our approach exemplifies the importance to account for latent heterogeneity present in the data, instead of a priori segmenting at the researcher's discretion ${ }^{1}$. Chapter 2 shows that households should not be treated as homogeneous, but instead individual differences on the effect of different psychological characteristics on savings amount between the segments need to be taken into account. Neglecting such differences might shape an incorrect picture about households' savings behavior.

Afterwards, in Chapter 3 we study the effect of framing of financial information on the way investors form expectations, that is, update their beliefs. When making financial decisions, research has shown that the way how information is presented has an impact on the outcome of an associated decision (called "framing"). This effect also exists for a temporal aggregation of data, when an individual investor is presented with return data on different performance horizons.

Chapter 3 experimentally analyzes how beliefs are updated over time and impacted by a default time horizon of return information displayed. Understanding belief updating and how to set defaults can beneficially influence (i.e. reduce) trading activity, and the total financial wealth saved and accrued by households during their savings accumulation phase. In particular, prior research has shown that investors with smaller belief updates trade less actively. This reduced activity positively affects their return performance. We examine the effect of different default frames of presenting past return information on investors' belief updating. In particular, we

\footnotetext{
${ }^{1}$ please note that a well-defined, justified, and theoretically reasoned a priori segmentation might very well make sense. However, several academic studies lack this justification which makes the decision on segmenting a dataset appear to be more or less arbitrarily chosen 4
} 
analyze whether presenting longer information horizons as a default is associated with smaller belief updates.

In lab and online experiments, we expose subjects to different past return information defaults and measure updates in their beliefs. Different from previous research, our subjects can easily opt out of the default to obtain additional information. We find that presenting long-term return information is not effective in reducing belief updates on average. Whereas belief updates are reduced for subjects who remain in their default, for those who opt out, we observe the opposite pattern. Again, this finding showcases the importance of properly accounting for heterogeneity between segments, as elaborated on in Chapter 2.

Chapter 4 relates to the third stage of a household's life cycle - the wealth decumulation phase. Households, due to a lack of perfect foresight, in association with carefulness, tend to decease with a positive financial balance that was still at their disposal. But not only lack of foresight plays a role in that. Some financial assets are sticky, illiquid, and lumpy, and cannot be easily sold in parts, as it might be desired by the household. Home equity is a perfect example which fulfills those requirements. During their life, households accumulate home equity, which forms the single largest asset of most retirees. During their retirement, they might actually benefit from (partially) consuming their home equity. Unfortunately, this is not easily possible, such as it is difficult to sell a fraction of one's home. A solution might be to sell the home entirely, to have the home equity completely liquidated, and to be able to consume the proceeds. However, this comes along with the necessity to move out of the home, search and find a new place to live. Especially elderly households have hard times with that, since they are attached to their homes and appreciate the steadiness and well-known surroundings of their home. Thus, many households inherit a large portion of their total wealth to their heirs instead of consuming it during their lifetime.

Chapter 4 picks up on a financial product called "reverse mortgage." Reverse mortgages allow elderly homeowners to unlock and consume home equity without leaving their homes. While theoretically appealing, the product is under-utilized comparing actual sales rates versus predicted theoretical demand. That is, relative to the number of elderly homeowners with limited financial resources, the take-up rates of reverse mortgages are low. Even when taking bequest 
motives for households with children into account, the question remains why those without bequest motives do not display higher acceptance rates for such a product.

To understand the low take-up rates we first survey U.S. homeowners aged 58 and older assessing their knowledge (literacy) about the most popular reverse mortgage product, the Home Equity Conversion Mortgage (HECM). Next, we study the relationship between knowledge and the intention to use a HECM. Awareness of reverse mortgages is high, but knowledge of contract terms is limited. More knowledgeable homeowners and those with peers who have a reverse mortgage express greater intention to use such a product. Respondents who would benefit most from reverse mortgages (those with low incomes and limited savings) express greater intention to use reverse mortgages, but lack knowledge of the contract terms. Lack of knowledge, problems understanding important contract terms, and low financial literacy are identified as some of the factors which relate to low product demand. Our findings suggest that take-up rates might be increased through improving knowledge about contract terms or changing the product's design to make it easier to understand in the first place.

The three essays on different aspects of household financial behaviors in Chapters 2-4 are then followed by a general summary of the findings and results of the studies in Chapter 5. Chapter 6 highlights the implications the findings have for existing research and policymakers. 


\section{Psychological Characteristics and Household Savings Behavior - The Importance of Accounting for Latent Heterogeneity ${ }^{2}$}

\subsection{Introduction}

Prior research highlights the important contribution of psychological characteristics in explaining household savings rates (Antonides et al., 2011; Canova et al., 2005; Loibl et al., 2011; Lunt and Livingstone, 1991; Petkoska and Earl, 2009). However, such research often treats the population of interest as homogeneous, thereby implicitly assuming that a psychological trait's influence will broadly extend across a range of demographic groups. Yet, it is also possible that psychological characteristics will influence an individual's propensity to save differently based on its life cycle stage, gender, education level, or income - factors which are themselves also found to influence savings rates (e.g., Alessie and Lusardi, 1997; DeVaney et al., 2007; Horioka and Watanabe, 1997; Lee et al., 1997; Wärneryd, 1999; Xiao and Fan, 2002; Xiao and Noring, 1994).

To accommodate for these differences across groups, previous studies have either divided their samples based on observable attributes such as age, gender or marital status, and then analyzed the resulting subsamples in isolation, or instead utilized regression interaction terms (e.g., Brown and Taylor, 2014; Cho et al., 2014; Nyhus and Webley, 2001). However, the complex associations between psychological characteristics and savings behavior across different groups of individuals are likely to be overlooked when using these standard multivariate techniques. Indeed, prior research has argued that observable characteristics, such as gender or age, are by themselves insufficient to capture heterogeneity adequately (see e.g., Wedel and Kamakura, 2000). We therefore propose a different approach. Instead of a priori segmenting survey

\footnotetext{
${ }^{2}$ This chapter is based on the co-authored paper with Joe Gladstone (University College London) and Arvid Hoffmann (University of Adelaide), which is published in the Journal of Economic Behavior and Organization.
} 
respondents based on observable characteristics, we explicitly accommodate for the role of latent (i.e., unobserved) heterogeneity in savings behavior by applying a finite mixture model.

Finite mixture models uncover latent heterogeneity by estimating the proportions of distinct behavioral types in a population and allocating each individual to one endogenously defined behavioral type, characterized by a unique set of parameter values (Bruhin et al., 2010). Within the broader class of finite mixture models, we adopt the Finite Mixture Partial Least Squares (FIMIX-PLS, henceforth) approach, which has been previously validated and is particularly suitable for our study explaining savings behavior as it is prediction-oriented (see Ringle et al., 2010). The FIMIX-PLS methodology simultaneously segments individuals into unique groups and estimates segment-specific path coefficients of the type used in Structural Equation Modeling (SEM) to predict savings behavior. This procedure allows for the objective identification of latent segments, and therefore provides the potential for a more accurate understanding of the variation which exists in savings behavior. Indeed, our findings indicate considerable heterogeneity in the influence of psychological characteristics across groups, suggesting that what motivates one group of individuals to save, does not (necessarily) motivate other groups to do the same.

It is an important goal to understand the psychological characteristics which drive savings behavior, because the decision to defer consumption today and save for the future is potentially the most crucial financial decision consumers make (Zhou and Pham, 2004). Savings act as a critical tool which households utilize to achieve their financial goals and maintain financial wellbeing (cf. Donnelly et al., 2012; Findley and Caliendo, 2015; Otto, 2013). Furthermore, changes in government policy mean understanding the determinants of individuals' savings behavior is becoming increasingly important. For example, the UK has recently liberalized the rules allowing individuals to withdraw retirement funds during the pension decumulation phase (Loibl et al., 2016). Given the established literature on hyperbolic discounting (Laibson, 1997) and the general trend towards an increasing self-responsibility for retirement, this suggests that some groups may become increasingly vulnerable to failing to smooth consumption over their lifetime. Therefore, an improved understanding of the characteristics and heterogeneity underlying savings behavior will help policymakers identify relevant subgroups to target with tailor-made interventions.

This essay makes several contributions to the literature on household finance and the individual differences which shape consumer financial decision making. First, we introduce an innovative 8 
methodological approach to the ongoing debate on the psychological and demographic predictors of individuals' savings behaviors. By highlighting the importance of unobserved heterogeneity, the results of the FIMIX-PLS approach offer a possible explanation of why previous research has often found contradictory results on the role of psychological characteristics in explaining savings behavior. In particular, focusing on average effects in a population and overlooking the heterogeneity in these effects across relevant subgroups might have contributed to an opaque relationship between psychological characteristics and savings behavior.

Second, by using a representative sample of the UK, our findings provide insights into the behaviors of real population groups. Those insights will help guide policymakers in deciding which psychological characteristics to target when attempting to improve savings behavior among specific subgroups. As such, we contribute to the emerging debate on how psychological theories can inform public policy (Lynch and Wood, 2006).

Third, while previous studies have typically examined the effect of household characteristics, personality traits, and saving motives in isolation, we aim to provide a more holistic perspective on the determinants of savings behavior. To do this, we systematically examine the joint effect on household savings behavior of not only personality traits, but also variables that have received less attention in the literature, but seem equally relevant, such as optimism, savings attitudes, and the types of goals set by savers.

Our study reveals several novel relationships between demographic and psychological variables, which highlight the importance of understanding latent heterogeneity in financial behavior. For example, while higher self-control and lower extraversion are associated with a greater accumulation of savings in a segment we describe as "established" (i.e., those who are older and richer), we do not find similar effects in a segment we describe as "striving" (i.e., those who are younger and lower-income). Instead, for the latter group, whether or not they set savings goals appears to be a key predictor of savings. These findings support the argument that different psychological characteristics - such as self-control or extraversion - will be more or less influential on savings behavior depending on the environment and the life-stage of the individual.

Finite mixture models are a data-driven approach in which segments of the population are automatically identified by the model based on the latent (i.e., unobserved) heterogeneity in the 
data. Next, differences in the relationships between psychological characteristics and savings behavior across these segments are examined. This process does not lend itself to the development of a priori hypotheses, and our objective is not to test a theoretical framework of how specific variables relate to savings. Instead, the approach provides a richer understanding of how psychological characteristics influence savings differently across (demographic) groups. The results can benefit theory development by comparing them with those from prior research, which did not account for the role of latent heterogeneity in explaining the effect of psychological characteristics on savings behavior, but instead has focused on average effects in a population.

The remainder of this essay is structured as follows. Section 2.2 reviews the literature on the interactions between demographic groups and key psychological characteristics identified as influencing savings behavior. Section 2.3 introduces the data set we use in our analyses and presents an overview of the FIMIX-PLS approach we employ to examine latent heterogeneity in savings behavior, including the model's main formulae. Sections 2.4 to 2.6 present the results, discuss their theoretical and practical implications, and conclude on how future applications of the FIMIX-PLS approach can enrich our understanding of consumer financial decision making.

\subsection{Literature Review}

\subsubsection{Interactions between Psychological Characteristics and Demographics}

A challenge in understanding a complex behavior such as households' savings is that models of behavior must not only contend with the complexity of two distinct factors (i.e., psychological and demographic characteristics), but also account for the interaction between these factors. As demographic characteristics shape the choices available to a person, this will, in turn, moderate when and how these psychological traits predict behavior. For example, while self-control has been linked to higher saving rates (e.g., Thaler and Benartzi, 2004), it might not be associated with higher savings in those who lack the financial resources to save. This ability to save will depend on factors such as the individuals' life stage, their household size, income level, and the financial products available to them. Indeed, Bertrand et al. (2006) state that the financial behavior of low income consumers is more controlled by circumstances independent of intention. 
Psychological traits will therefore influence savings outcomes only when certain environmental conditions are met. This notion is supported by previous research illustrating how psychological traits interact with demographic factors in influential ways. Mosca and McCrory (2016) studied how personality traits contributed to wealth accumulation in older groups, finding that individuals higher in conscientiousness accumulate more wealth. However, they also found this relationship to only be significant for those at the lower end of the income distribution. This suggests that for those with higher levels of income, the role of other factors beyond personality become greater drivers of wealth accumulation. For example, one explanation is that higher income employees are likely to receive more generous pension contributions from their employer, meaning wealth accumulation may become less dependent on the active choices for these employees. Similarly, Cobb-Clark et al. (2016) investigated wealth accumulation across income segments in Australia, studying the effects of locus of control. Their results suggested that locus of control had a greater influence on wealth accumulation for lower-income segments.

These examples highlight previous work which has investigated how psychological traits might influence savings behavior differently across demographic groups. However, the advantage of using a FIMIX-PLS approach is that we do not make a priori decisions on how to segment individuals. For example, we do not arbitrarily define groups based on gender, marital status, wealth level, or household size, but instead, utilize the latent structure in the data to segment the sample according to what best fits the underlying structural equation model. In so doing, we aim to achieve a clearer understanding about the heterogeneity in the associations between psychological characteristics and savings behavior, and thereby help explain the current literature's lack of consensus and develop new opportunities for theory development and testing.

Furthermore, while previous research has often focused on only a small number of predictors of savings, we instead aim to holistically and simultaneously assess many of the key psychological drivers of household savings behavior. These drivers of savings behavior can be classified into the following groups: household characteristics (financial literacy), personality traits (the Big Five, self-control, optimism, and attitude towards savings), and saving motives (the selfregulation systems promotion and prevention). We include these variables based on a review of the relevant literature on consumer financial decision making and household finance, which identified them as fundamental to understanding the differences regarding savings behavior across households. In this regard, we draw from research across a range of social science 
disciplines, including (social) psychology, consumer behavior, economics, and finance. By examining the joint effect of these characteristics, our aim is to provide a more holistic perspective on the determinants of household savings behavior than previous studies have done, which typically only examined the effects of these characteristics in isolation.

In the following sub-sections, we briefly summarize and review each of these psychological drivers of savings behavior, thereby providing a rationale for their inclusion in our model, and highlighting the inconsistencies in past research, which our approach may be able to help explain.

\subsubsection{Household Characteristics: Financial Literacy}

Financial literacy characterizes an individual's knowledge of basic financial concepts (Lusardi, 2008), and has been identified as a key variable to explain variation in a household's tendency to build up wealth (e.g., van Rooij et al., 2011). Individuals who are financially literate have the capacity to make more informed choices regarding financial matters, such as whether and how much to save (e.g., Stango and Zinman, 2009). Grasping basic financial concepts, such as the effect of compounded interest on the value of one's savings, is indispensable in understanding the value of starting to save early for retirement. Similarly, knowledge about the costs of credit is invaluable in deciding whether to save for unexpected expenditures, such as those related to the breakdown of home appliances, or to take up credit to cover such costs. A significant percentage of households, however, do not understand even very basic concepts within personal finance, at least as measured through standard financial literacy tests. In fact, Klapper et al. (2014) show that only $57 \%$ of U.S. and $67 \%$ of UK households can be considered financially literate in this regard. These figures are concerning, as not understanding basic financial concepts can adversely impact both An individual's health and welfare (see e.g., Lusardi and Mitchell, 2007).

\subsubsection{Personality Traits: The 'Big Five'}

The 'Big Five' model is the dominant paradigm for the measurement of personality traits. It originates from psychology and has become increasingly applied in economic research. The five personality traits are agreeableness, conscientiousness, extraversion, neuroticism, and openness to experience. McCrae and John (1992) provide an overview of the model. While several studies 
have used the Big Five to try and predict savings behavior, to date, the findings lack consensus on which of the personality traits are most-closely related to savings behavior and in what way.

Brown and Taylor (2014), for example, analyzed data from the British Household Panel Survey. They focused on the effect of the Big Five on financial outcomes, in particular on the amounts of unsecured debt and savings. The authors split their dataset into single persons and couples, and analyzed these groups separately. Overall, the authors found that specific personality traits are significantly associated with debt and asset holdings. However, they also found a large variation across their sample, with personality traits being associated with financial outcomes depending on both the type of household and the types of debt and assets. For example, the authors found a consistent negative relationship between conscientiousness and unsecured debt holdings, while also finding extraversion to have a negative association with asset holdings, but only for those living as a couple. Contrary to earlier work by Nyhus and Webley (2001), which found that neuroticism negatively affected savings, Brown and Taylor (2014) did not find any effect of neuroticism. As another example of the lack of consensus in the current literature, Mosca and McCrory (2016) find a positive relationship between extraversion and wealth accumulation in The Irish Longitudinal Study on Ageing, which is at odds with results from Nyhus and Webley (2001), who document a negative relationship of extraversion with savings.

\subsubsection{Personality Traits: Self-Control}

Self-control refers to an individual's capacity to control impulses, emotions, desires, and actions in order to protect a valued goal (e.g., having a financially secure retirement) or resist a temptation (e.g., spending money on non-essential items). Self-control is the process of selfregulation in contexts involving a clear trade-off between long-term interests and immediate gratification (Bernheim et al., 2015; Thaler and Shefrin, 1981; Vohs et al., 2012). There is large variation in individuals' capacities for self-control, and those with less of it are less likely to save for the future and more likely to give in to temptations to spend today (cf. Thaler and Benartzi, 2004). Indeed, having poor self-control is associated with lower credit scores (Arya et al., 2013).

Research has found a positive relationship between self-control and higher income (Haushofer and Fehr, 2014). Various authors have attempted to explain this phenomenon. Within economics, 
Bernheim, Ray and Yeltekin (2015) argue poverty can be self-perpetuating, by undermining the capacity for self-control, while work in developmental psychology finds that exposure to poverty in childhood may adversely affect children's socio-emotional adjustment through its impact on self-regulatory skills (Aber, Jones, and Cohen, 2000; Raver, 2004). Another recent perspective is that poverty forces people to spend time thinking about what they do not have, leaving less mental bandwidth for more abstract thought, such as planning for the future (Mullainathan and Shafir, 2013). For example, Mani et al. (2013) found that the psychological impact of resource scarcity was comparable to the effect of a drop in IQ of 13 points, demonstrating how wealth (or the lack of it) can be an important environmental factor in influencing psychological processes.

\subsubsection{Personality Traits: Optimism}

Dispositional optimism is related to numerous positive life outcomes. The more positive people expect their futures to be, the better their mood, the fewer their psychiatric symptoms, and the better their adjustment to diverse situations including college transition, pregnancy, cardiac surgery, and caregiving (for a review, see Carver and Scheier, 1999). The degree to which individuals are optimistic about the future can also exert an influence on their savings behavior.

On the one hand, more optimistic individuals might be more likely to save as they feel more confident to be able to reach their savings target. Indeed, Puri and Robinson (2007) found that optimists save more than pessimists. They also found that optimism is related to portfolio choice: optimists are more likely to own individual stocks, and for these stocks to make up a greater proportion of their overall wealth. On the other hand, however, individuals who are optimistic about future prospects may not allocate sufficient money to precautionary savings, as they do not feel the need to save. Additionally, they might underestimate the risk of undesirable events. Even risk-averse individuals, if sufficiently optimistic about the certainty of future income, would be inclined to reduce precautionary savings. An overly optimistic individual might overestimate potential returns on savings, or underestimate the time needed to accomplish a certain savings goal, and therefore save less money than necessary to reach their savings target.

Research in health suggests optimism may also be more important for certain groups than others. For example, Geers et al. (2010) found that the relationship between optimism and health- 
promoting behaviors is moderated by a person's goals. Other research has found that optimism is related to lower cancer risk, but only among younger patients (Schulz et al., 1996). Therefore, the impact of optimism on financial outcomes such as savings behavior may also vary across groups.

\subsubsection{Personality Traits: Attitude towards Savings}

An attitude is "a relatively enduring organization of beliefs, feelings, and behavioral tendencies towards socially significant objects, groups, events or symbols" (Hogg and Vaughan, 2005: 150). Attitudinal factors have been found to be important drivers of a household's financial decisions. Livingstone and Lunt (1992), for example, find that a household's attitude towards debt can discriminate debtors from non-debtors, explain how far households get into debt, and predict how much of their debts they will repay. Davies and Lea (1995), in turn, showed how such attitudes correlate with various demographic (e.g., age) and psychological variables (e.g., locus of control). These findings suggest that the effect of debt attitudes may vary across (demographic) groups, reinforcing the need to examine the role of latent heterogeneity in explaining savings behaviors. An examination of the attitude towards debt scale by Davies and Lea (1995) indicates that a household's attitude towards savings is to be understood as a subcomponent of its more general attitude towards debt. In particular, the following statement from this scale directly refers to a household's savings attitude: "You should always save up first before buying something."

\subsubsection{Saving motives: Promotion versus Prevention Regulatory Focus}

Because savings decisions are typically made to fulfil goals that are distant in time, these decisions are likely to be guided by processes of self-regulation. Self-regulation refers to the processes individuals use to set goals, select means to attain these goals, and assess their progress toward these goals (e.g., Brockner and Higgins, 2001). Zhou and Pham (2004) explained how the promotion system, which originates in the regulation of nurturance needs, relies on approach strategies when regulating toward desirable ends. This system is especially active in the pursuit of ideal situations, such as wishes, dreams, and aspirations. In contrast, the prevention system, which originates in the regulation of security needs (Zhou and Pham, 2004), relies on avoidance strategies when regulating toward desirable ends. The prevention system is especially active in the pursuit of oughts, such as the fulfilment of responsibilities, obligations, and duties. 
Within household savings behavior, the promotion system invokes the desire to achieve financial gains, whereas the prevention system invokes the desire to avoid financial losses. The latter motivation corresponds to the notion of precautionary savings, which provide households with an emergency cushion in the case of a sudden loss or an unexpected spike in expenditures. In contrast, the former motivation describes how households save to attain a future goal. However, as Cho et al. (2014) pointed out, neither of the two motivators entails that the ultimate goal of savings needs to be either gain- or loss-focused. One may save preventively to ensure the gains which accrue from peace of mind, whilst saving promotionally to avoid having to delay retirement. Furthermore, decision makers are differently sensitive to gains and losses for financial products, depending on their personal predisposition towards promotion or prevention (Zhou and Pham, 2004). It is possible that different life stages will be more closely associated with one system than another (e.g., younger people being more concerned with accumulating wealth, and older people being more concerned with avoiding losing wealth). Therefore, there is likely to be an interaction between regulatory focus and demographic characteristics such as age or income.

\subsection{Data and Methodology}

\subsubsection{Data Collection}

Our data source is a unique household survey commissioned in 2013 by a large independent consumer body in the UK and designed in collaboration with one of the study authors. The survey investigates the household savings behavior of $4,170 \mathrm{UK}$ individuals. Conducted by a large UK polling organization, the survey is representative of the overall UK population in terms of socio-demographics and was run online, via telephone, and in person to ensure a full representation of different groups. It contains questions on household savings, as well as several demographic and socio-economic variables, including age, gender, income, and educational attainment. The survey also measures self-assessed financial literacy, self-control, optimism, savings attitude, and the Big Five personality traits. Item order was randomized to prevent any ordering effects. Table 2.1 provides an overview of all the variables and scales we use, as well as descriptive statistics. 
Table 2.1 Scale and variable definitions

\begin{tabular}{|c|c|c|c|c|c|}
\hline Scale & Item Wording & Mean & $\begin{array}{l}\text { Std. } \\
\text { Dev. }\end{array}$ & $\begin{array}{c}\text { Item } \\
\text { Loading }\end{array}$ & $\begin{array}{l}\text { Cronbach's } \\
\text { Alpha }\end{array}$ \\
\hline The Big Five & $\begin{array}{l}\text { [answers recorded on a scale ranging from: (1) does not apply to me at all - (7) applies to } \\
\text { me perfectly] }\end{array}$ & & & & 0.72 \\
\hline \multirow[t]{3}{*}{ Agreeableness } & I see myself as someone who is sometimes rude to others* & 5.23 & 1.68 & 0.62 & 0.56 \\
\hline & I see myself as someone who is considerate and kind to almost everyone & 5.03 & 1.46 & 0.84 & \\
\hline & I see myself as someone who has a forgiving nature & 5.60 & 1.13 & 0.76 & \\
\hline \multirow[t]{2}{*}{ Conscientiousness } & I see myself as someone who does a thorough job & 5.80 & 1.08 & 0.81 & 0.43 \\
\hline & I see myself as someone who tends to be lazy* & 4.89 & 1.75 & 0.81 & \\
\hline \multirow[t]{3}{*}{ Extraversion } & I see myself as someone who is talkative & 4.27 & 1.67 & 0.84 & 0.72 \\
\hline & I see myself as someone who is outgoing, sociable & 4.46 & 1.59 & 0.86 & \\
\hline & I see myself as someone who is reserved* & 3.65 & 1.64 & 0.69 & \\
\hline \multirow[t]{3}{*}{ Neuroticism } & I see myself as someone who worries a lot & 4.39 & 1.78 & 0.88 & 0.77 \\
\hline & I see myself as someone who gets nervous easily & 3.91 & 1.82 & 0.85 & \\
\hline & I see myself as someone who is relaxed, handles stress well* & 3.65 & 1.60 & 0.75 & \\
\hline \multirow{3}{*}{$\begin{array}{l}\text { Openness to } \\
\text { experience }\end{array}$} & I see myself as someone who is original, comes up with new ideas & 4.62 & 1.45 & 0.83 & 0.71 \\
\hline & I see myself as someone who values artistic, aesthetic experiences & 4.64 & 1.60 & 0.75 & \\
\hline & I see myself as someone who has an active imagination & 5.18 & 1.42 & 0.82 & \\
\hline \multirow[t]{8}{*}{ Self-Control } & [answers recorded on a scale ranging from: (1) very much like me - (5) not at all like me] & & & & 0.85 \\
\hline & I have a hard time breaking bad habits & 3.30 & 1.16 & 0.65 & \\
\hline & I get distracted easily & 3.52 & 1.15 & 0.70 & \\
\hline & I say inappropriate things & 3.83 & 1.12 & 0.72 & \\
\hline & Pleasure and fun sometimes keep me from getting work done & 3.64 & 1.14 & 0.69 & \\
\hline & I do things that feel good in the moment but regret later on & 3.67 & 1.09 & 0.80 & \\
\hline & Sometimes I can't stop myself from doing something, even if I know it is wrong & 3.87 & 1.13 & 0.78 & \\
\hline & I often act without thinking through all the alternatives & 3.82 & 1.12 & 0.76 & \\
\hline \multirow[t]{7}{*}{ Optimism } & [answers recorded on a scale ranging from: (1) I disagree a lot - (5) I agree a lot] & & & & 0.86 \\
\hline & In uncertain times, I usually expect the best & 2.98 & 1.03 & 0.71 & \\
\hline & If something can go wrong for me, it will* & 3.05 & 1.17 & 0.75 & \\
\hline & I'm always optimistic about my future & 2.70 & 1.11 & 0.74 & \\
\hline & I hardly ever expect things to go my way* & 3.03 & 1.16 & 0.81 & \\
\hline & I rarely count on good things happening to me* & 3.12 & 1.15 & 0.77 & \\
\hline & Overall, I expect more good things to happen to me than bad & 2.66 & 1.09 & 0.80 & \\
\hline
\end{tabular}


Table 2.1 Scale and variable definition - continued

\begin{tabular}{|c|c|c|c|c|c|}
\hline Scale & Item Wording & Mean & $\begin{array}{l}\text { Std. } \\
\text { Dev. }\end{array}$ & $\begin{array}{c}\text { Item } \\
\text { Loading }\end{array}$ & $\begin{array}{l}\text { Cronbach's } \\
\text { Alpha }\end{array}$ \\
\hline \multirow[t]{6}{*}{$\begin{array}{l}\text { Financial } \\
\text { literacy }\end{array}$} & $\begin{array}{l}\text { How would you assess... [answers recorded on a scale ranging from: (1) very low - (7) very } \\
\text { high] }\end{array}$ & & & & 0.83 \\
\hline & ... your overall financial knowledge & 4.68 & 1.47 & 0.86 & \\
\hline & $\ldots$ your ability at math & 5.16 & 1.55 & 0.63 & \\
\hline & $\begin{array}{l}\text {... your ability at dealing with day-to-day financial matters (e.g. checking your accounts, } \\
\text { managing payments, etc) }\end{array}$ & 5.69 & 1.39 & 0.74 & \\
\hline & ... your tendency to keep up with financial news & 4.13 & 1.80 & 0.79 & \\
\hline & $\ldots$ how engaged you feel with your finances & 4.94 & 1.64 & 0.83 & \\
\hline \multirow[t]{3}{*}{$\begin{array}{l}\text { Attitude } t / w \\
\text { savings }\end{array}$} & [answers recorded on a scale ranging from: (1) definitely false - (5) definitely true] & & & & 0.66 \\
\hline & You should always save up first before buying something & 3.84 & 1.00 & 0.87 & \\
\hline & I try to avoid debt at all costs & 3.92 & 1.20 & 0.87 & \\
\hline Age: 18-24 & Indicator variable: $1=$ respondent being between 18 and 24 years old, $0=$ otherwise & 0.08 & & & \\
\hline Age: $25-34$ & Indicator variable: $1=$ respondent being between 25 and 34 years old, $0=$ otherwise & 0.16 & & & \\
\hline Age: $35-44$ & Indicator variable: $1=$ respondent being between 35 and 44 years old, $0=$ otherwise & 0.17 & & & \\
\hline Age: $45-54$ & Indicator variable: $1=$ respondent being between 45 and 54 years old, $0=$ otherwise & 0.20 & & & \\
\hline Age: 55-64 & Indicator variable: $1=$ respondent being between 55 and 64 years old, $0=$ otherwise & 0.17 & & & \\
\hline Age: $65+$ & Indicator variable: $1=$ respondent being 65 years or older, $0=$ otherwise & 0.23 & & & \\
\hline Income & Annual household income (in $£ \times 1,000$ ) & 26.36 & 17.22 & & \\
\hline Married & Indicator variable: $1=$ respondent married, $0=$ otherwise & 0.48 & 0.50 & & \\
\hline $\begin{array}{l}\text { High education } \\
\text { (university) }\end{array}$ & Indicator variable: $1=$ respondent has attended university, $0=$ otherwise & 0.43 & 0.50 & & \\
\hline \# HHmembers & Number of people living in same household & 2.47 & 1.23 & & \\
\hline
\end{tabular}


Table 2.1 Scale and variable definition - continued

\begin{tabular}{|c|c|c|c|c|c|}
\hline Scale & Item Wording & Mean & $\begin{array}{l}\text { Std. } \\
\text { Dev. }\end{array}$ & $\begin{array}{c}\text { Item } \\
\text { Loading }\end{array}$ & $\begin{array}{c}\text { Cronbach's } \\
\text { Alpha }\end{array}$ \\
\hline Employed & Indicator variable: $1=$ respondent is full-time or part-time employed, $0=$ otherwise & 0.54 & 0.50 & & \\
\hline $\begin{array}{l}\text { Child in } \\
\text { household }\end{array}$ & Indicator variable: $1=$ person of age $<18$ living in household, $0=$ otherwise & 0.28 & 0.45 & & \\
\hline Female & Indicator variable: $1=$ respondent being female, $0=$ otherwise & 0.50 & 0.50 & & \\
\hline $\begin{array}{l}\text { Total } \\
\text { household } \\
\text { savings }\end{array}$ & Total household savings (in $£ \times 1,000$ ) & 18.32 & 26.45 & & \\
\hline
\end{tabular}

Note: This table provides an overview of the scales used in this study, including all items that comprise the scales as well as how answers to the questions are recorded (in brackets). '*' denotes reverse coding of an item. Item loading indicates the individual item's factor loading. All numbers reported in this table are based on the 3,382 observations in the total sample. 
The survey utilizes a stepwise approach, containing several questions with an exit-clause or which redirect respondents to a later question in the survey. We exclude 266 respondents who are not responsible for their household finances and 522 respondents with missing data regarding their total household savings. We are thus left with 3,382 households for further analysis.

\subsubsection{Measurement Scales}

To ensure reliability, we conduct a factor analysis on all constructs that we employ in this research. A list of individual item wordings, individual item loadings, and values for the reliability measure Cronbach's alpha (Cronbach, 1951) for all constructs is provided in Table 2.1.

Optimism is measured using Scheier et al.'s (1994) LOT-R scale, the "Life Orientation Test Revised". Four questions are "filler" items, and after removing these from the analysis, the remaining six items load sufficiently high on a single factor without noteworthy cross-loadings. Cronbach's alpha is 0.86 , providing evidence for internal consistency of the optimism measure.

Self-control is measured using the questions in Tangney et al. (2004). Factor analysis reveals a single-factor solution with satisfactory item loadings after eliminating three out of ten items. There are no significant cross-loadings and internal consistency is high with a Cronbach's alpha of 0.85 .

The Big Five personality traits were assessed using a fifteen-item scale taken from the British Household Panel Survey (for details about this survey, see Brice et al., 2002). The Big Five is a five-factor model of personality traits, which have been established as stable and reliable constructs (Cobb-Clark and Schurer, 2012). Due to a mistake in the survey execution, one question was left unusable for the purposes of analysis. Therefore, fourteen items measure how individuals exhibit the traits agreeableness, conscientiousness, extraversion, neuroticism, and openness to experience. Factor loadings are reasonable and Cronbach's alpha is generally sufficient, ranging between 0.56 and 0.77. One exception is the scale measuring conscientiousness, the only trait measured using two instead of three items, which has a Cronbach's alpha of 0.43 . Although the latter reliability coefficient seems low by traditional standards, past research suggests that these alpha coefficients underestimate the actual reliability of these scales due to their brevity (Donnellan and Lucas, 2008; Lucas and Donnellan, 2011). 
We measured promotion versus prevention regulatory focus by categorizing motivations for saving according to whether they represented a promotion- or prevention-focused savings goal. The survey included eleven items inspired by Zhou and Pham (2004), asking respondents about the reasons why they save. We recruited a sample of 94 individuals via Amazon's Mechanical Turk, who were briefed about the two self-regulation systems and instructed to classify items as belonging to either a promotion versus a prevention savings goal. Results of this classification are summarized in Appendix A2.1. Seven items are classified as related to promotion, four as related to prevention. In our analyses, we use two count variables for each survey respondent, indicating how many saving motives the respondent selected that are classified as either promotion or prevention, respectively. As the promotion versus prevention measure represents a formative scale, there is no Cronbach's alpha to report (see e.g., Hair et al., 2009).

We measure (self-reported) savings behavior using a question asking respondents about their total household savings. We use this measure because it captures the aggregated outcome of all saving decisions for a household and is often used in the literature (Nyhus and Webley, 2001).

The survey also measured self-assessed financial literacy, using five items inspired by Lynch et al. (2010) and similar to Dholakia et al. (2016). Factor analysis confirms a single factor, and the Cronbach's alpha of the financial literacy scale is high at 0.83 . The survey also included a savings attitude measure inspired by Davies and Lea (1995) and Watson (2003), which contains two items. Factor analysis indicates a single factor, and Cronbach's alpha is acceptable at 0.66.

\subsubsection{The FIMIX-PLS Method}

We use a FIMIX-PLS approach to structure and identify unobserved heterogeneity (Sarstedt and Ringle, 2010). FIMIX-PLS is a finite mixture model based on log-likelihood maximization and is implemented in Smart-PLS, a stand-alone software package commercially available from SmartPLS GmbH. ${ }^{3}$

A growing number of academic studies have utilized FIMIX-PLS to address latent heterogeneity across a variety of social science contexts, but we are not aware of any application of FIMIX-PLS within the household finance literature. Examples of its application include Valette-Florence et

\footnotetext{
${ }^{3}$ The Smart-PLS program can be purchased from SmartPLS GmbH through their website: http://www.smartpls.de/
} 
al. (2011), who demonstrate that the relative impact of brand personality and sales promotions on brand equity varies across different consumer groups. Similarly, Lai et al. (2017) investigate the psychological impact on residents of unconventional gas developments in their area (this is where natural gas is extracted from coal beds through deep drilling). These authors find that the psychological impact varies across different groups of residents based on their age, lengths of residence, and distances of their properties from the development. A further example is Forkmann et al. (2016), who document how the effectiveness of supplier relationship management capability strategies is contingent on characteristics of the supply base and business environment across groups of firms identified using FIMIX-PLS.

While these applications differ markedly in the constructs under investigation, an important commonality of using the FIMIX-PLS approach is that uncovering latent heterogeneity may result in finding path coefficients which differ in sign across different segments. Ringle et al. (2010), for example, use data of the American Customer Satisfaction Index to show that although the overall effect of customer expectations of quality on perceived value is positive, the effect will be positive or negative across different segments of customers, based on age and income.

The FIMIX-PLS approach optimizes segmentation based on estimates of the underlying model to best structure the latent heterogeneity in the data. It simultaneously probabilistically classifies observations into latent segments and estimates path coefficients of the type used in Structural Equation Modeling (SEM) separately for each segment.

In our case, these segment-specific path coefficients predict savings behavior from the demographic and psychological characteristics of the survey sample. Essentially, the method integrates segmentation with SEM path modeling, allowing us to generate the most appropriate segments regarding savings behavior. Those segments differ in their relationship between independent variables and the corresponding outcome variable (i.e., savings behavior), and are each estimated using the households which best fit to the underlying structure of the structural equation model. Thus, the method is advantageous over a stepwise estimation, in which the firststage segmentation results are used in a second stage for model estimation, or simply grouping the data based on well-known observable characteristics. A brief overview of the most important aspects of the methodology of the FIMIX-PLS approach, including the model's main formula's, 
based on the derivation used in Ringle et al. (2010), is outlined below. A more detailed review of the FIMIX-PLS approach can be found in Ringle et al. (2010).

The model is expressed by:

$$
\mathrm{A} \gamma_{i}+\mathrm{B} \delta_{i}=\varepsilon_{i}
$$

where $\mathrm{A}$ and $\mathrm{B}$ represent path coefficient matrices for relationships between endogenous and exogenous variables, respectively. $\gamma_{i}\left(\delta_{i}\right)$ is a vector of endogenous (exogenous) variables for observation $\mathrm{i}$, and $\varepsilon_{i}$ denotes the random vector of residuals for observation $\mathrm{i}$.

$\gamma_{i}$ is distributed with $\mathbf{J}$ segments $(\mathrm{J}<\infty)$ as mixture of densities $f_{i \mid j}(\cdot)$ :

$$
\gamma_{i} \sim \sum_{j=1}^{J} \rho_{j} f_{i \mid j}\left(\gamma_{i} \mid \delta_{i}, \mathrm{~A}_{j}, \mathrm{~B}_{j}, \Theta_{j}\right)
$$

with $\rho_{j}$ as the proportion of segment $\mathrm{j}, \rho_{j}>0 \forall j, \sum_{j=1}^{J} \rho_{j}=1$, while $\mathrm{A}_{j}$ and $\mathrm{B}_{j}$ represent the segment-specific vector for segment $\mathrm{j}$, and $\Theta_{j}$ indicates the regression variance matrix.

The FIMIX-PLS algorithm is based on log-likelihood (LnL, henceforth) maximization, which uses an Expectation-Maximization (EM, henceforth) formulation to ensure model convergence. The objective function to be maximized can be formalized as:

$$
L n L=\sum_{i=1}^{I} \sum_{j=1}^{J} \zeta_{i j} \ln \left(f\left(\gamma_{i} \mid \delta_{i}, \mathrm{~A}_{j}, \mathrm{~B}_{j}, \Theta_{j}\right)\right)+\sum_{i=1}^{I} \sum_{j=1}^{J} \zeta_{i j} \ln \left(\rho_{j}\right)
$$

where $\zeta_{\mathrm{ij}}$ is expected to be 1 whenever observation $\mathrm{i}$ is part of segment $\mathrm{j}$ ( 0 otherwise). Expected values for $\zeta_{\mathrm{ij}}$ define the segment-specific probability membership $\mathrm{P}_{\mathrm{ij}}$ of observation $\mathrm{i}$ belonging to segment $\mathrm{k}$, and are calculated using Bayes' theorem. The EM procedure is repeated until convergence is achieved. In each iteration, new segment proportions are calculated, which are based on the previously estimated expected values of $\mathrm{P}_{\mathrm{ij}}$. Afterwards, $\mathrm{N}$ ordinary least squares regressions are estimated, whereby $\mathrm{N}$ is equal to the number of defined relationships in the model structure. Those regressions are used in the next iteration to improve the outcome of $P_{i j}$. The procedure continues until the LnL no longer improves noticeably, and a pre-defined convergence criterion is met. Further detail on the FIMIX-PLS algorithm can be found in Ringle et al. (2010). 


\subsection{Results}

In this section, we present evidence on unobserved heterogeneity in savings behavior, obtained through FIMIX-PLS. Following the recommended approach of Ringle, Sarstedt, and Mooi (2010), we use Partial Least Squares (PLS) path coefficients as inputs for the FIMIX-PLS procedure. We first motivate the appropriate number of segments and explain how households are assigned to segments. Then, based on individual bootstrapping for each segment, we estimate segment-specific path coefficients for the psychological characteristics and compare the segments across demographic and socio-economic variables. Appendix A2.2 provides FIMIX-PLS pseudocode, including all details of our analysis and statistical procedure, as well as screenshots.

\subsubsection{Latent Heterogeneity and Total Household Savings}

Total household savings reflect a household's aggregate savings at the time of the survey. Model estimation starts with two segments and is repeated for an ever-increasing number of segments. To ensure the size of each segment remains meaningful for interpretation given the sample size, we stop the procedure after seven segments. In line with the general recommendations of Ringle et al. (2010) as well as Sarstedt et al. (2011), we choose the appropriate number of segments not only based on how the different segment solutions score regarding various information criteria, but also based on an assessment of whether the resulting individual segments are well-separated from each other as indicated by the entropy statistic (EN), are balanced in terms of their relative size, and are readily identifiable in terms of displaying meaningful differences regarding the various demographic and socio-economic variables (e.g., age, education, income). Following this procedure, a two-segment solution is selected. This segment solution features balanced segment sizes, with Segment 1 containing 52\% of respondents and Segment 2 containing $48 \%$ of respondents. Moreover, there are consistent differences between the two segments in terms of the demographic and socio-economic variables. Finally, this solution has an entropy statistic (EN) of 0.87, which is considerably above the minimum threshold of 0.50 as suggested by Ringle et al. (2010). Accordingly, the individual segments that we analyze are well-separated from each other.

The segmentation procedure describes each household in terms of the probability it belongs to any given segment. In FIMIX-PLS, subjects are typically simply assigned to the segment for which the probability of segment membership is highest (cf. Matthews et al., 2016). However, to 24 
be conservative and ensure that we unambiguously classify each individual to a segment, we required a minimum probability and used this as a cutoff level when assigning individuals to segments.

Table 2.2 Total household savings - FIMIX-PLS results

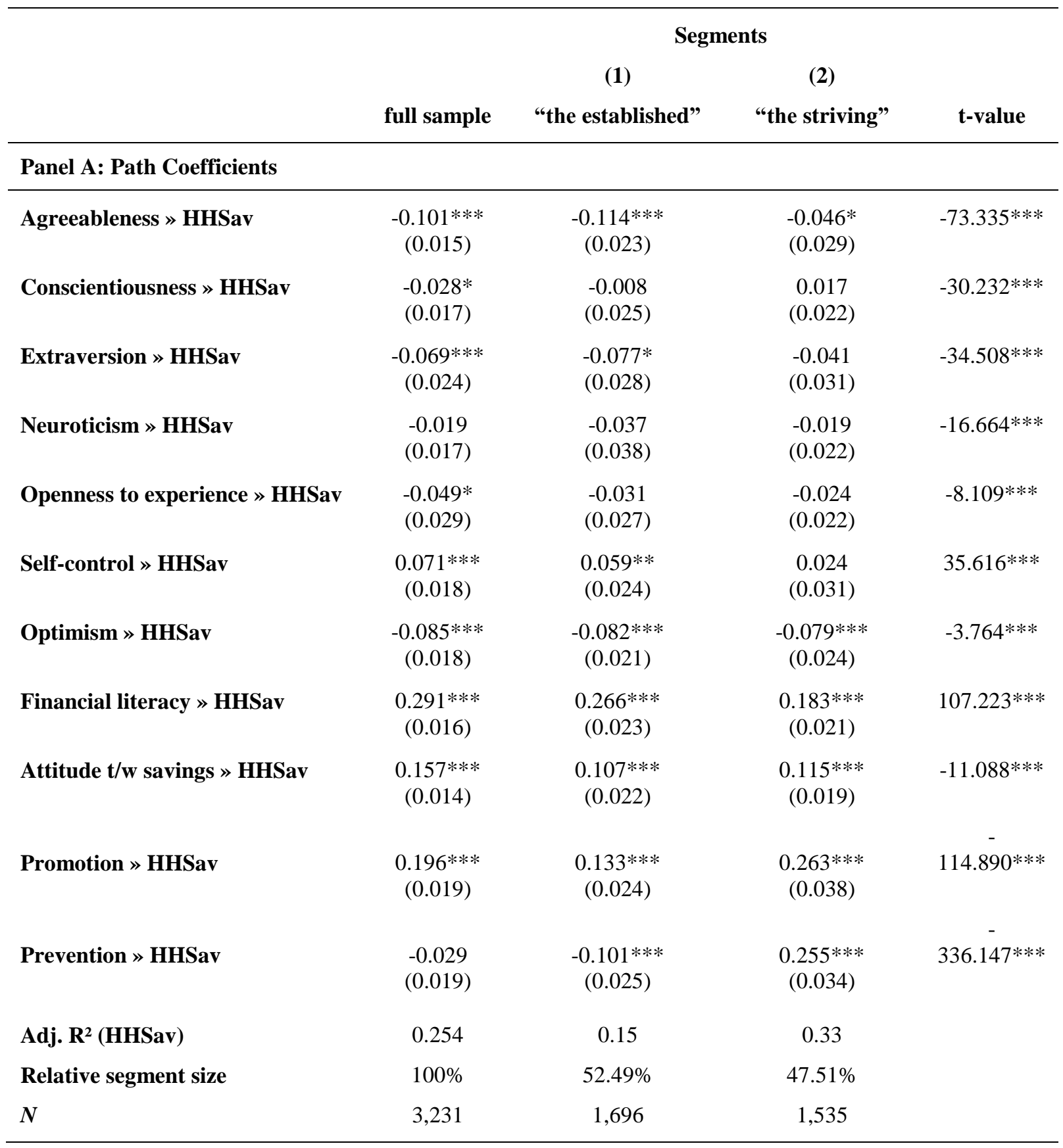


Table 2.2 Total household savings - FIMIX-PLS results - continued

Segments

(1)

(2)

full sample "the established" "the striving" t-value

\begin{tabular}{lcccc}
\hline Panel B: Descriptive Statistics & & & & \\
\hline Age: 18-24 & 0.07 & 0.04 & 0.11 & $-7.689^{* * *}$ \\
Age: $\mathbf{2 5 - 3 4}$ & 0.16 & 0.11 & 0.20 & $-7.097^{* * *}$ \\
Age: $35-44$ & 0.17 & 0.12 & 0.21 & $-7.100^{* * *}$ \\
Age: $45-54$ & 0.20 & 0.16 & 0.24 & $-5.317^{* * *}$ \\
Age: 55-64 & 0.17 & 0.21 & 0.13 & $5.681^{* * *}$ \\
Age: 65+ & 0.23 & 0.35 & 0.10 & $17.665^{* * *}$ \\
Income (in £ x1,000) & 26.43 & 31.21 & 21.13 & $17.238^{* * *}$ \\
Married & 0.49 & 0.57 & 0.39 & $10.456^{* * *}$ \\
High education (university) & 0.44 & 0.51 & 0.35 & $9.608^{* * *}$ \\
\# HHmembers & 2.47 & 2.31 & 2.63 & $-7.403^{* * *}$ \\
Employed & 0.54 & 0.50 & 0.59 & $-4.863^{* * *}$ \\
Child in household & 0.28 & 0.20 & 0.37 & $-10.691^{* * *}$ \\
Female & 0.50 & 0.45 & 0.55 & $-5.800^{* * *}$ \\
Total household savings (in $\mathfrak{E}$ & & & & $50.022^{* * *}$ \\
x1,000) & 19.04 & 35.91 & 0.40 & \\
\hline
\end{tabular}

Note: This table presents global and individual path coefficients based on FIMIX-PLS procedures in Panel A and descriptive statistics for the entire sample and the different segments in Panel B. Standard errors in parentheses. 'HHSav' abbreviates total household savings. In Panel A, t-values are based on a multi-group analysis to determine statistically significant differences in path coefficients between segments following Chin (2000) and Chin and Diddern (2010). T-values in Panel B are based on a comparison between the two segments. ***, **, and * denote statistical significance at the $1 \%, 5 \%$, and $10 \%$ level, respectively. Of the 3,382 observations in the total sample, $4.46 \%$ could not be uniquely classified to a particular segment in the FIMIX-PLS procedure and are excluded from the analysis (see Appendix A2.3 for details). Accordingly, the total number of observations reported in this table is 3,231 instead of 3,382 .

As there are no strict guidelines in the literature as to which cutoff level to employ, we assessed the distribution of segment membership probabilities, and selected the most conservative 
probability cut-off level for which we can uniquely assign the majority of the sample to a segment.

Based on this process, we selected an $85 \%$ probability cutoff level for individuals to be classified as belonging to a particular segment, which is considerably more conservative than the minimum $50 \%$ probability cutoff level used by Matthews et al. (2016). Overall, $95.54 \%$ of the 3,382 households exceed the $85 \%$ probability threshold and can be unambiguously classified to one of the two segments, resulting in analyzing a final sample of 3,231 households. This result confirms that the individual segments that we analyze are well-separated from each other, as already indicated before by the high entropy statistic (EN) of this segment solution. Appendix A2.3 gives detail on the segment membership probability distribution.

Panel A of Table 2.2 provides an overview of the global (i.e., full sample) path coefficients as well as individual path coefficients for each of the two segments. The coefficients in Panel A can be interpreted analogously to SEM path coefficients. We follow Chin (2000) and Chin and Diddern (2010) in conducting a multi-group analysis based on $t$-tests to determine the statistical significance of differences in path coefficients between the two segments. A comparison of both segments on their demographic and socio-economic variables is presented in Panel $\mathrm{B}$. We use $t$ tests to establish whether the segments are significantly different from each other regarding these descriptive variables. To provide meaningful labels to the segments, we inspect the demographic and socio-economic variables in Panel B for differences. While all variables are significantly different across the two segments, the largest differences are in household wealth and income. Comparing household savings, the mean (median) in Segment 1 is $£ 35,910$ ( $£ 25,000$ ), while the mean (median) in Segment 2 is only $£ 401$ (£50). Similarly, whereas households in Segment 1 have a mean (median) annual income of $£ 31,214$ ( $£ 24,500)$, households from Segment 2 have a mean (median) annual income of only $£ 21,135$ (£17,500). Those individuals classified as belonging to Segment 1 are also more likely to be university-educated, to be older with fewer dependent children, to be married, and to be more likely not to work. The difference in employment levels is likely due to more retirees in this older segment, who are not classified as being active in the labor market. Given the differences between the segments, particularly in age and income, we label Segment 1 as "the established" and Segment 2 as "the striving". In the next section, we describe and interpret differences between the groups regarding the impact of the psychological characteristics on savings behavior. 
The reported path coefficients in Panel A of Table 2.2 show that agreeableness is significantly negatively associated with total household savings, both for the established segment and for the striving segment. For the established, scoring one point higher on agreeableness reduces total household savings by $£ 114$. For the striving, a one-point increase in agreeableness corresponds to a $£ 46$ reduction in total household savings. Given the low mean household savings for the striving, however, the economic effect of agreeableness on total household savings is much stronger for this group than for the established. More specifically, for the striving, a one-point increase in agreeableness translates into a reduction of total household savings of approximately $11 \%$ at the mean, while for the established, the comparable economic effect on total household savings is less than $1 \%$. The findings regarding the impact of agreeableness on total household savings complement previous work in other areas of financial behavior, where recent research has found that agreeable people earn less and have lower credit scores than their less agreeable peers (Bernerth, Taylor, Walker, and Whitman, 2012; Judge et al., 2014). The results also extend previous findings within the household savings literature. In particular, neither Nyhus and Webley (2001) nor Brown and Taylor (2014) found a significant effect of agreeableness. Nyhus and Webley (2001) provide a rationale for why agreeable people might save less. This is because agreeableness describes people's propensity to act pro-socially towards others, and this concern for others might translate into generosity in terms of gift-giving, inter vivos transfers, or charitable giving. In contrast, less agreeable individuals may be more likely to keep their money for themselves, and will thus be able to build up higher household savings.

Members of the established segment show a marginally significantly negative relationship between extraversion and household savings, while we do not find such an effect for the striving segment. For the established, scoring one point higher on the scale for extraversion corresponds to a reduction in total household savings of about $£ 77$. The negative effect of extraversion on total household savings is consistent with the results reported by Brown and Taylor (2014), who also found a significant negative association between extraversion and a household's asset levels. One mechanism which could explain why extraversion is not related to savings in the striving segment is the tendency for extraverts to be more concerned with social status (Roberts and Robins, 2000). For example, extraverts actively seek out status at work (Barrick, Stewart, and Piotrowski, 2002). Those with higher incomes might face greater financial pressures to express their status through expenditure (i.e., "keeping up with the Joneses"), decreasing the resources 
available to save for the future. Alternatively, Nyhus and Webley (2001) suggest that extraverts' disposition towards spending time with others could explain this relationship. Through meeting other people, extraverts might be more frequently exposed to consumption patterns that make them less inclined to save.

Additionally, more frequent interaction with other people is typically also associated with additional expenditures. Inviting people home, visiting other homes, and going out for dinner, parties, or concerts involves spending in one way or another, which will reduce one's opportunity to save. Potentially, the difference in the presence of an effect of extraversion across the two segments can be explained by the fact that the limited budget and/or the more modest living conditions of the striving may lead them to not even consider giving in to any extravert tendencies and go out for dinner or host a party at their home, leading to an absence of an effect of this personality trait on total household savings, while for the established, giving in to extravert tendencies is a real possibility.

Financial literacy, which is typically associated with higher savings levels (Lusardi and Mitchell, 2007; van Rooij et al., 2011), is found to have a strong, positive relationship with total household savings, both for the established segment as well as for the striving segment. Due to the low amount of savings of the striving segment, financial literacy has a particularly strong economic effect for these individuals, with an additional point on the financial literacy scale being associated with $£ 183$ more in savings, which corresponds to an increase of $46 \%$ at the mean. As such, those in the striving group may be in a position to benefit to a greater degree from higher levels of financial sophistication.

Self-control, which is often associated with increases in the rate at which people save for the future (Thaler and Shefrin, 1981; Thaler and Benartzi, 2004), is significantly and positively associated with total household savings for the established segment. An additional point on the self-control scale amounts to an increase of $£ 59$ in total savings for these households. In contrast, we find that self-control has no significant effect on household savings for striving households. This suggests self-control may only contribute to determining savings outcomes for those who have the financial opportunities to save. For example, as established households face fewer financial constraints, this means they have more discretionary expenditure they can choose to defer into the future, or spend in the present period. As those with greater self-control will resist 
immediate temptations to consume, they will achieve greater savings rates. Self-control can work for these individuals in that it helps them to be able to resist immediate consumption temptations. For the striving, however, given their higher levels of financial constraints (and thus smaller amount of discretionary expenditure), giving in to immediate consumption temptations may not even be an option, and this would explain why self-control is not related to total savings for households in this segment. In other words, self-control will only impact household savings in the presence of opportunities to save money.

We next consider the role of optimism on household's savings, where we find that more optimistic individuals hold less in savings. This result holds for households in both the striving and the established segment. Given that the dispositional optimism literature views optimism as generalized positive expectations about future events (Scheier, Carver, and Bridges, 1994), we would therefore expect households who are optimistic about future prospects to not allocate sufficient money to savings, as they do not feel the need to save. These results are also consistent with previous research, such as Vanden Abeele (1988), who showed a relationship between shortterm savings and consumer optimism (using Katona's index of consumer expectations, which was later developed into the well-known University of Michigan Consumer Sentiment Index).

The impact of saving motives differs again between the two segments. Promotion-oriented saving motives relate to objectives such as saving to build up a deposit to buy a property, while prevention-oriented saving motives relate to objectives such as saving to reduce the impact of future financial burdens, such as a car repair. For established households, saving motives that are promotion-oriented are associated with an increase in total household savings, while holding more prevention-oriented saving motives are associated with having less in total household savings. One explanation for this finding is that even among relatively high income populations, many people still live under financial constraints (Lusardi, 2009). For example, almost half of all Americans could not make an unplanned expenditure of just $\$ 400$ without increasing their debt or selling a possession (Federal Reserve Board, 2016). Therefore, the objective to save to avoid financial harm might characterize those living in financial constraints (and therefore who cannot afford to experience financial problems), which then explains the differences in savings within this segment. A related explanation is that those in the established group might only be worried 
about their future (and thus focus on prevention motives) if they have previously experienced adverse financial settings, which explains the differences in savings.

In comparison, both promotion and prevention motives are positively related to household savings for striving households. The economic impact of promotion and prevention motives are also approximately equally pronounced (£263 vs $£ 255$ more total household savings per additional saving motive held, respectively). For the striving, having specific savings motivations, regardless of whether they are related to trying to achieve gains or avoid losses, seems to promote greater savings. This effect might be explained by the fact that having a saving motive makes the relatively abstract notion of "saving money" more concrete, while having a reason to save could also act as a commitment device which increases the motivation to follow through in putting aside money, even when one's household budget is relatively limited. Ashraf et al. (2006) support the notion that goals can act as such commitment devices, while Gugerty (2007) discusses how commitment devices might be especially valuable for the savings behavior of the less affluent.

Finally, for both the striving and established segment, savings attitude is positively associated with total household savings. Having a more favorable attitude towards savings might make it easier to save as the benefits are clearer and there is less of a barrier to overcome when convincing oneself to save. In line with process models of attitude-behavior relations (e.g., Fazio, 1986), this result suggests that a positive inclination towards savings benefits its actual execution. Moreover, this finding is consistent with studies that find that a household's debt attitude has a strong impact on being indebted or not (e.g., Livingstone and Lunt, 1992; Davies and Lea, 1995).

\subsection{Discussion of Results}

Our findings demonstrate the importance of accounting for latent heterogeneity in models predicting savings behavior from psychological characteristics. We find that the Big Five personality traits do not always influence savings behavior similarly across different groups of individuals. For example, extraversion negatively influences total household savings, but only for those in the established segment. Similarly, while financial literacy positively influences total household savings for both the established and striving segment, self-control only has a positive 
impact on household savings for those in the established segment. Moreover, the economic effect sizes of these psychological characteristics vary greatly across the different groups of households.

Previous work has frequently found inconsistent relationships between the Big 5 personality traits and savings outcomes: the variation across (demographic) segments as reported in this paper may help explain these irregular findings. Exploring the differences in how psychological characteristics relate to savings behavior can provide new theoretical insights. Saving motives, for example, no matter whether they are promotion- or prevention-oriented, are positively related to total household savings for those categorized as striving, while there is more differentiation in the relationship between different types of saving motives and total household savings for those categorized as established. This might suggest that for less affluent groups, having a savings objective per se acts as a commitment device to save, in the spirit of Gugerty (2007) and Ashraf et al. (2006). A study by Kast et al. (2012) on the effectiveness of self-help groups and peer pressure as a commitment device for precautionary savings suggests that especially the social dimension of such commitment devices are effective in increasing savings.

Combined with the strong effect of financial literacy on total household savings for the striving, interventions to improve financial outcomes in low income groups might therefore particularly benefit from trying to improve their perceived need as well as motivation to save, either through financial training, or initiatives such as savings clubs, which can act as commitment devices. Recent work on the impact of financial education on downstream financial behaviors suggests that traditional forms of classroom training have limited effectiveness, and point to the need of providing just-in-time financial training through, for example, coaching (Fernandes et al., 2014). In this regard, Linardi and Tanaka (2013) stress the critical role of focusing on building individuals' capacity to save, for example, through offering career advice.

Finally, a more positive attitude towards savings is associated with higher total household savings for both the striving and the established segment, indicating it is a powerful motivator to improve savings behavior. The aforementioned personal coaching or savings clubs could help households develop a more positive savings attitude and thus build more savings. In particular, the social dimension of meeting individuals facing similar challenges might be encouraging. 


\subsection{Implications and Conclusion}

Understanding heterogeneity in individuals' savings behaviors as well as the psychological motivators of this behavior is increasingly important as the self-responsibility of individuals to manage long-term savings, such as pensions, increases (cf. van Rooij et al., 2011). The ongoing liberalization of regulation regarding the ability to withdraw funds during the pension decumulation phase means understanding the motivations underlying different groups' propensity to save is crucial for society's (financial) wellbeing (Loibl et al., 2016). Although there have consistently been found to be differences across individuals in savings behavior, a systematic study on the effect of household characteristics, personality traits, and saving motives is lacking.

The results of this study contribute to understanding the differential impact of psychological and household characteristics across various groups of individuals. The findings have implications for policymakers, who in order to promote savings behavior in subgroups less pre-disposed to save, can incorporate an appreciation of the complexity of the relationships between psychological as well as household characteristics on savings behavior. Currently, most policymakers are concerned with using financial literacy programs to improve savings rates. Recent research indicates that, overall, formal financial education has limited effectiveness of improving financial behavior long-term and studies point to an important role of just-in-time financial training as well as psychological characteristics to understand the true effects of financial literacy interventions on downstream financial behavior (cf. Fernandes et al., 2014).

Indeed, Bertrand et al. (2006) suggest that standard public policy interventions aimed at improving financial literacy may be ineffective when financial behavior is controlled more by circumstances than by intentions, as would be the case for more vulnerable consumers. Our study complements existing research by indicating that it is not only important for policymakers to be aware of the psychological characteristics of the individuals whose financial literacy they are trying to improve, but also to realize that there is often latent heterogeneity across groups in terms of the impact psychological characteristics have on savings behavior. For example, interventions to improve self-control might be effective, but only for certain subgroups of the population, and not for the population as a whole. We find that for a more vulnerable segment of society, which we label as the striving, instead of focusing on self-control, policymakers interested in 
stimulating saving should look into ways to stimulate the adoption of a positive savings attitude as well as saving goals, which can act as commitment devices to follow through.

Policymakers often segment the population using their behavior and sometimes psychological characteristics to efficiently identify and target specific groups of interest. For example, the UK Financial Conduct Authority (2014) issued a report on consumer credit in which they segment individuals based on their credit usage and classify them into different borrower typologies. This segmentation reveals major differences in credit usage between segments. However, such approaches are limited in the sense that they only use observed behavioral differences and may overlook the latent heterogeneity in the data. Moreover, standard segmentation approaches may be potentially biased by the subjective perspectives of the investigators who may hold preconceived ideas about how to categorize groups. Applying an approach such as FIMIX-PLS provides a more objective segmentation which is free from potential investigator bias.

A limitation of the approach is that it is data-driven and hence not suited to test a priori hypotheses. Despite this, should FIMIX-PLS be applied more widely, specific patterns emerging across different samples of individuals will help in the development of new theory, as complex patterns emerge and require new explanations. Accordingly, we encourage follow-up studies applying the FIMIX-PLS methodology to other samples, to examine the results' generalizability across different respondent pools and countries. It is important to note that the aim of our paper is not to provide a "cure-all" or "final" segmentation regarding household savings behavior, but rather to encourage researchers to step away from the typical "average effect" approach that tries to generalize across the available sample of the population.

In conclusion, our study provides a novel set of results which indicate that the impact of household characteristics, personality traits, and saving motives on savings behavior varies across different (demographic) segments. The main implication of these findings is that it is important to explicitly take unobserved heterogeneity into account when studying the role of personality traits, saving motives, and other household characteristics in consumer financial decision making, such as savings behaviors. By applying the innovative FIMIX-PLS methodology to a new setting, we hope our research encourages others studying consumer financial decision making to consider the benefits of this approach in understanding the rich complexity of the relationships between demographic groups and psychological characteristics. 


\section{Past Performance Framing and Investors' Belief Updating - Is Seeing Long-Term Returns Always Associated with Smaller Belief Updates? ${ }^{4}$}

\subsection{Introduction}

Prior research shows that updates in individual investors' beliefs, such as return expectations and risk perceptions, drive their investment decisions (Hoffmann, Post, and Pennings 2013). When updating their beliefs, individual investors often extrapolate past return experiences (Dominitz and Manski 2011; Greenwood and Shleifer 2014). In this paper, we examine how framing of past performance information affects individual investors' belief updating. In particular, we analyze whether presenting longer information horizons as a default option leads to smaller updates in investors' beliefs. Because smaller belief updates are associated with less active trading, effective framing of past performance information would have the capacity to positively affect investors' return performance (Barber and Odean 2000; Hoffmann and Post, 2016). We find that the effectiveness of showing long-term returns on reducing updates in beliefs depends on whether investors can easily opt out of their assigned default or not.

Our paper builds on previous work that examines how different evaluation and/or reporting frequencies as well as information horizons influence individual investors' decision making, such as Benartzi and Thaler (1995), Gneezy and Potters (1997), Fellner and Sutter (2009), Beshears et al. (2017), and Shaton (2015). These other studies typically recommend longer evaluation and information horizons to improve individual investor decision making in terms of overcoming myopic loss aversion, making fund flows less sensitive to past returns, or reducing trading volume. An important distinction of our paper compared to previous work is that we focus on the

\footnotetext{
${ }^{4}$ This chapter is co-authored with Arvid Hoffmann (University of Adelaide) and Thomas Post (Maastricht University) and is published in the Journal of Behavioral and Experimental Finance.
} 
effect of different information horizon defaults on belief updates when investors have access to additional information. Prior studies analyze interventions which restrict access to information and make it cumbersome or even impossible for subjects to opt out of the default. Our setting more closely resembles individual investors' actual decision making environment where individuals have immediate access to alternative information horizons and can easily opt out of the default.

We perform two experiments, one in the lab and one online, in which we place subjects in a situation resembling an online brokerage environment. We present them with a stock portfolio to assess their belief updates over six evaluation rounds. Subjects receive portfolio performance information after each round. Subjects are randomly assigned to three experimental conditions, which differ regarding the default information horizon that is shown to them (i.e., annual, monthly, daily). For each subject, this default information horizon is held constant over subsequent rounds of the experiment. We conduct our first experiment in a controlled laboratory environment. The lab experiment focuses on the effect of varying the default information horizon. Subjects can easily opt out of the default and obtain past performance information on each of the three information horizons in each round. To test the generalizability of our laboratory results to situations outside the lab and compare with past studies that restrict subjects' opportunity to view alternative information horizons, we conduct a second experiment online. This experiment includes both an exact replication of the original laboratory experiment, as well as an alternative version of the experiment in which subjects cannot opt out of the default and have to stay in the assigned default information horizon, consistent with previous studies on the effect of restrictive interventions by Beshears et al. (2017) and Shaton (2015).

We find that in the restrictive version of our experiment, a longer past return horizon reduces belief updating of subjects. In the non-restrictive version of our experiment, when subjects are able to opt out of the default they are assigned to, varying the default does not, on average, impact the magnitude of belief updating. However, an important result emerges when comparing subjects staying in the default versus those opting out of the default (about half of the subjects opt out of the default). Specifically, similar to the results for the restrictive version, subjects who stay in the default option reduce the magnitude of their belief updating when being shown returns over a longer information horizon. We find the opposite result for subjects opting out of the default. For subjects originally assigned to the longer information horizon, opting out presents them with 36 
returns over a shorter horizon, which are consequently associated with larger updates in their beliefs.

\subsection{Related Literature and Predictions}

We align and build on two streams of literature. The first stream of literature analyzes various interventions on the return information that investors receive and their impact on investor decision making. Most interventions address myopic loss aversion by manipulating the frequency by which investors either receive information or the investment horizon for which investors have to commit in advance. Benartzi and Thaler (1995) show that investors who evaluate their investment portfolios more frequently are less willing to invest in risky securities. Gneezy and Potters (1997) experimentally evaluate myopic loss aversion and show that a longer evaluation period puts subjects in a broader frame, which leads to increased risk-taking. They restrict the choices of their subjects by not allowing them to switch between evaluation frequencies. When subjects are allowed to choose the evaluation frequency, however, they display a preference for frequent feedback (Charness and Gneezy, 2010). Related, Fellner and Sutter (2009) find that longer investment horizons and less frequent feedback are associated with less myopic loss aversion. When given the choice, subjects prefer on average shorter investment horizons and more frequent feedback, though.

Beshears et al. (2017) address myopic loss aversion using a field experiment in which subjects invest in mutual funds. They modify the degree of information given to subjects and observe the resulting equity allocation in a self-managed portfolio. Their results show that, in contrast to not providing any graphical past return information, presenting a graph of historical returns significantly increases the share of wealth allocated to equities. Looney and Hardin (2009) analyze default options for $401 \mathrm{k}$ retirement accounts. They employ simulations of retirement investments and investigate the effect of different information horizons, by modifying the horizon on which average historical stock market performance information is provided to investors. Their results show that longer information horizons reduce conservatism in retirement portfolios. Looney and Hardin (2009) also impose restrictions on subjects' choices. The work closest to ours in terms of the intervention studied is Shaton (2015). She analyzes the impact of a regulatory change in Israel requiring retirement funds to report performance using at least a 12-month time 
horizon for past returns (whereas, previously, the default was one month). After this regulatory intervention was implemented, fund flows were less sensitive to past returns, investors reduced their trading volume, and they invested more in riskier funds. As the regulation applied to a broad range of information outlets, past return information on shorter horizons was, however, virtually no longer available to investors. Our experimental manipulation differs, in that investors can access the shorter-term return information horizons as well.

The second stream of literature that we build on analyzes how investor belief updating impacts trading decisions. In general, investors have a tendency to trade frequently, and because of that earn lower returns (Barber and Odean, 2000). Hoffmann et al. (2013) and Hoffmann and Post (2016) show that frequent trading can be traced back to investors' belief updating. These authors find that investors change their assessment of expected returns and risk frequently and by large amounts. Moreover, they find that larger updates in beliefs induce more trading, resulting in lower returns. Thus, for a typical individual investor, frequent and large updating of beliefs does not seem to be consistent with a normatively rational strategy. Investors update beliefs by using simple heuristics. In particular, beliefs are formed and updated by extrapolating past returns (Dominitz and Manski, 2011; Greenwood and Shleifer, 2014). Experiencing positive returns makes investors more optimistic about future returns (and vice versa) and larger return experiences are associated with larger belief updates.

In our paper, we reconcile the literature on framing and defaults regarding past return information horizons with the literature on belief updating induced trading. That is, we implement an intervention that is aligned to investors' tendency to update beliefs by extrapolating past returns and at the same time is feasible to implement. Prior studies have restricted subjects' access to return information. Doing so is an intervention that may often not be possible to mandate. A milder and easier to implement intervention is setting a default for the past return information shown, but not restricting access to different information. However, it is unclear whether previous results generalize to settings where subjects can easily opt out of a default. In consequence, we investigate how different default information horizons affect belief updating in a setting which is more ecologically valid. In a brokerage account, investors usually get to see some overview table of portfolio summary statistics. They have the ability to view their portfolio performance for different time periods, such as the last day, month, or year. Brokers generally decide which time horizon to present as the default. Different performance horizons are available 38 
with a few mouse clicks. One version of our experiment restricts choices regarding the default and measures the resulting belief updates. Another version sets a default for the information presented first, but does not restrict subjects' access to additional information.

We expect that presenting longer portfolio evaluation horizons has a mitigating effect on individual investors' belief updating, at least when placing investors in a situation that restricts their choices by not allowing them to opt out of the default presentation format to view additional information on other return horizons. As returns appear less volatile in the longer-term, we expect subjects who are presented with portfolio performance over a longer information horizon to update their return expectations and risk perceptions less between the various evaluation rounds when compared to subjects who are presented with a shorter information horizon. When we introduce the opportunity to opt out of the default presentation format, we expect a different pattern. We expect the exact same pattern just described for subjects who remain in the default option and do not opt out. These subjects face the same scenario as those who were not given the choice to opt out of the default. In contrast, we expect the opposite pattern for subjects who opt out of the default. Subjects who opt out of the default are initially presented with a longer information horizon, but they retrieve additional information on a shorter return horizon when they opt out of the default, and vice versa. As argued above, returns over a shorter horizon appear more volatile and hence, subjects are expected to display an increase in belief updating when opting out of the default. On the contrary, if subjects are initially presented with a short return horizon and decide to opt out (thus viewing information on a longer horizon, which appears more stable), doing so will likely reduce belief updating.

\subsection{Study 1}

\subsubsection{Experimental Design}

Our experimental setup resembles an online brokerage environment. We present subjects with the performance of a stock portfolio and analyze the updating of their beliefs (return expectations and risk perceptions) over six evaluation rounds. The experiment is conducted in a laboratory setting and is designed in a way that all subjects are able to opt out of the default. Before the first round, we randomly allocate subjects to one of three treatments. Over all six rounds, subjects stay in the 
same treatment. The treatments differ in their default information horizon regarding past portfolio performance. Specifically, each subject will either see the last day's return, the last month's return, or the last year's return of their portfolio as a default, together with the Euro-values of their holdings. This scenario is ecologically valid, as online brokerage interfaces and the periodical brokerage statements that banks send to investors, often summarize portfolio performance for individual securities on an aggregate level and across different time frames.

We recruit subjects from a pool of business students enrolled at a medium-sized European university who complete the experiment in exchange for partial course credit. ${ }^{5}$ Before signing up, we informed subjects that the experiment would be about decision making behavior. At the start of the experiment, subjects were seated in a cubicle equipped with a computer and were instructed not to interact with each other. If a problem came up or any instructions were unclear, subjects were instructed to remain seated, raise their hand, and wait for the assistance of a proctor. Completion of the experiment took seven minutes on average. In total, 339 subjects completed the experiment. One hundred-and-fourteen subjects $(33.63 \%)$ were assigned to the daily condition, 113 subjects $(33.33 \%)$ to the monthly condition, and 112 subjects $(33.04 \%)$ to the yearly condition.

At the beginning of the experiment, subjects read an introductory text explaining that in the upcoming tasks they would be presented with a stock portfolio that they should imagine to be theirs. They were informed that they would be asked a series of questions about their beliefs and then shown their stock portfolio again. Subjects were instructed to assume that for each evaluation round, one month had passed since their last stock portfolio evaluation. To prevent subjects' beliefs being influenced by unobservable affective evaluation beyond mere financial returns (cf. Aspara and Tikkanen, 2010), the portfolio presentations do not contain any information about which individual stocks are contained in the portfolio. Likewise, returns are, regardless of their sign, presented in black font to avoid any impact on belief updates through displaying, for example, positive returns in green font and negative returns in red font (see e.g., Bazley et al., 2016). To rule out any possible identification effects in return patterns presented to subjects, we generate portfolio performance by simulating a random draw from a return

\footnotetext{
${ }^{5}$ On purpose, subjects are not incentivized based on performance. Whether returns follow, for example, a random walk, exhibit momentum or mean reversion is up to debate. Therefore, there is no clear objective answer to what would constitute a right or wrong belief update. 40
} 
distribution which mimics the first two moments of the Standard \& Poor's 500 stock market index over the 10 -year period preceding the experiment (i.e., daily mean return of $0.03 \%$, daily standard deviation of $1.26 \%$ ).

Figure 3.1 Examples of Returns Presented in Different Treatments

a. Daily information horizon

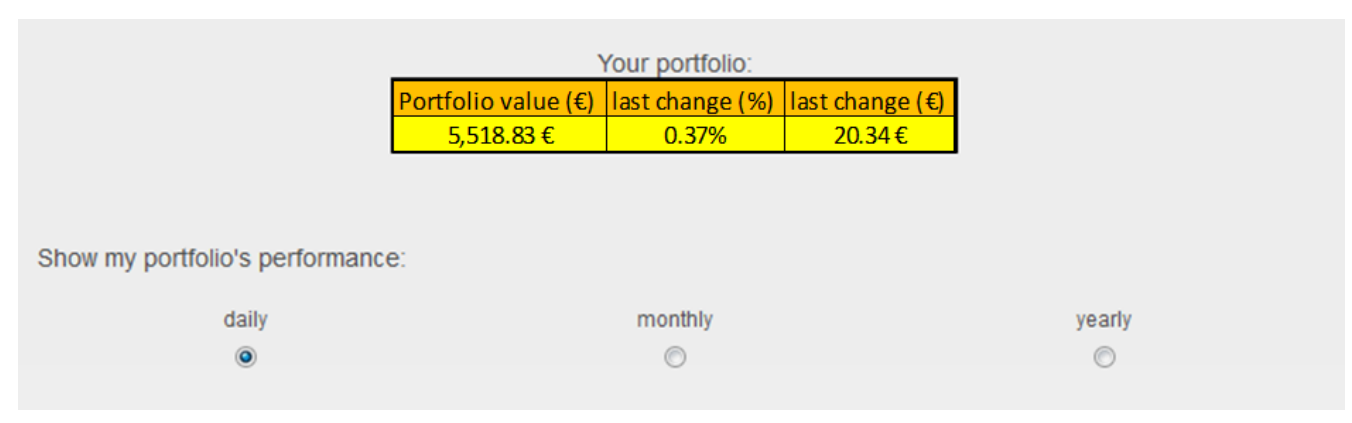

b. Monthly information horizon

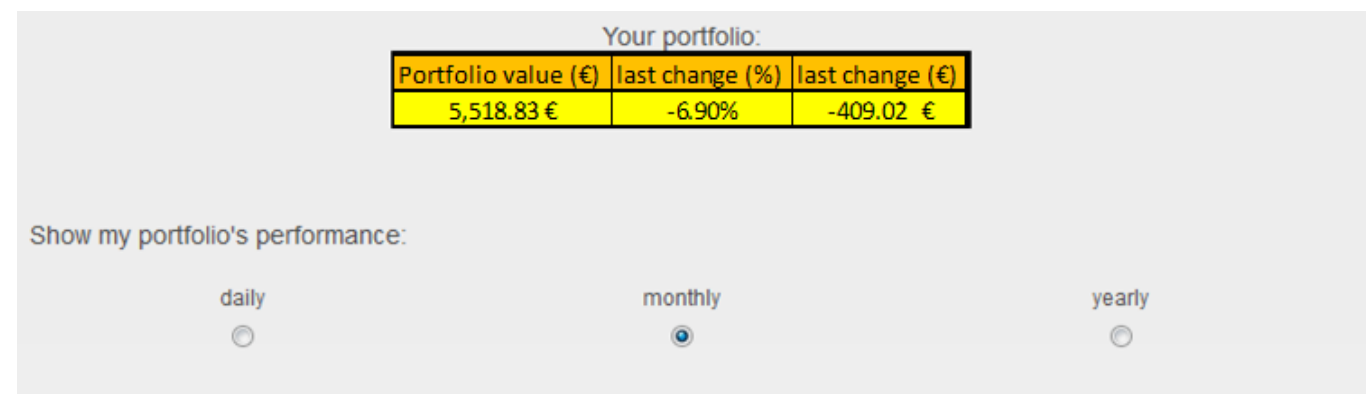

c. Yearly information horizon

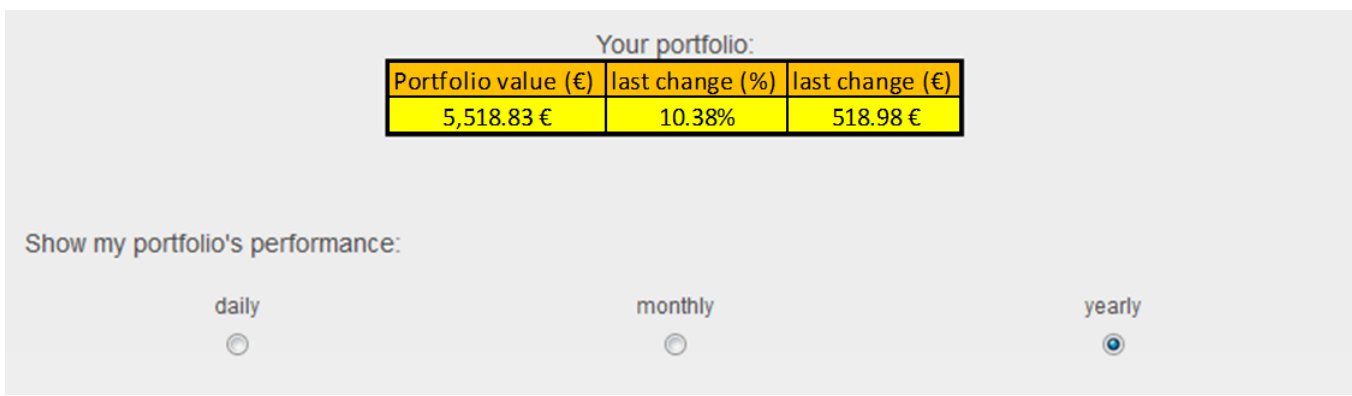

We present portfolio performance information to subjects in a table (Figure 3.1) indicating the total portfolio value in Euro, the last percentage change, as well as the last Euro change. This reflects a "typical" online brokerage interface where investors are able to see an overview table 
with summary statistics related to their portfolio when accessing their account. A real-world example is given in Figure 3.2.

Figure 3.2 Example of a Typical Brokerage Interface

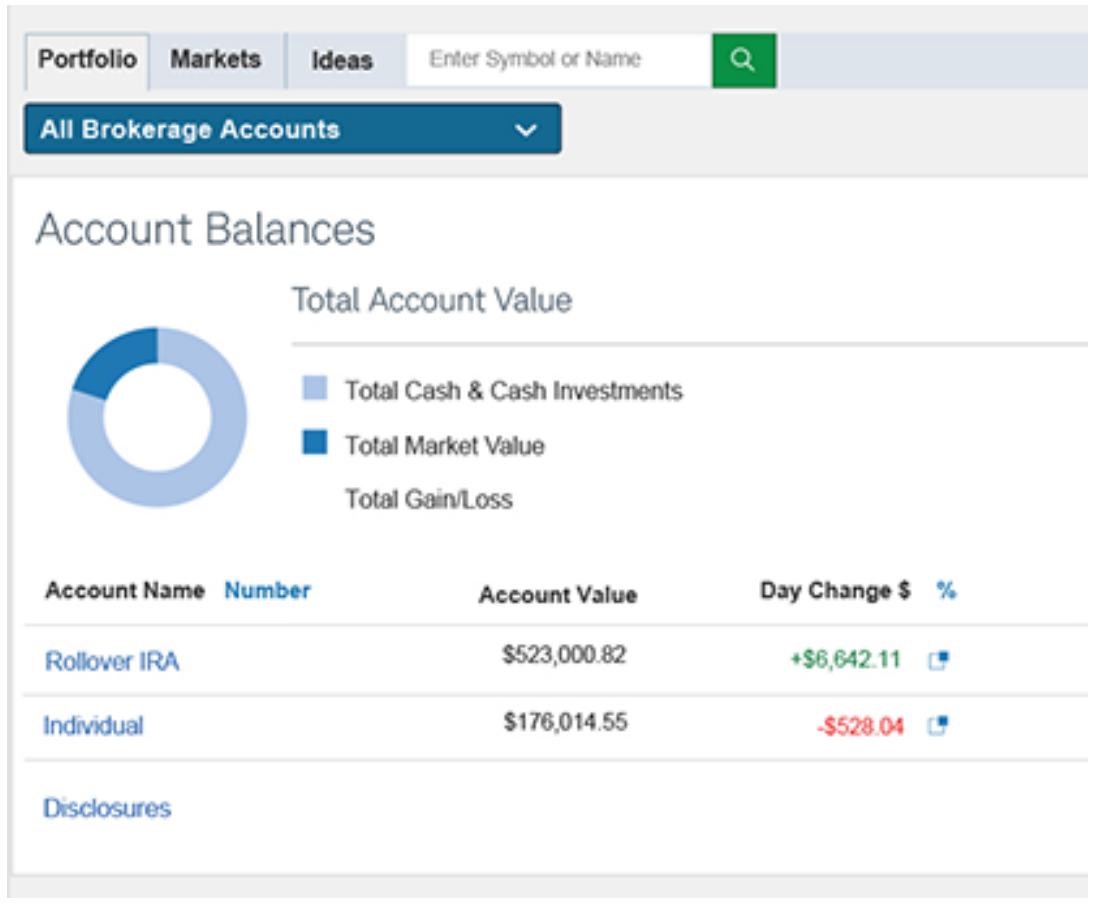

Note: This figure presents a screenshot from the Internet advertisement materials of a leading U.S. online brokerage service provider.

We focus on an overview table which is easier to comprehend since it is reduced to the most important information. In our setup, the initial information horizon of the "last" percentage and Euro change in portfolio value refers to a subject's respective experimental treatment group. Thus, each subject gets to see performance of either the last day, last month, or last year. Percentage changes shown reflect the relative change in value of the portfolio within the respective information horizon, that is, they are not scaled to the same terms (e.g., annual). Within one round of the experiment, the returns shown to subjects within each information horizon (i.e., daily, monthly, yearly) are the same across subjects. Even though displaying benchmark returns is required for the prospectus of certain financial products, such as mutual funds, online brokers typically do not add benchmark returns for comparison purposes on an overview page of their client's portfolio. Hence, we also decide to not display any benchmark returns. 
Below the table summarizing the portfolio, subjects see three radio buttons enabling an easy switch between the three different information horizons. Upon clicking on one of the buttons, the table provides return information about the corresponding horizon. We track subjects who opt out of the default. We also monitor the information horizon last viewed by each subject.

Below the table summarizing portfolio performance, we ask each subject to respond to two statements adapted from previous research measuring investor beliefs by Hoffmann et al. (2013). These belief measures predict trading behavior and have been shown to be reliable and crossvalidated measures of a subject's return expectations and risk perceptions. Hoffmann and Post (2016) use brokerage account data of actual individual investors to show that higher absolute updates in these beliefs lead to higher portfolio turnover. The first statement measures subjects' return expectations and asks how much a subject agrees with the following statement: "I expect my investment portfolio to have good returns next month." We measure risk perceptions by the second statement: "I consider investing to be risky next month." Answers are recorded on a seven-point Likert scale, anchored at 1="totally disagree" and 7="totally agree". 6

After each subject answers the statements measuring beliefs, that particular round of the experiment is complete and the subject will move on to the next round. Each subsequent round represents a one-month time lapse from the previous round. Subjects are again presented with the same screen with an overview table, radio buttons, and the statements measuring beliefs. The only difference from the previous round is that the corresponding returns and portfolio values are updated based on the monthly returns data. This procedure is repeated six times until we have elicited six subsequent beliefs in terms of return expectations and risk perceptions.

Once subjects finished the six rounds, further questions and scales are administered. We measure risk aversion with a single-item question from Dohmen et al. (2011). To measure financial literacy and the degree of a subject's financial sophistication, we use eight questions. A correct answer to each question counts as one point on a financial literacy scale. We use three basic financial literacy questions from Lusardi and Mitchell (2007a; 2007b). Because the subjects in our lab experiment are business students and we expect them to uniformly score high on basic

\footnotetext{
${ }^{6}$ As we are interested in within-subject changes in belief updates (i.e., changes in beliefs from one evaluation round to the other) we don't need to define what constitutes a "good return" or what is "risky." Each subject will have their own reference points in mind when participating in the experiment and as long as this reference point is stable during the experiment, we can consistently analyze changes in beliefs in our experimental setting.
} 
financial literacy, we also include five advanced financial literacy questions from the list of van

Rooij, Lusardi, and Alessi (2011). Finally, we ask subjects to indicate their age, gender, and nationality.

Table 3.1 Question Wordings

\begin{tabular}{|c|c|}
\hline Variable & Definition \\
\hline Age & Age in years \\
\hline Gender & Indicator variable: $1=$ subject being female, $0=$ otherwise \\
\hline Financial literacy & $\begin{array}{l}\text { Aggregate financial literacy score ranging from } 0 \text { to } 8 \text {, based on the number of correctly } \\
\text { answered questions }\end{array}$ \\
\hline Basic financial literacy & $\begin{array}{l}\text { Aggregate basic financial literacy score based on three basic questions from Lusardi and } \\
\text { Mitchell (2008) }\end{array}$ \\
\hline 1 & $\begin{array}{l}\text { Suppose you had } 100 € \text { in a savings account and the interest rate was } 2 \% \text { per year. After } 5 \text { years, } \\
\text { how much do you think you would have in the account if you left the money to grow? [More } \\
\text { than } 102 € \text { ] [Exactly } 102 € \text { ] [Less than } 102 € \text { ] [Do not know] [Refuse to answer] }\end{array}$ \\
\hline 2 & $\begin{array}{l}\text { Imagine that the interest rate on your savings account was } 1 \% \text { per year and inflation was } 2 \% \text { per } \\
\text { year. After } 1 \text { year, how much would you be able to buy with the money in this account? [More } \\
\text { than today] [Exactly the same] [Less than today] [Do not know] [Refuse to answer] }\end{array}$ \\
\hline 3 & $\begin{array}{l}\text { Please tell me whether this statement is true or false. 'Buying a single stock usually provides a } \\
\text { safer return than a stock mutual fund'. [True] [False] [Do not know] [Refuse to answer]. }\end{array}$ \\
\hline $\begin{array}{l}\text { Advanced financial } \\
\text { literacy }\end{array}$ & $\begin{array}{l}\text { Aggregate advanced financial literacy score based on five advanced question from van Rooij et } \\
\text { al. (2011) }\end{array}$ \\
\hline 1 & $\begin{array}{l}\text { Which of the following statements is correct? If somebody buys the stock of firm B in the stock } \\
\text { market: [He owns part of firm B] [He has lent money to firm B] [He is liable for B's debts] } \\
\text { [None of the above] [Don't know] }\end{array}$ \\
\hline 2 & $\begin{array}{l}\text { Considering a long time period (for example } 10 \text { or } 20 \text { years), which asset normally gives the } \\
\text { highest return? [Savings accounts] [Bonds] [Stocks] [Don't know] }\end{array}$ \\
\hline 3 & $\begin{array}{l}\text { Normally, which asset displays the highest fluctuations over time? [Savings accounts] [Bonds] } \\
\text { [Stocks] [Don't know] }\end{array}$ \\
\hline 4 & $\begin{array}{l}\text { When an investor spreads his money across different assets, the risk of losing money: } \\
\text { [Increases] [Decreases] [Stays the same] [Don't know] }\end{array}$ \\
\hline 5 & $\begin{array}{l}\text { If the interest rate falls, what should happen to bond prices? [Rise] [Fall] [Stay the same] [None } \\
\text { of the above] [Don't know] }\end{array}$ \\
\hline Risk aversion & $\begin{array}{l}\text { Risk aversion based on response to the following question: "Are you generally a person who is } \\
\text { willing to take risk or do you try to avoid taking risks?" } 1 \text { = completely unwilling to take risks } \\
\ldots 11 \text { = fully prepared to take risks (Dohmen et al. 2011) }\end{array}$ \\
\hline Click & Indicator variable: $1=$ subject expressed beliefs in different treatment than default, $0=$ otherwise \\
\hline Time & Time needed to complete experiment (in minutes) \\
\hline Nationality & $\begin{array}{l}\text { Dummy variables taking the value } 1 \text { if subject's nationality is either Dutch, German, or another } \\
\text { nationality ("Other") }\end{array}$ \\
\hline Treatment & $\begin{array}{l}\text { Subject's randomly assigned treatment group (daily, monthly, or yearly) (determines default } \\
\text { return horizon presented) }\end{array}$ \\
\hline Return Expectation & $\begin{array}{l}\text { Return expectation, based on the statement "I expect my investment portfolio to have good } \\
\text { returns next month." ( } 1 \text { = totally disagree ... } 7 \text { = totally agree) (adopted from Hoffmann et al. } \\
\text { 2013) }\end{array}$ \\
\hline Risk Perception & $\begin{array}{l}\text { Risk Perception, based on the statement "I consider investing to be risky next month." ( } 1= \\
\text { totally disagree } \ldots 7=\text { totally agree) (adapted from Hoffmann et al. 2013) }\end{array}$ \\
\hline Returns & Portfolio returns \\
\hline
\end{tabular}

Note: This table presents variable definitions and an overview of the questions posed to subjects. Possible answers to multiple choice questions are shown in brackets, the correct answer is underlined. 
Table 3.2 Study 1: Summary Statistics

\begin{tabular}{|c|c|c|c|c|}
\hline Variable & mean & fraction & std & median \\
\hline Age & 22.1 & & 2.71 & 23 \\
\hline Gender & 0.42 & & & \\
\hline Financial literacy & 6.15 & & 1.66 & 7 \\
\hline Basic financial literacy & 2.61 & & 0.65 & 3 \\
\hline 1 & & $97 \%$ & & \\
\hline 2 & & $89 \%$ & & \\
\hline 3 & & $75 \%$ & & \\
\hline Advanced financial literacy & 3.54 & & 1.23 & 3 \\
\hline 1 & & $84 \%$ & & \\
\hline 2 & & $56 \%$ & & \\
\hline 3 & & $84 \%$ & & \\
\hline 4 & & $88 \%$ & & \\
\hline 5 & & $42 \%$ & & \\
\hline Risk aversion & 6.59 & & 2.28 & 7 \\
\hline Click & & $52 \%$ & 0.38 & 0.5 \\
\hline Time & 6.9 & & 1.77 & 7 \\
\hline \multicolumn{5}{|l|}{ Nationality } \\
\hline Dutch & & $32 \%$ & & \\
\hline German & & $43 \%$ & & \\
\hline Other & & $24 \%$ & & \\
\hline \multicolumn{5}{|l|}{ Treatment } \\
\hline Daily & & $34 \%$ & & \\
\hline Monthly & & $33 \%$ & & \\
\hline Yearly & & $33 \%$ & & \\
\hline Return Expectation & 4.13 & & 1.49 & 4 \\
\hline Risk Perception & 3.83 & & 1.49 & 4 \\
\hline$N$ & \multicolumn{4}{|c|}{339} \\
\hline
\end{tabular}

Note: This table presents summary statistics of selected key questions from Study 1. Standard deviation is abbreviated by "std". Percentages correspond to the fraction of correct answers for financial literacy questions and to the fraction of respondents who select a certain answer or belong to a certain group (for click, nationality and treatment).

\subsubsection{Descriptive Statistics and Data Quality}

Table 3.1 defines all variables used in our analyses. Table 3.2 provides summary statistics. The mean age of subjects is 22.1 years. The mean financial literacy score is 6.15 out of a maximum of 8 points. Fifty-two percent of subjects opt out of the default return information horizon and click 
to view a different return information horizon. The three treatment groups do not differ significantly regarding age, gender, or financial literacy, indicating that the random allocation of subjects to the different experimental conditions was successful.

To confirm the ecological validity of our experiment, we verify whether the experimental subjects behave similarly to actual individual investors who tend to update their beliefs by extrapolating past returns (Dominitz and Manski, 2011; Greenwood and Shleifer, 2014). Table 3.3 summarizes random effects panel regressions using belief updates as dependent variables. Belief updates are defined as the difference between beliefs expressed in one round and the previous round of the experiment. In model 1, the dependent variable is updates in return expectations, in model 2 updates in risk perceptions are the dependent variable. According to model 1, returns have a strong and significant positive effect on updates of return expectations. Higher past returns lead to increased expectations about future returns. Thus, our experimental results are consistent with real investor behavior. Subjects update their beliefs by extrapolating past returns.

Table 3.3 Study 1: Impact of Returns and Clicking Behavior on Belief Updating

\begin{tabular}{lcc}
\hline & $(1)$ & $(2)$ \\
\hline \multirow{4}{*}{ Returns } & $\begin{array}{l}\text { dependent variable: updates } \\
\text { of return expectations }\end{array}$ & $\begin{array}{c}\text { dependent variable: updates } \\
\text { of risk perception }\end{array}$ \\
\multirow{4}{*}{ Constant } & $2.56^{* * *}$ & $-1.74^{* * *}$ \\
& $(0.36)$ & $(0.35)$ \\
Observations & -0.012 & -0.03 \\
$N$ & $(0.05)$ & $(0.05)$ \\
& 1,695 & 1,695 \\
\end{tabular}

Note: This table presents random effects panel regression results with robust standard errors (in parentheses) clustered at the individual level. The dependent variables are updates of return expectations (model 1) and updates of risk perceptions (model 2). Updates are defined as the difference between beliefs in round $t$ and round $t+1$. Due to analyzing the data as panel, and having six evaluation rounds, we have five belief updates per subject, which is why the number of observations is five-times the number of subjects. ***, **, and $*$ denote statistical significance at the $1 \%, 5 \%$, and $10 \%$ level, respectively.

Model 2 shows that returns are significantly negatively related to updates in risk perceptions. Thus, a stock portfolio is regarded as less risky if returns were higher in the preceding round. This finding is consistent with the stylized fact that individuals implicitly assume a negative riskreturn relationship (Fischhoff et al., 1978; Ganzach, 2000; and Shefrin, 2001), which defies 46 
standard economic theory, but is consistent with reliance on affect and the representativeness heuristic.

Figure 3.3 Study 1: Return Expectations and Risk Perceptions

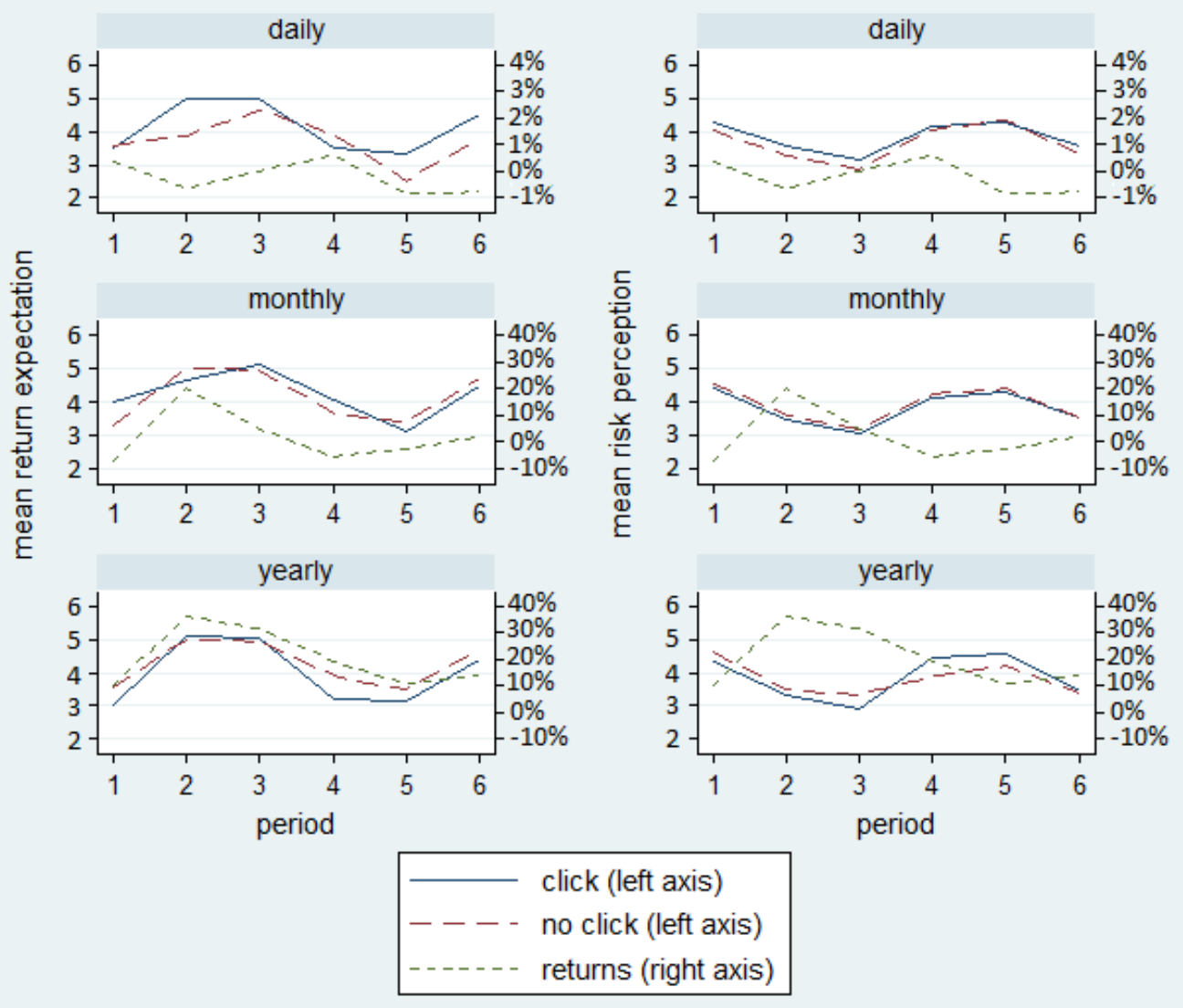

Note: This figure presents subjects' beliefs over the six experimental rounds. The left panel presents mean return expectations and the right panel shows mean risk perception. "Click" and "no click" refers to subjects who did or did not opt out of the default information horizon, respectively. Returns shown for each treatment in each round are summarized on the right-hand scale.

Figure 3.3 plots subjects' beliefs for each experimental version over the different evaluation rounds of the experiment. Return expectations are shown in the left panel and risk perceptions in the right panel. Each panel contains a separate graph for the different default information horizons. Each graph plots the returns specific to each treatment group. The positive association between past returns and updates of return expectations can be seen in the left panel, whereas the negative relationship between past returns and risk perceptions is visible in the right panel. 
Overall, the experimental subjects behave in line with previously reported findings on individual investors' belief updating (Hoffmann et al. 2013).

Figure 3.4 Study 1: Belief Updating Across Treatments
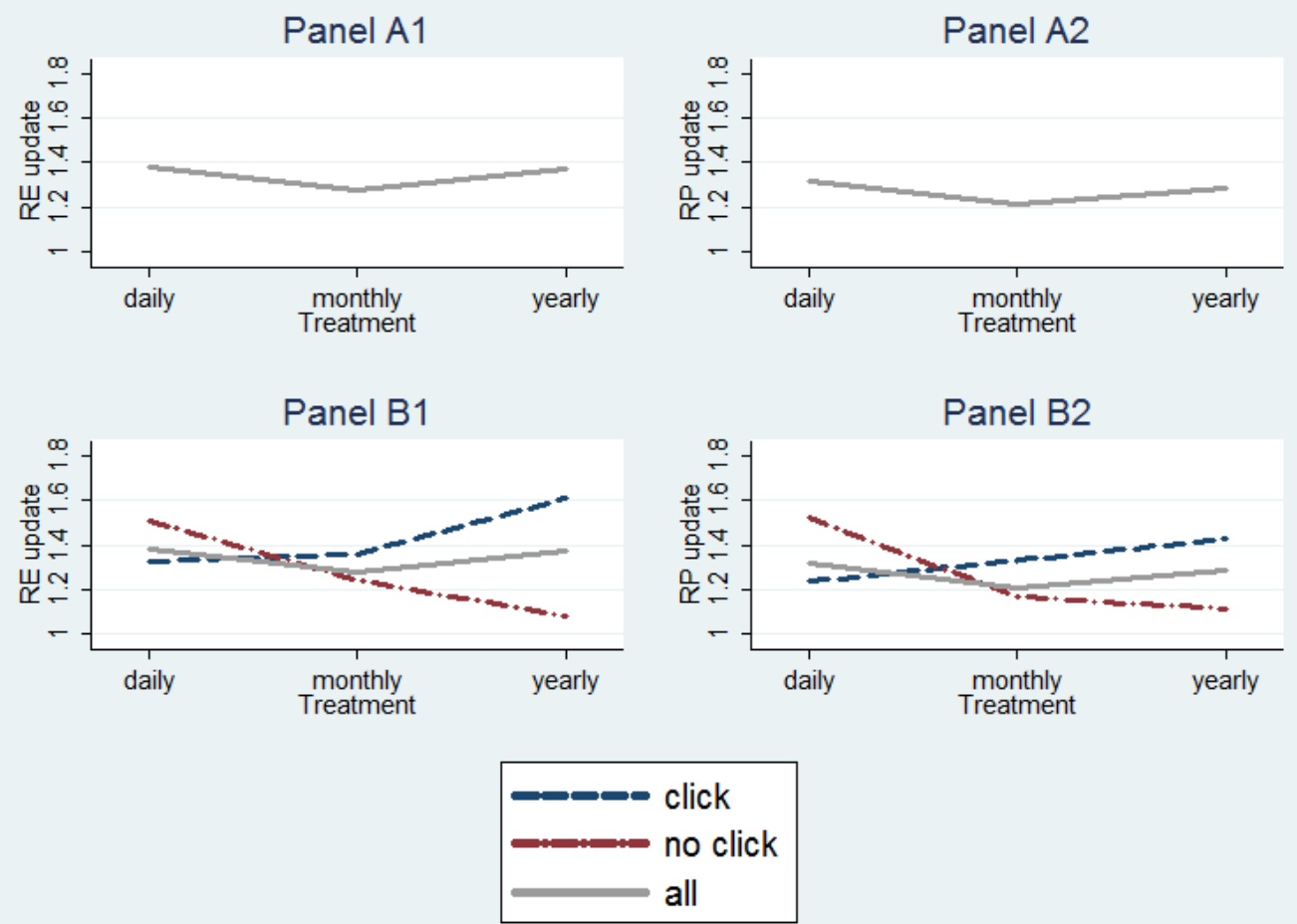

Note: This figure presents subjects' belief updating based on the three treatment groups. Analysis is based on subjects who completed the experiment in a laboratory environment. The graphs on the left summarize updates in return expectations ("RE"), whereas the graphs on the right show updates in risk perceptions ("RP"). Updates are calculated as the absolute difference between expressed beliefs and their counterpart from the previous evaluation round, leaving the figure to be an average of five individual assessments of belief updating. The three lines correspond to the group of all subjects as well as splitting them up based on whether they decided to opt out of the default in any given round ("click") or not ("no click").

\subsubsection{Results}

\subsubsection{Belief Updating Across Treatments}

Panel A of Figure 3.4 highlights differences in belief updating for the entire sample across treatments. We use absolute changes in beliefs as the dependent variable of interest, as both positive and negative belief updates provide reason to trade and have been shown to predict portfolio turnover in samples of actual investors (Hoffmann and Post, 2016). That is, belief 
updates are defined as the absolute value of the difference between the beliefs expressed in one evaluation round compared to the previous round. The graph on the left refers to updates in subjects' return expectations; the one on the right depicts updates in their risk perceptions.

As Figure 3.4 (Panel A) illustrates, differences between treatment groups for updates in return expectations and risk perceptions are very small across all experimental subjects (i.e., including those that opt out of the default information horizon and those that do not opt out). The monthly treatment group appears to express slightly lower belief updates than the daily and yearly groups. However, this difference is insignificant. Table 3.4 shows statistics on belief updating across treatments. Panels A1 and B1 summarize belief updating in terms of mean absolute changes in return expectations (Panel A1) and risk perceptions (Panel B1), respectively. The first two columns give an overview of the treatment groups and their respective sizes. The third column provides mean values for the entire sample and confirms that differences between treatments are very small. This finding illustrates that belief updating is not different when comparing the treatment groups across all experimental subjects. As an alternative measure of belief updating, Panels A2 and B2 contain the within-subject standard deviation of belief updating. The results using this measure are in line with mean absolute changes, which indicates that our results are robust to alternative measures.

Extending previous literature on default information horizons, we find that the default displayed for past return information has, on average, no effect on investor belief updating when opting out is easy. Next, we analyze if opting out of the default impacts a subject's belief updating. Besides the treatment itself, belief updating might be influenced by whether subjects remain in the default or opt out to see another information horizon.

\subsubsection{Opting Out of the Default Information Horizon and Belief Updating}

The bottom panel of Figure 3.4 plots subjects' belief updates based on whether or not they decide to opt out of the default information horizon. For both return expectations and risk perceptions, a new result emerges. First, belief updating for subjects who opted out of the default information horizon is positively associated with the length of the information horizon. For the yearly group, belief updates are larger than for the monthly group, which are again larger than for the daily group. That is, opting out of the default treatment increases updates of return expectations for the 
yearly group as compared to the monthly and daily group. Second, when looking at subjects who did not opt out of the default information horizon, the pattern reverses. For those staying in the default, there is a negative relation between belief updating and length of information horizon. That is, subjects in the yearly treatment update their beliefs less than those in the shorter information horizon treatments. All these differences, summarized in Table 3.4, columns (4) to (8), are statistically significant. Column (4) contains values for subjects who opted out of the default ("click"), Column (5) presents the corresponding values for those who did not opt out ("no click"). Columns (6) to (8) show the difference in means between columns (4) and (5) as well as the $t$-statistic and $p$-value.

Table 3.4 Study 1: Belief Updating Across Treatments

\begin{tabular}{|c|c|c|c|c|c|c|c|}
\hline & $\mathrm{N}$ & all & click & no click & difference & $t$-stat & $p$-value \\
\hline \multicolumn{8}{|c|}{ Panel A1: mean absolute changes in return expectations } \\
\hline daily & 114 & 1.38 & 1.33 & 1.51 & -0.18 & -2.63 & $0.01 * * *$ \\
\hline monthly & 113 & 1.27 & 1.36 & 1.24 & 0.12 & 1.88 & $0.06^{*}$ \\
\hline yearly & 112 & 1.38 & 1.61 & 1.08 & 0.53 & 9.22 & $0.00 * * *$ \\
\hline \multicolumn{8}{|c|}{ Panel A2: average within subject standard deviation of return expectations } \\
\hline daily & 114 & 1.21 & 1.16 & 1.32 & -0.16 & -3.07 & $0.00^{* * * *}$ \\
\hline monthly & 113 & 1.18 & 1.26 & 1.15 & 0.11 & 2.22 & $0.03 * *$ \\
\hline yearly & 112 & 1.24 & 1.40 & 1.05 & 0.35 & 7.42 & $0.00 * * *$ \\
\hline \multicolumn{8}{|c|}{ Panel B1: mean absolute changes in risk perceptions } \\
\hline daily & 114 & 1.32 & 1.24 & 1.52 & -0.29 & -4.14 & $0.00 * * *$ \\
\hline monthly & 113 & 1.21 & 1.33 & 1.17 & 0.16 & 2.60 & $0.01 * * *$ \\
\hline yearly & 112 & 1.29 & 1.43 & 1.11 & 0.31 & 5.20 & $0.00 * * *$ \\
\hline \multicolumn{8}{|c|}{ Panel B2: average within subject standard deviation of risk perceptions } \\
\hline daily & 114 & 1.21 & 1.16 & 1.31 & -0.15 & -2.68 & $0.01 * * *$ \\
\hline monthly & 113 & 1.12 & 1.23 & 1.08 & 0.14 & 2.86 & $0.00^{* * * *}$ \\
\hline yearly & 112 & 1.25 & 1.36 & 1.10 & 0.26 & 5.18 & $0.00 * * *$ \\
\hline
\end{tabular}

Note: This table provides an overview of belief updating across treatment groups. "Click" refers to subjects deciding to opt out of the default treatment imposed on them, whereas "no click" captures those subjects who do not opt out of the default presentation format. "Difference" refers to the difference between "click" and "no click". T-statistics and p-values shown refer to t-tests for difference in means between "click" and "no click" subgroups for each treatment group. Updates are defined as the difference between beliefs in round $\mathrm{t}$ and round $\mathrm{t}+1 . * * *$, **, and * denote statistical significance at the $1 \%, 5 \%$, and $10 \%$ level, respectively.

We find a mitigating effect of a longer information horizon on the magnitude of belief updating for subjects who remain in their default information horizon. Subjects who do not opt out of their 
default, update their return expectations by 0.43 points less on the 1-7 return expectations scale when shown yearly versus daily returns for their stock portfolio. This decrease corresponds to slightly less than a one-third smaller update of return expectations. The effect reverses for subjects who do not stay in their default information horizon. For these subjects, being originally assigned to a default information horizon presenting yearly returns and subsequently viewing different return horizons increases return expectations by 0.28 points or one-fifth, as compared to those subjects who opted out of the shortest (daily) horizon. Whereas opting out of the default reduces belief updating for subjects assigned to the daily treatment by 0.18 points $(t=2.63$, $p<0.01$ ), belief updating is increased by 0.53 points for those subjects who opted out of the yearly information horizon default condition $(t=9.22, p<0.001)$.

Overall, on average, presenting subjects with longer return horizons does not have an effect on subjects' belief updating (see Figure 3.4). However, when we compare subjects who opt out of the default with those who do not, we find important differences in belief updating. Note that a mitigating effect due to a longer evaluation period is present, but only for the subsample of subjects who decide to remain in the (long) default information horizon. However, if subjects opt out of their default information horizon, belief updating exhibits the opposite effect: Subjects have larger belief updates, both for return expectations and risk perceptions. Looking at the subsample of subjects who were randomly allocated to the daily default group, the pattern reverses compared to the yearly group. That is, those viewing the shortest information horizon update less when they decide to switch to a different (i.e., longer) information horizon.

An important question regarding the above mentioned effects is whether subjects who do not opt out of the default are simply "clicking through" the different rounds of the experiment without paying attention, often giving the same or almost the same response to the questions. Such behavior would lead to incorrectly classifying subjects who did not take the experimental task seriously as having little or no belief updates. Column (3) in Table 3.5 shows that the amount of time taken to complete the experiment is significantly and positively associated with a subject's tendency to opt out of the default. The data on belief updates, however, are not consistent with such a concern. When comparing subjects assigned to the different treatment groups, those who opt out of their treatment exhibit similar or even slightly higher (for the daily treatment group) variation in levels of beliefs (see Figure 3.3). Furthermore, Figure 3.4 shows that subjects in the daily treatment, who decide to remain in the default, actually express larger belief updates 
compared to subjects who opt out of the treatment. Finally, we find no statistically significant differences between the fractions of subjects in each treatment who do not update their beliefs at all. For return expectations, this fraction is $28.2 \%($ S.E. $=0.019)$ for the daily group, 32.6\% (S.E. $=0.020)$ for the monthly group, and $30.5 \%($ S.E. $=0.020)$ for the yearly group.

\subsubsection{Determinants of Opting Out of the Default}

The analysis of our subjects' opting out behavior over the six evaluation rounds for the different treatment groups is graphically summarized in Figure 3.5. Across all evaluation rounds and treatment conditions, more than half of the subjects $(51.47 \%)$ opt out of their default and view different information horizons. Of the subjects in the monthly treatment, on average $27.14 \%$ opt out of their default, which is less than in the daily $(71.35 \%)$ or yearly $(55.80 \%)$ treatment.

Figure 3.5 Study 1: Opting Out of the Default Information Horizon

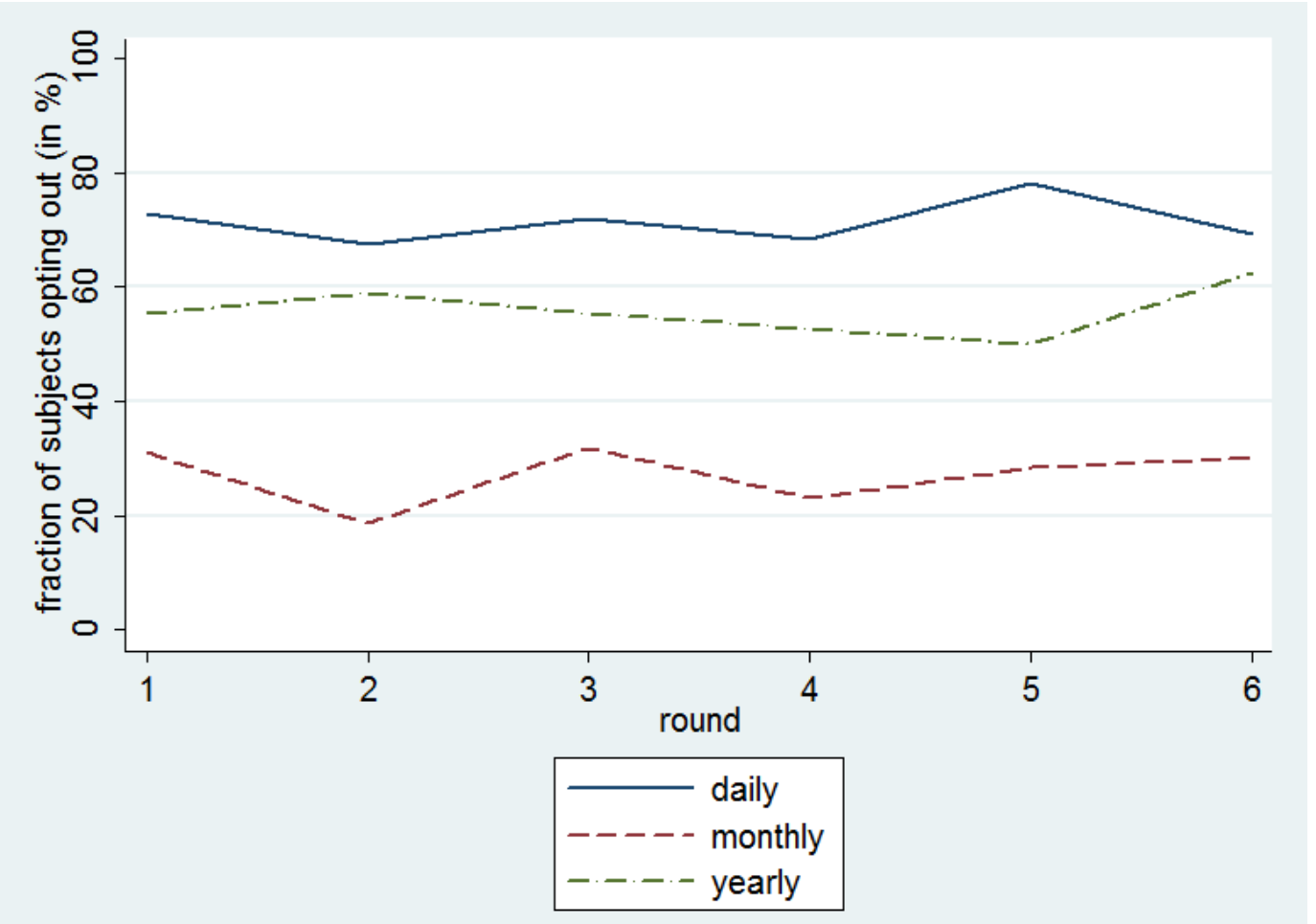

Note: This figure presents laboratory subjects' opting out behavior based on the three treatment groups over the six experimental rounds. "Daily", "monthly", and "yearly" correspond to the default information horizon. 
As there are differences in belief updating between subjects who opt out of the default information horizon versus those who do not, an important follow-up question is: Who opts out? To identify determinants of opting out of the default, we summarize the opting-out behavior of all evaluation rounds for each subject creating the dependent variable "average click", and regress it on subject-specific attributes. Average click is constructed as the average within-subject decision to opt out of the default over the evaluation rounds. As it is constructed as the average, it varies between 0 (for subjects who never opt out of the default) and 1 (for subjects who opt out of the default every single round). Results in Table 3.5 indicate that risk aversion is slightly negatively associated with a subject's decision to opt out of the default information horizon, while financial literacy is positively related to opting out. As the insignificant interaction effects in column (2) indicate, it is financial literacy that influences the decision to opt out of the default and not merely realizing that another information horizon might be needed to form beliefs about the portfolio.

The effect of financial literacy is consistent with findings by van Rooij and Teppa (2014). These authors find that financial literacy is positively related with the tendency to opt out of default options in economic decision making. One potential reason is that more financially literate individuals have lower costs of information processing, whereas less literate individuals are more likely to shy away from these decisions. This explanation is consistent with Agnew and Szykman (2005), who show that for complicated tasks, financial literacy is associated with a more pronounced tendency to opt out of the default, and Brown et al. (2016), who find that individuals with higher self-assessed investment skills are less likely to choose a default retirement plan. Finally, being assigned to either the daily or yearly treatment increases a subject's likelihood to opt out of the default. Subjects in the monthly default information horizon, which matches the time horizon specified by each evaluation round, are less likely to switch to another information horizon. Additionally, we asked subjects after the last evaluation round whether they had observed a trend in the portfolio returns by selecting one of four answer choices: "upward," "sideways drift," "downward," or "no trend." Responses to this question (i.e., the fraction of experimental subjects selecting each particular answer) do not differ significantly by treatment. Neither do we observe significant differences when comparing subjects that never opted out versus those that opted out at least once. 
Table 3.5 Study 1: Determinants of Opting Out

\begin{tabular}{|c|c|c|c|}
\hline & $\begin{array}{c}\text { average click } \\
\text { (1) }\end{array}$ & $\begin{array}{c}\text { average click } \\
\text { (2) }\end{array}$ & $\begin{array}{l}\text { average click } \\
\text { (3) }\end{array}$ \\
\hline Age & $\begin{array}{l}-0.01 \\
(0.01)\end{array}$ & $\begin{array}{l}-0.01 \\
(0.01)\end{array}$ & $\begin{array}{l}-0.01 \\
(0.01)\end{array}$ \\
\hline Gender & $\begin{array}{l}-0.05 \\
(0.04)\end{array}$ & $\begin{array}{l}-0.05 \\
(0.04)\end{array}$ & $\begin{array}{l}-0.05 \\
(0.04)\end{array}$ \\
\hline Risk aversion & $\begin{array}{l}-0.02 * \\
(0.01)\end{array}$ & $\begin{array}{l}-0.01 * \\
(0.01)\end{array}$ & $\begin{array}{l}-0.02 * \\
(0.01)\end{array}$ \\
\hline Financial literacy & $\begin{array}{l}0.03^{* *} \\
(0.01)\end{array}$ & $\begin{array}{l}0.04 * \\
(0.02)\end{array}$ & $\begin{array}{l}0.04 * \\
(0.02)\end{array}$ \\
\hline Treatment: daily & $\begin{array}{c}0.44 * * * \\
(0.04)\end{array}$ & $\begin{array}{c}0.52 * * * \\
(0.16)\end{array}$ & $\begin{array}{c}0.51 * * * \\
(0.16)\end{array}$ \\
\hline Treatment: yearly & $\begin{array}{c}0.28 * * * \\
(0.04)\end{array}$ & $\begin{array}{l}0.40 * * \\
(0.17)\end{array}$ & $\begin{array}{l}0.41 * * \\
(0.17)\end{array}$ \\
\hline $\begin{array}{l}\text { Financial literacy * } \\
\text { Treatment: daily }\end{array}$ & & $\begin{array}{l}-0.01 \\
(0.03)\end{array}$ & $\begin{array}{l}-0.01 \\
(0.03)\end{array}$ \\
\hline $\begin{array}{l}\text { Financial literacy * } \\
\text { Treatment: yearly }\end{array}$ & & $\begin{array}{l}-0.02 \\
(0.03)\end{array}$ & $\begin{array}{l}-0.02 \\
(0.03)\end{array}$ \\
\hline Time (minutes) & & & $\begin{array}{l}0.02 * * \\
(0.01)\end{array}$ \\
\hline Constant & $\begin{array}{c}0.49 * * * \\
(0.16)\end{array}$ & $\begin{array}{c}0.42 * * \\
(0.19)\end{array}$ & $\begin{array}{c}0.20 \\
(0.21)\end{array}$ \\
\hline $\begin{array}{l}\text { Observations } \\
\text { adjusted } \mathrm{R}^{2}\end{array}$ & $\begin{array}{l}339 \\
0.24\end{array}$ & $\begin{array}{l}339 \\
0.24\end{array}$ & $\begin{array}{r}339 \\
0.27\end{array}$ \\
\hline
\end{tabular}

Note: This table presents Ordinary Least Squares regression results. The dependent variable is the average withinsubject clicking behavior over the six experimental rounds. Thus, "average click" indicates the fraction of total rounds a subject decided to opt out of the default. $* * * * *$, and $*$ denote statistical significance at the $1 \%, 5 \%$, and $10 \%$ level, respectively.

\subsubsection{Discussion}

Consistent with previous studies, we find that subjects extrapolate past returns when updating beliefs. Extending prior literature, we find that when opting out is easy, displaying returns over longer information horizons has no effect on belief updates, on average. Analyzing the subsamples of subjects who choose to opt out of the default and those that do not, however, yields new results as the treatment default information horizon implies different reactions for the two groups. Subjects in the short default horizon group who opt out of the default, reduce belief updating while subjects in the long default information horizon who stay in the default also 
reduce their beliefs. Regression results show that financial literacy is positively associated with the tendency to opt out of the default. Given prior evidence that smaller updates in investor beliefs are associated with lower trading activity, which ultimately has positive return consequences, these experimental results are relevant to consider when choosing a default to present to investors.

\subsection{Study 2}

\subsubsection{Experimental Design}

The second experiment is an online study using a subject pool recruited from Amazon Mechanical Turk (henceforth, MTurk). MTurk gives access to a large and diverse subject pool, and results from traditional samples have been replicated with MTurk subjects (cf. Casler, Bickel, and Hackett, 2013; Buhrmester, Kwang, and Gosling, 2011; Paolacci, Chandler, and Ipeirotis, 2010). In order to ensure comparability with Study 1, the experimental design of Study 2 is identical to the lab version, except for a few necessary changes. First, because MTurk is a USbased platform and the majority of subjects are from the US, monetary values presented in the overview tables throughout the experimental rounds are given in U.S. Dollars instead of Euros.

Second, to allow better comparison of our results with previous work which did not allow subjects to opt out of the default, we implement two experimental versions in Study 2. In one version it is possible to opt out of the default, in the other version it is not possible to opt out. Subjects in the version that does not give the option to opt out see just a single radio button that informs them of the information horizon they are viewing. None of the subjects in this version of the experiment are informed about the existence of other treatments. Thus, these subjects do not know about other information horizons, nor do they know that other subjects have the option to opt out of the default. Subjects are randomly allocated to one of the two versions.

Third, we add an attention check at the end of the experiment. Since subjects completed the experiment outside a controlled lab, the attention check can serve as an exclusion criterion to ensure sufficient attention. We employ an instructional manipulation check (Oppenheimer, Meyvis, and Davidenko, 2009), which entails a short text in which subjects are instructed to answer a question in a specific way, disregarding the actual content of the question. Subjects who 
follow instructions and read the text will pass the attention check, while those who do not pay attention to the text and only read the question will fail the attention check. On purpose, we included the instructional manipulation check at the end of the experiment to avoid any differences in the actual experiment. Hence, the sequence of rounds and screens shown to online subjects is the same as for the lab subjects.

In total, 613 subjects completed the experiment, of which 29 (4.7\%) failed to pass the attention check. These subjects are excluded from further analysis and the remainder of the paper focuses on the 584 subjects which passed the attention check. Of those 584 subjects, 284 (48.63\%) completed the experiment in the non-restrictive setup, allowing them to opt out of the default, and the remaining $300(51.37 \%)$ subjects were allocated to the restrictive version, which did not allow opting out of the default. Mean completion time is 6 minutes. Subjects given the opportunity to opt out of the default take slightly longer (6.2 minutes). Subjects not given the option to opt out of the default take, on average, a shorter length of time to complete the experiment (5.9 minutes). We paid \$1 to each subject completing the experiment, resulting in an average hourly wage of $\$ 10$.

Subjects participating in either version of Study 2 were again randomly allocated to one of three default treatment groups. Of the 284 subjects allowed to opt out of the default, 96 (33.80\%) subjects were placed in the daily treatment, 95 (33.45\%) were placed in the monthly treatment group, and $93(32.75 \%)$ completed the experiment viewing yearly returns by default. The random division of the subgroup of 300 subjects who did not have the option of opting out of the default resulted in $102(34.00 \%)$ subjects in the daily, 100 (33.33\%) in the monthly treatment, and 98 $(32.67 \%)$ subjects in the yearly treatment group.

\subsubsection{Descriptive Statistics and Data Quality}

Table 3.6 presents summary statistics. Forty-six percent of the subjects are female. Mean age is 35.3 years. Subjects have a mean score of 5.83 for the financial literacy questions. Of those subjects having the option to opt out of the default, $53 \%$ opt out of their default information horizon. Recall that one experimental version has by definition $0 \%$ of subjects opting out, since they are not given the option to do so. There is no significant difference in age, gender, or 
financial literacy within each experimental version of the three treatment groups. Hence, the random allocation of subjects to the experimental conditions was successful.

Table 3.6 Study 2: Summary Statistics

\begin{tabular}{|c|c|c|c|c|}
\hline Variable & mean & fraction & std & median \\
\hline Age & 35.5 & & 11.06 & 33 \\
\hline Gender & 0.46 & & & \\
\hline Financial literacy & 5.83 & & 1.8 & 6 \\
\hline Basic financial literacy & 2.44 & & 0.84 & 3 \\
\hline 1 & & $89 \%$ & & \\
\hline 2 & & $78 \%$ & & \\
\hline 3 & & $77 \%$ & & \\
\hline Advanced financial literacy & 3.39 & & 1.21 & 4 \\
\hline 1 & & $76 \%$ & & \\
\hline 2 & & $57 \%$ & & \\
\hline 3 & & $90 \%$ & & \\
\hline 4 & & $82 \%$ & & \\
\hline 5 & & $36 \%$ & & \\
\hline Click & & $53 \%$ & 0.50 & 1 \\
\hline Time & 6.05 & & 2.64 & 5.48 \\
\hline Experiment version & & & & \\
\hline Opt out possible & & $49 \%$ & & \\
\hline Opt out not possible & & $51 \%$ & & \\
\hline Treatment & & & & \\
\hline Daily & & $34 \%$ & & \\
\hline Monthly & & $33 \%$ & & \\
\hline Yearly & & $33 \%$ & & \\
\hline Return Expectation & 4.30 & & 1.55 & 4 \\
\hline Risk Perception & 3.98 & & 1.54 & 4 \\
\hline$N$ & \multicolumn{4}{|c|}{584} \\
\hline
\end{tabular}

Note: This table presents summary statistics of selected key questions from Study 2. "std" abbreviates "standard deviation". Percentages correspond to the fraction of correct answers for financial literacy questions and to the fraction of respondents who select a certain answer or belong to a certain group (for click, experiment version, and treatment). All values are based on the total number of subjects, except for click, which is based on those 300 subjects who were assigned to the experiment version in which opting out was possible, since for the remaining subjects, the value of click is by definition zero, as they are not granted the possibility to opt out of the default. 
Table 3.7 replicates Table 3.3 from Section 3.3.2, but using data gathered from subjects who completed the online experiment, allowing us to compare the samples of Study 2 and Study 1. Model specifications in Table 3.7 are identical to those in Table 3.3. The setup used in models (1) and (2) (once each for the experimental version in which opting out of the default is possible vs. not possible) show a similar picture as for the lab sample in Study 1. A higher past return leads to increased expectations about future returns. In comparison to Study 1, the coefficients are only slightly different, and the significance and sign of effects, as well as interpretation of the results remain the same. Also, when looking at columns (3) and (4), which focus on risk perceptions, the interpretation is the same as in Study 1. Higher returns are associated with lower risk perceptions. In conclusion, the lab experiment as well as both versions of the online experiment yield results in line with real investor behavior. That is, subjects update their beliefs by extrapolating from past returns.

Table 3.7 Study 2: Returns and Clicking Behavior

\begin{tabular}{lcccc}
\hline & $(1)$ & $(2)$ & $(3)$ & $(4)$ \\
\hline & $\begin{array}{l}\text { dependent variable: updates of } \\
\text { return expectations }\end{array}$ & $\begin{array}{r}\text { dependent variable: updates of } \\
\text { risk perception }\end{array}$ \\
\hline \multirow{4}{*}{ opt out } & opt out not & opt out & opt out not \\
& possible & possible & possible & possible \\
\hline Constant & $2.42 * * *$ & $2.47 * * *$ & $-1.98 * * *$ & $-1.66^{* * *}$ \\
& $(0.40)$ & $(0.37)$ & $(0.40)$ & $(0.37)$ \\
Observations & -0.05 & $-0.27 * * *$ & -0.02 & $0.15^{* * *}$ \\
$N$ & $(0.06)$ & $(0.06)$ & $(0.06)$ & $(0.06)$ \\
& 1,420 & 1,500 & 1,420 & 1,500 \\
& 284 & 300 & 284 & 300 \\
\hline
\end{tabular}

Note: This table presents random-effects panel regression results with robust standard errors (in parentheses) clustered at the individual level. The dependent variables are updates of return expectations (models 1 and 2 ) and updates of risk perceptions (models 3 and 4).Updates are defined as the difference between beliefs in round $t$ and round $t+1$. Due to analyzing the data as panel, and having six evaluation rounds, we have five belief updates per subject, which is why the number of observations is five-times the number of subjects. ***, **, and * denote statistical significance at the $1 \%, 5 \%$, and $10 \%$ level, respectively. "opt out possible/not possible" refers to the experimental version of experiment 2 - for "opt out possible", subjects had the possibility to opt out of the default; for "opt out not possible", opting out of the default was impossible.

Figures 3.6.A and 3.6.B plot the beliefs of our subjects over the different evaluation rounds of the experiment for both experimental versions of Study 2. Return expectations are shown in the left panel, while the right panel presents risk perceptions. Figure 3.6.A reveals a similar pattern as Figure 3.3 did for Study 1. Again, updates of return expectations are positively associated with 
past returns. Updates of risk perceptions are negatively associated with past returns. Hence, Figure 3.6.A shows that subjects in both the lab as well as online experiment exhibit similar belief updating behavior. Figure 3.6.B contains two lines per graph, because in this version of the experiment, subjects could not opt out of their default and therefore there are no observations for opting out of the treatment. Nonetheless, when comparing the two versions of Study 2, beliefs from the version where opting out was not possible closely resemble the pattern yielded by those subjects who were granted the possibility to opt out, but did not do so (compare the light dashed lines in Figure 3.6.A with the solid line in Figure 3.6.B). Thus, subjects in both experiments display similar beliefs, which provides additional support to the validity of our experiment and makes it unlikely that results are driven by the fact that subjects were exposed to a controlled laboratory environment in Study 1 as compared to the online environment of Study 2.

Figure 3.6.A Study 2: Opting Out Possible: Return Expectations and Risk Perceptions
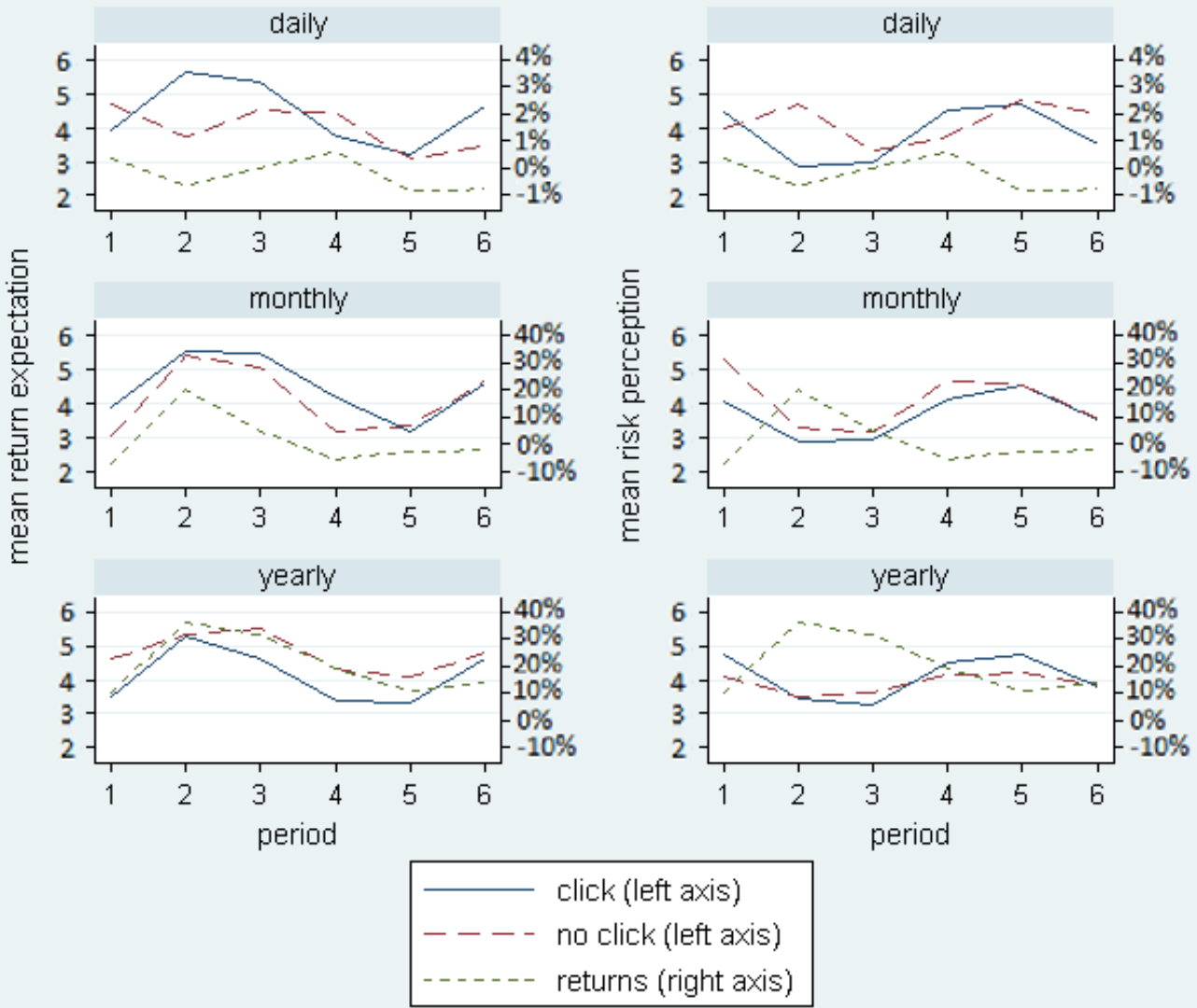
Figure 3.6.B Study 2: Opting Out Not Possible: Return Expectations and Risk Perceptions

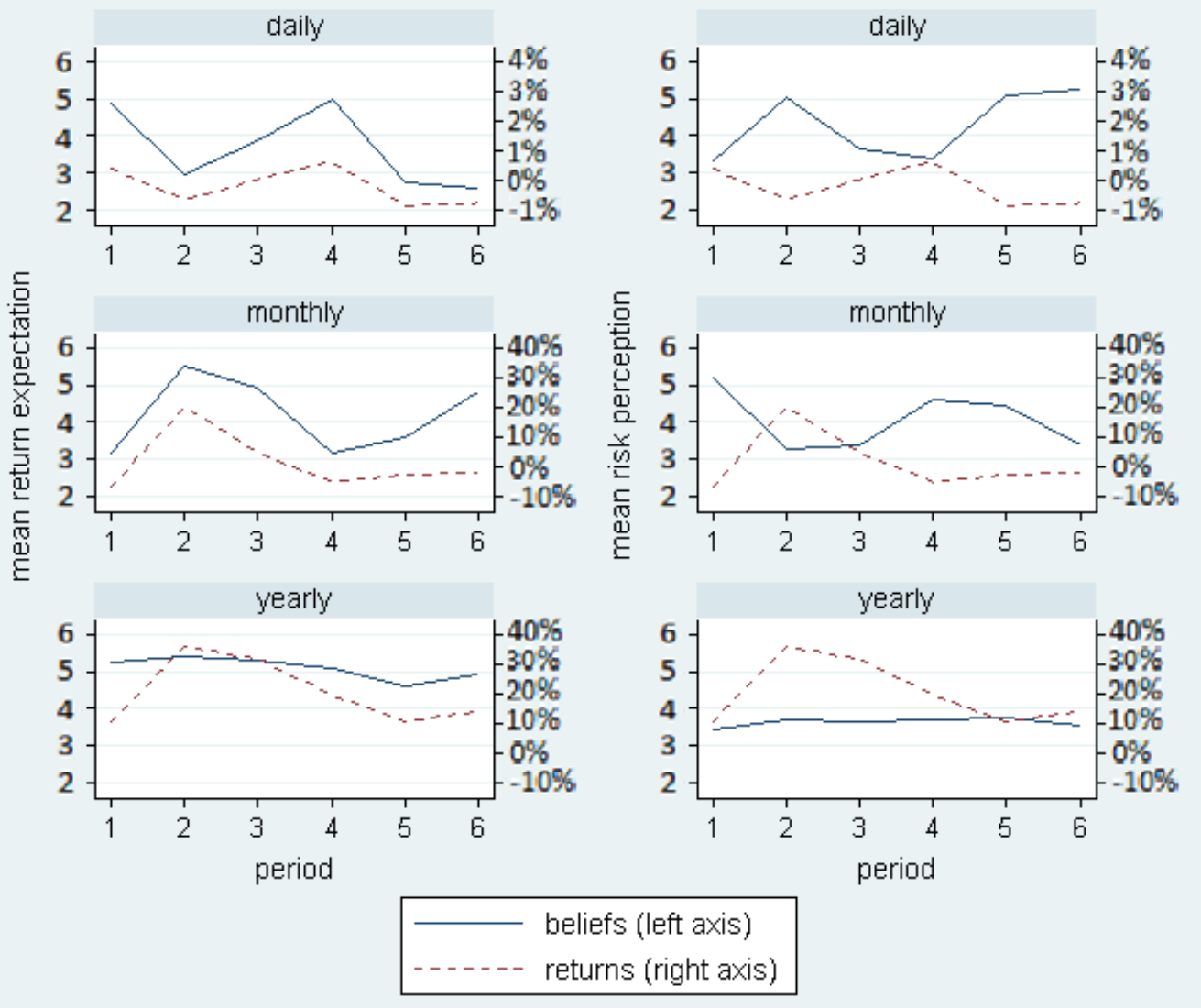

Note: These figures present subjects' beliefs over the six experimental rounds. The header explains which experimental version the graphs are based on. The left panel presents mean return expectations and the right panel shows mean risk perception. "Click" and "no click" refers to subjects who did or did not opt out of the default information horizon, respectively. Returns shown for each treatment in each round are summarized on the right-hand scale.

\subsubsection{Results}

\subsubsection{Belief Updating When Opting Out is Possible}

Figure 3.7 replicates Figure 3.4 from Section 3.3.3.1, but using data gathered from subjects who completed the online experiment and were allowed to opt out of the default information horizon presented to them. Again, Panel A refers to return expectations and Panel B to risk perceptions. Once more, we find that there are only small differences in the magnitude of belief updates across 
treatment groups, and the differences are not statistically significant. The corresponding tests are given in Table 3.8. Column (3) contains mean values for the three treatment groups.

Figure 3.7 Study 2: Opting Out Possible: Belief Updating Across Treatments
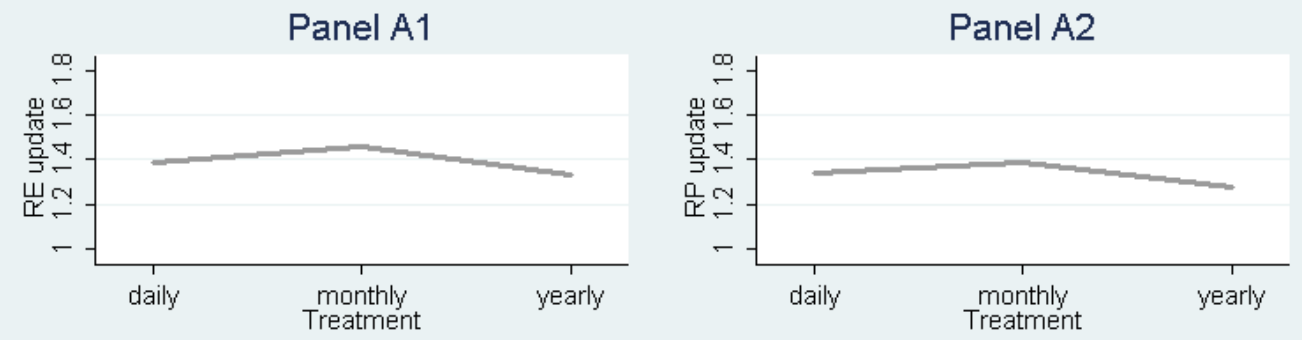

Panel B1

Panel B2
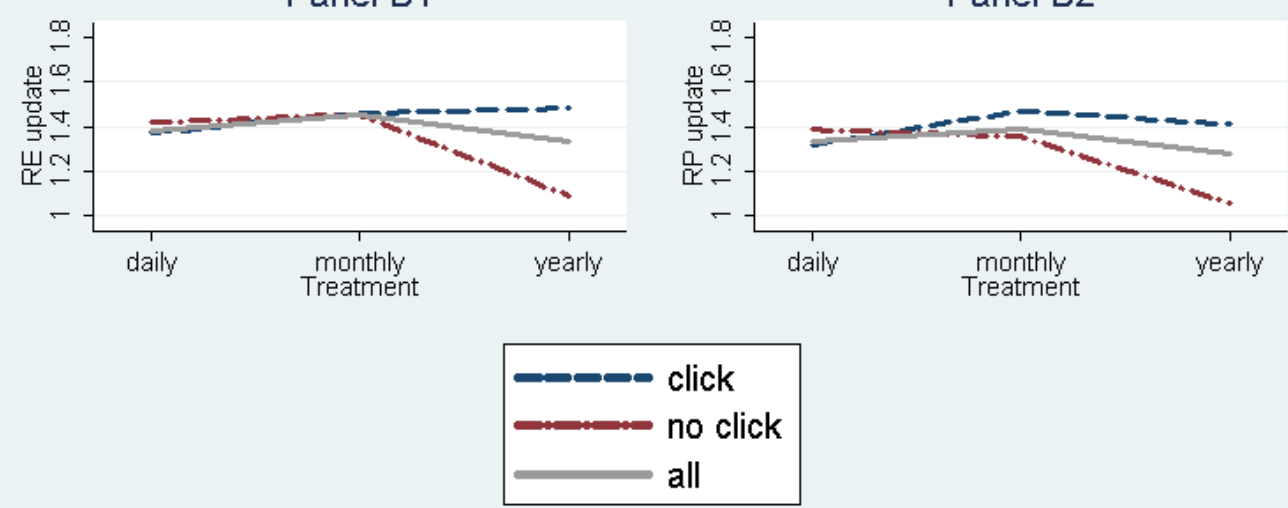

Note: This figure presents subjects' belief updating based on the three treatment groups. Analysis is based on subjects who completed the online experiment and were allocated to the experimental version in which they had the option to opt out of the default information horizon presented to them. The graphs on the left summarize updates in return expectations ("RE"), whereas the graphs on the right show updates in risk perceptions ("RP"). Updates are calculated as the absolute difference between expressed beliefs and their counterpart from the previous evaluation round, leaving the figure to be an average of five individual assessments of belief updating. The three lines correspond to the group of all subjects as well as splitting them up based on whether they decided to opt out of the default in any given round ("click") or not ("no click").

The bottom panels of Figure 3.7 split up the total sample of online subjects into the two subgroups of subjects who decide to opt out of the default and those that do not. Subjects who decide to opt out of the default information horizon (called "click") show a slight increase in belief updating with increasing return horizons. Subjects who do not choose to opt out of their treatment exhibit almost no difference in their belief updating (both for return expectations, as well as for risk perceptions), no matter whether they are presented daily or monthly returns. As 
soon as subjects who do not opt out of the treatment are shown yearly returns, however, their belief updating is reduced. Table 3.8 contains statistical tests for differences in means between those subjects who decide to opt out and those who elect not to do so. The differences are insignificant for both the daily and monthly treatment group. However, for the yearly treatment, differences are statistically and economically significant, as not opting out decreases belief updates by 0.39 points, which amounts to more than one quarter of the size of the updates.

Table 3.8 Study 2: Belief Updating Across Treatments

\begin{tabular}{|c|c|c|c|c|c|c|c|}
\hline & $\mathrm{N}$ & all & click & no click & difference & $t$-stat & $p$-value \\
\hline \multicolumn{8}{|c|}{ Panel A1: mean absolute changes in return expectations } \\
\hline daily & 96 & 1.39 & 1.37 & 1.42 & -0.05 & -0.69 & 0.24 \\
\hline monthly & 95 & 1.46 & 1.46 & 1.46 & 0.00 & 0.07 & 0.53 \\
\hline yearly & 93 & 1.33 & 1.48 & 1.09 & 0.39 & 5.94 & $0.00 * * *$ \\
\hline \multicolumn{8}{|c|}{ Panel A2: average within subject standard deviation of return expectations } \\
\hline daily & 96 & 1.29 & 1.28 & 1.33 & -0.05 & -0.84 & 0.20 \\
\hline monthly & 95 & 1.32 & 1.31 & 1.32 & -0.01 & -0.10 & 0.46 \\
\hline yearly & 93 & 1.21 & 1.31 & 1.03 & 0.28 & 5.33 & $0.00 * * *$ \\
\hline \multicolumn{8}{|c|}{ Panel B1: mean absolute changes in risk perceptions } \\
\hline daily & 96 & 1.34 & 1.32 & 1.39 & -0.07 & -1.00 & 0.16 \\
\hline monthly & 95 & 1.39 & 1.47 & 1.35 & 0.12 & 1.57 & $0.06^{*}$ \\
\hline yearly & 93 & 1.28 & 1.41 & 1.05 & 0.36 & 4.92 & $0.00 * * *$ \\
\hline \multicolumn{8}{|c|}{ Panel B2: average within subject standard deviation of risk perceptions } \\
\hline daily & 96 & 1.24 & 1.23 & 1.25 & -0.02 & -0.34 & 0.37 \\
\hline monthly & 95 & 1.26 & 1.31 & 1.24 & 0.07 & 1.10 & 0.14 \\
\hline yearly & 93 & 1.18 & 1.29 & 1.00 & 0.29 & 4.91 & $0.00 * * *$ \\
\hline
\end{tabular}

Note: This table provides an overview of belief updating across treatment groups. "Click" refers to subjects deciding to opt out of the default treatment imposed on them, whereas "no click" captures those subjects who do not opt out of the default presentation format. "difference" refers to the difference between "click" and "no click". T-statistics and p-values shown refer to t-tests for difference in means between "click" and "no click" subgroups for each treatment group. Updates are defined as the difference between beliefs in round $\mathrm{t}$ and round $\mathrm{t}+1 . * * *, * *$, and $*$ denote statistical significance at the $1 \%, 5 \%$, and $10 \%$ level, respectively.

Overall, when we compare the results of the online experiment with those of the lab experiment, the yearly treatment group has identical patterns. The patterns for the shorter return horizons (daily and monthly) allow for a similar interpretation, but the differences are less pronounced and mostly not statistically significant. 
Subjects in Study 2 also behave similarly to those in Study 1 in terms of their decision to opt out of the default. Figure 3.8 plots the percentage of subjects who decide to opt out of their treatment over the six rounds of the experiment. Over all rounds and across all three treatments, 53.29\% of online subjects decide to opt out of the default shown to them. Similar to Study 1, the numbers differ based on the exact treatment. Whereas subjects assigned to the daily condition opt out most frequently (70.31\%), those randomly selected to view yearly returns as a default opt out slightly less $(62.01 \%)$. A monthly return horizon makes subjects opt out of the default less, as only $27.54 \%$ show such behavior.

Figure 3.8 Study 2: Opting Out of the Default Information Horizon

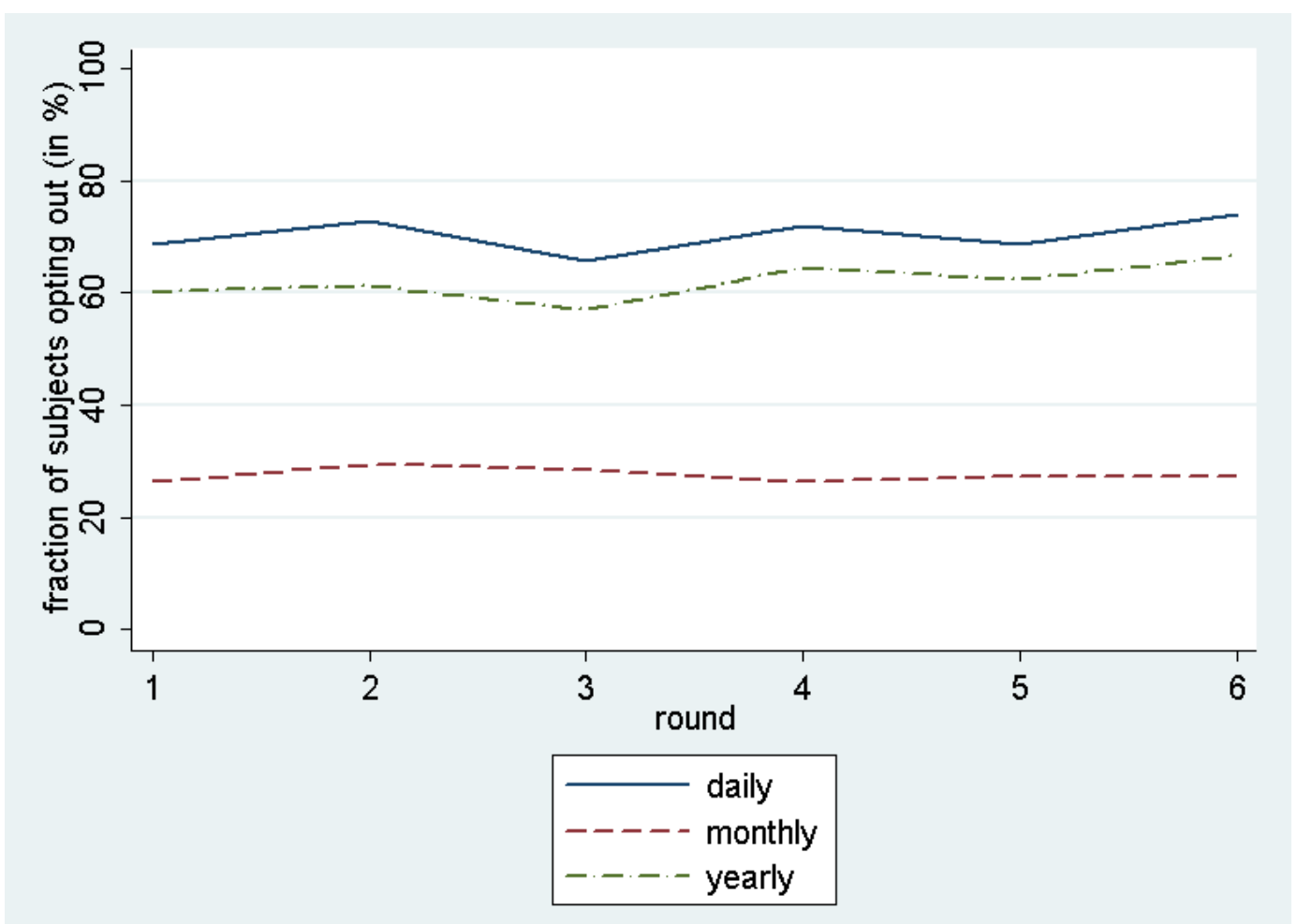

Note: This figure presents online subjects' opting out behavior based on the three treatment groups over the six experimental rounds. "Daily", "monthly", and "yearly" correspond to the default information horizon.

\subsubsection{Belief Updating when Opting Out is Not Possible}

Figure 3.9 summarizes belief updating across treatments for those subjects who were allocated to the experimental version in which they had no option to opt out of the default. The organization 
of the figure is the same as before: The left panel refers to return expectations, whereas the right panel depicts risk perceptions.

Subjects in the daily and monthly treatments display similar belief updating, both for return expectations and risk perceptions. The yearly treatment group, however, displays significantly reduced belief updating. The downward slope for belief updates in the yearly treatment group is comparable to the subgroup of subjects not opting out in Panel B in Figure 3.7. Thus, in conjunction with Figure 3.7, Figure 3.9 shows that subjects update beliefs less when they face only a long information horizon, resembling the findings of previous literature from restrictive settings.

Figure 3.9 Study 2: Opting Out Not Possible: Belief Updating Across Treatments
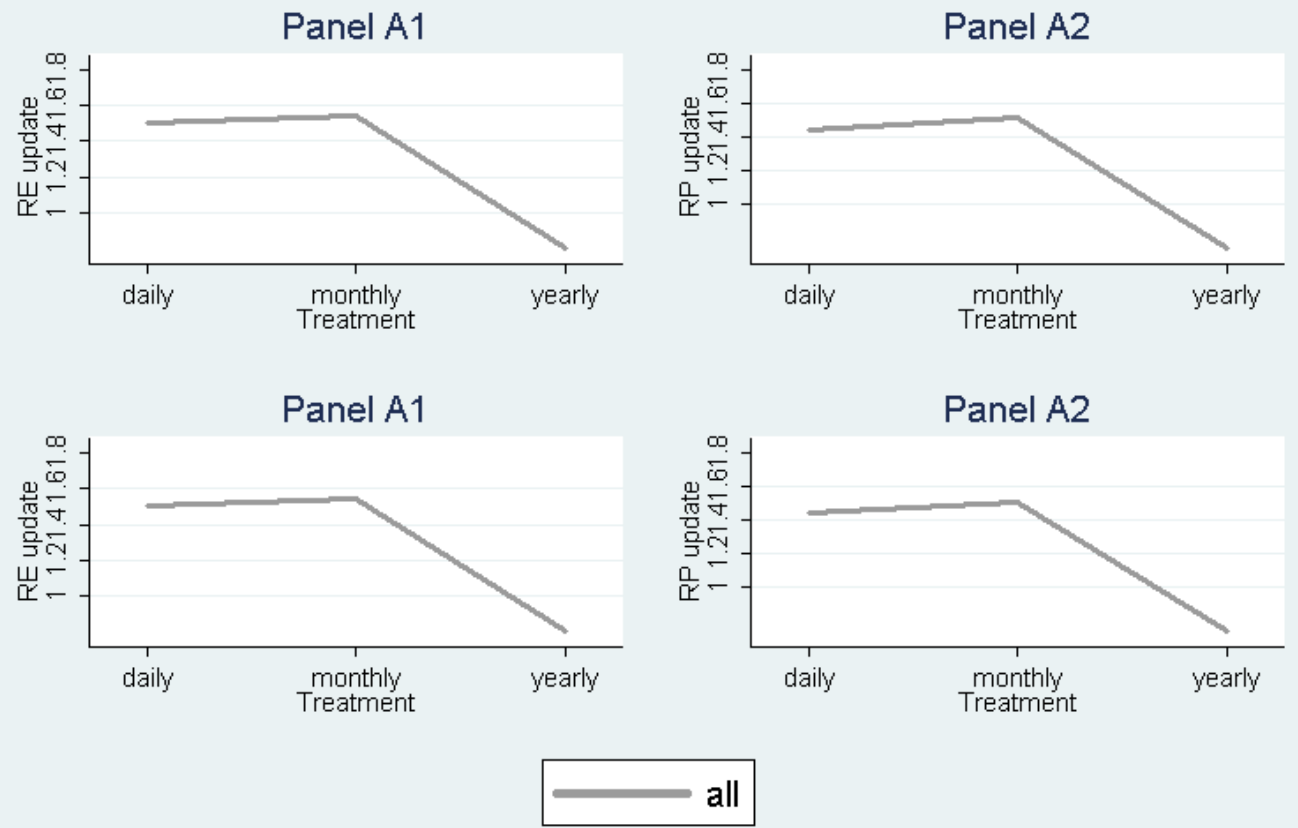

Note: This figure presents subjects' belief updating based on the three treatment groups. Analysis is based on subjects who completed the online experiment and were allocated to the experimental version in which they were not given the option to opt out of the default information horizon. The graphs on the left summarize updates in return expectations ("RE"), whereas the graphs on the right show updates in risk perceptions ("RP"). Updates are calculated as the absolute difference between expressed beliefs and their counterpart from the previous evaluation round, leaving the figure to be an average of five individual assessments of belief updating. As subjects could not opt out of the default, by definition the line plot for the entire subsample used coincides with the line plot of those who did not opt out, as there are no subjects who were able to opt out of the default. 


\subsubsection{Discussion}

Study 2 supports the generalizability of the experimental results of Study 1. Switching from a lab environment to an online setting did not change the results obtained in Study 1. In Study 2, when our subjects are allowed to opt out of the default, they exhibit a similar pattern of belief updating found in Study 1. The differences in belief updating are most pronounced in the yearly default, where opting out increases belief updates as compared to staying in the longer horizon. Results for the shorter horizons are similar to the lab experiment. The version of Study 2 where opting out is not permitted, highlights that in this type of setting, a longer information horizon is to be recommended, as this is associated with reduced belief updates, which attenuates trading activity (Hoffmann and Post, 2016).

\subsection{Conclusion}

In two experimental designs resembling an online brokerage environment, we present subjects with the performance of a stock portfolio over six evaluation rounds. We measure their beliefs in terms of return expectations and risk perceptions and analyze the effect of different default information horizons on the magnitude of their belief updates. When subjects have the possibility to opt out of the default, we find that the default information horizon does not, on average, impact the magnitude of belief updating. An important result emerges, however, when we divide the sample into subjects staying in the default vs. those opting out of the default. For subjects who stay in the default condition, showing returns over a longer information horizon reduces the magnitude of their belief updating. For subjects who opt out of their default treatment, we find the opposite result.

Our results extend previous work that examines how different information horizons influence the decision making behavior of individual investors (e.g., Beshears et al. 2017, Shaton 2015). These studies typically recommend longer information horizons to improve individual investor decision making (e.g., to increase their stock market participation or equity allocations in retirement funds). The results of these previous studies, however, are based on restricting access to information and making it very cumbersome or even impossible for subjects to opt out of the 
default. Our findings support previous results in the sense that when subjects do not have the possibility to opt out, a longer default presentation format indeed reduces belief updates and thus seems beneficial for investors. However, based on our experiments, we find that when subjects have immediate access to alternative information horizons and can easily opt out of the default, presenting returns over a longer information horizon is not always beneficial. Presenting portfolio performance over a longer horizon benefits only those subjects who choose to stay in their default information horizon. For these subjects, the longer horizon has a mitigating effect on the magnitude of their belief updates.

Since we find that financial literacy is positively related to subjects' likelihood of opting out of the default, our findings suggest that showing long information horizon returns is an effective default only if investors have low financial literacy. In order to set an appropriate information horizon default for past returns, it is thus crucial to understand and assess the personal characteristics of investors that lead to a tendency for remaining in a default condition. Investment mistakes are most detrimental for investors with low financial literacy because of their higher level of vulnerability (cf. Financial Conduct Authority 2014). Accordingly, public policymakers may find it particularly worthwhile to consider long information horizons as a default option for this group of investors. 


\section{Reverse Mortgages}

\section{- What Homeowners (Don't) Know and How it Matters ${ }^{7}$}

\subsection{Introduction}

Reverse mortgage demand is low despite the substantial consumption smoothing benefits they can provide to cash-poor elderly homeowners (Davidoff, 2015). Mounting evidence suggests that the elderly may find reverse mortgages difficult to understand and for that reason shy away from using them. In his 2016 Ely Lecture delivered at the annual meeting of the American Economic Association John Y. Campbell specifically highlighted reverse mortgages as one of three examples (the others are retirement asset allocation and consumer credit) of markets that are prone to households making suboptimal financial decisions because of, for example, lack of financial literacy and a poor understanding of product terms (Campbell, 2016). We use a survey to determine and assess elderly homeowners' knowledge about the dominant U.S. reverse mortgage product, the Home Equity Conversion Mortgage (HECM, henceforth), and how this knowledge relates to homeowners' intention to use the product. We find that general awareness of HECMs among U.S. elderly homeowners is high. However, product knowledge (productspecific literacy) is fairly low and lack of knowledge relates to low intention to use reverse mortgages. Strikingly, homeowners with limited financial resources who would benefit the most from reverse mortgages lack product knowledge as well. Knowing others with a reverse mortgage is a strong predictor of the intention to use reverse mortgages. Offering survey participants the opportunity to read a short text explaining product features was not found to be a successful intervention to increase the intention to use the product.

\footnotetext{
${ }^{7}$ This chapter is co-authored with Thomas Davidoff (University of British Columbia) and Thomas Post (Maastricht University) and is published in the Journal of Economic Behavior and Organization.
} 
Reverse mortgages enable homeowners to liquidate and consume home equity without relocating. Most retired households own a home and home equity is a large fraction of wealth for those households. According to the 2013 Survey of Consumer Finances, 87\% of U.S. households aged $65+$ own a home (the 2016 U.S. census figure is 79\%), and the value of the primary residence represents $56 \%$ of total assets at the median. Housing assets provide a valuable stream of services to their owners, but adjustment of these services and partial liquidation of those assets is difficult and costly. Millions of American retirees may be classified as "house rich and cash poor" and so seem likely to benefit from reverse mortgages (Mayer and Simons, 1994a, 1994b; Rasmussen et al., 1995). ${ }^{8}$ With 582,000 HECM reverse mortgages outstanding in 2012 (the most popular reverse mortgages type with 90\% market share) (Shan, 2011; CFPB, 2012), actual demand is substantially behind predictions.

According to life cycle saving and consumption theory, reverse mortgages increase a household's utility if they reduce liquidity constraints (allowing smoothing consumption over the life cycle) and bequest motives are weak (Artle and Varaiya, 1978; Davidoff, 2009, 2010a, 2010b; Nakajima and Telyukova, 2017; Cocco and Lopes, 2014; Hanewald, Post, and Sherris, 2016; Yogo, 2016). Moreover, reverse mortgages allow the household members to continue residing in their own house and to consume homeownership-specific utility, for example, derived from the opportunity to "age in place" (Davidoff, 2010c).

Apart from potentially high costs (e.g., Lucas, 2015), the empirical literature hints at several factors including financial literacy and limited product knowledge as potential explanations for the low demand for reverse mortgages. Dillingh et al. (2013) find evidence that bequest motives are related to low demand in household survey data from the Netherlands. Based on Italian household survey data, Fornero et al. (2016) find that high financial literacy is related to lower interest in reverse mortgages as more literate households might be better prepared for retirement. In both the Dutch and the Italian market, however, reverse mortgages are virtually unavailable and the general public has little awareness of the product. Duca and Kumar (2014) find in U.S. household survey data that more financially literate households use fewer home equity lines of credit (HELOC). Davidoff (2015) and Davidoff and Wetzel (2014) find that HECM borrowers do

\footnotetext{
${ }^{8}$ Home equity lines of credit (HELOCs) or conventional mortgages are alternatives to reverse mortgages and allow homeowners to tap into their home equity. However, those homeowners who might especially benefit from reverse mortgages (low savings, low income) often do not pass the required payment to income tests. For reverse mortgages these tests are of lesser importance (see Section 4.2).

68
} 
not recognize the significant value of the put option on the borrowers home embedded in HECMs protecting the borrower from home price risk. ${ }^{9}$ Based on 31 qualitative interviews in Massachusetts (U.S.), Leviton (2002) conjectures that a reason for low reverse mortgage demand is homeowners' fear of losing their home, because of the their misconceptions and lack of understanding. Anecdotal evidence from the U.S. (CFPB, 2012, 2015; Stark et al., 2014) and survey evidence from Australia (Reed, 2009) suggest that the product's features may be misunderstood by the elderly with potentially negative implications for demand. In addition, a particular feature of the HECM market in the U.S. is that the product is primarily marketed through television and media advertising. Distribution of the product is primarily accomplished through call-centers or brokers, not through banks and community financial institutions (Lucas, 2015). In that sense, it is a unique market where information about the product may not be well diffused. Even the acquisition and interpretation of information about the product may pose a challenge to the elderly. As reverse mortgages are targeted to the elderly, age-related cognitive decline may impair their ability to make appropriate financial decisions (e.g., Li et al., 2013, 2015). The fact that consumers are required to attend a counseling session before entering into a HECM contract (see Section 4.2), indicates that the government views targeted consumers as having insufficient knowledge.

In general, it is difficult to identify the role of product knowledge in reverse mortgage demand, as large household surveys like the Survey of Consumer Finances (SCF) or Health and Retirement Study (HRS) do not contain information on reverse mortgage holdings. Reverse mortgage origination data is available from the U.S. Department of Housing and Urban Development (HUD). Shan (2011) matches this data with ZIP code level demographic data and county home price growth, and studies ZIP code characteristics correlated with reverse mortgage originations. Moulton et al. (2014) compare the demographic characteristics of households in the HRS with households attending a reverse mortgage counseling session, and those that took a reverse mortgage after attending counseling. These studies find that reverse mortgage take-up rates are higher among households with low income, high home values, and high payments for conventional mortgage debt. Due to the nature of the data used in both studies, however, the

\footnotetext{
${ }^{9}$ HECMs include a no-negative equity guarantee for the borrower (see Section 2). That is, the borrower is not liable for the part of the loan amount that might exceed the home value when the loan is paid back. Thus, in essence, the borrower owns a put option for selling the home (underlying) to the lender with the loan amount as the strike price.
} 
focus is on demographic variables rather than an assessment of knowledge about reverse mortgages in the respective overall target group.

Our research contributes to the literature on retirement finance in two ways. First, we assess the knowledge of U.S. elderly homeowners about reverse mortgages. That is, we provide a snapshot of the current knowledge and perceptions of reverse mortgages based on a survey among eligible homeowners. Second, we study how product knowledge and general financial literacy relate to the intention to use reverse mortgages. In doing so, we disentangle general and product-specific literacy. We build on earlier works that study literacy and knowledge for complex financial decisions and products, like debt literacy (Lusardi and Tufano, 2009) and stock market-specific literacy (Van Rooij, Lusardi, and Alessie, 2011). Those studies suggest that for complex products, both domain-specific knowledge and general financial literacy drive financial choices. Our results complement the literature dealing with the difficulties consumers have understanding financial products that generate retirement income. Brown et al. (2012) analyze annuities and find that product complexity, misunderstanding of the product, and the inability to value the product explain why annuities are rarely used. The HECM is a particularly interesting case because it is a highly complex product that embeds liquidity, longevity and home price insurance in the form of limited liability protection and complex refinancing options, while being geared toward poorer and older households who may be expected to have limited financial literacy.

\subsection{Reverse Mortgages and the U.S. HECM Program}

A reverse mortgage is a non-recourse loan from a private lending institution using the borrower's home as collateral. While a conventional mortgage is used to finance the purchase of a home (and over time home equity is built up), a reverse mortgage works the other way around. Reverse mortgages let borrowers spend home equity or create a credit line without moving out of the home, and without any need to make capital or interest payments to the lender until they move or die.

The loan balance of a reverse mortgage grows over time. Interest accrued is not paid regularly, but added to the loan balance. To ensure that the collateral for the loan stays sufficiently large, the initial loan balance is set well below the appraised home value. The borrower may defer 
repayment of principal and interest until the loan becomes due when the borrower dies, moves out, or wants to sell the home. Upon one of those events, the borrower (or his heirs) can decide to repay the total outstanding loan balance or to have the property sold. In the latter case, any remaining positive difference between sales proceeds and loan amount will be paid out to the borrower or his heirs. If there is a shortfall, however, the borrower or heirs are not liable (nonegative equity guarantee). Borrowers' longevity and home price risk are thus transferred to the lender.

To protect lenders from the risk of insufficient collateral when the reverse mortgage loan is due, the U.S. Congress created the Home Equity Conversion Mortgage (HECM) program in 1987. This program is backed by the U.S. government. Under this program the lending institution purchases insurance from the Federal Housing Administration to cover the risk of a shortfall. HECMs dominate the U.S. reverse mortgage market, making up about $90 \%$ of outstanding reverse mortgages (Shan, 2011). ${ }^{10}$ In this study, we focus on HECM contracts.

In addition to the general reverse mortgage characteristics described above, HECM contracts have a number of specific features. To be eligible for a loan the youngest borrower in a household on the home's title has to be at least 62 years old. The maximum loan value is capped at $\$ 625,500$. The home either needs to be debt free or the remaining conventional mortgage debt needs to be repaid with the reverse mortgage proceeds. Borrowers can choose between line-ofcredit, annuity, or lump-sum as payout options. The most commonly chosen option is lump-sum (CFPB, 2012). In 2014, a limit of $60 \%$ of the maximum loan amount was placed as the maximum lump-sum available in the first year of the contract (Munnell and Sass, 2014). Finally, households interested in HECM loans are required to attend a counseling session. Hosted by an independent counselor, the purpose of the session is to clarify any questions about the product, to make sure that specific product knowledge is provided and that households properly understand the implications and consequences of the loan (MetLife report, 2012). Costs for HECM loans include origination fees, third party closing costs and insurance premiums and total approximately 3-7\% of home value. ${ }^{11}$ The homeowner remains responsible for paying taxes and insurances, as well as maintaining the home. Not paying taxes or insurance premiums can trigger a foreclosure

\footnotetext{
${ }^{10}$ Most private competitors to HECM disappeared during the home price bust, so Shan (2011) likely understates today's HECM's market share.

${ }^{11} \mathrm{http} / / / \mathrm{www}$. newretirement.com/reverse-mortgage/reverse-mortgage-interest-rates.aspx
} 
process. ${ }^{12}$ At the time of our survey, there were no income or credit rating checks for the borrower. Beginning in 2015, the borrower is required to undergo a financial assessment to ensure he is able to pay taxes and insurance (HUD, 2014). Borrowers who are deemed unable to make principal and interest payments must hold back some loan proceeds in an escrow account.

\subsection{Data and Methodology}

\subsubsection{Survey Design}

To assess reverse mortgage product knowledge and relate it to demand we need data that matches information on product knowledge, product demand, and socio-demographic control variables. Large-scale household surveys such as the HRS or SCF do not specify reverse mortgage holdings or knowledge. The FIT (Financial Interview Tool) survey data, which is collected from each HECM applicant during the mandatory counseling session contains some demographic data, as well as some data about the reasons why a household might consider a reverse mortgage. However, this data includes only the selected subsample of households who are already interested in a HECM and potentially have a more favorable attitude towards them when compared to the general population. Thus, existing data is not suited to address our research question. For that reason, we designed a survey to elicit the information of interest.

The survey was distributed to a representative sample of U.S. homeowners aged 58+ in November 2013 by SurveyMonkey. Thus, our sample population is not limited to the target group for reverse mortgages (house rich, cash poor), and is close to or already eligible for a HECM reverse mortgage, as the lower age boundary for HECM contracts is 62 (see Section 4.2). SurveyMonkey recruited participants and incentivized them by donating 50 cents to a charitable organization to be chosen by the participant and by letting participants take part in a lottery to win \$100. The questionnaire assesses respondents' reverse mortgage knowledge and perceived complexity of HECMs, and their intention to use a reverse mortgage. Drawing on predictions from life cycle models and previous studies' arguments explaining low product demand, we also

\footnotetext{
${ }^{12}$ Moulton, Haurin, and Shi (2015) report that $12 \%$ of HECM loans experienced a technical default due to not paying insurances or taxes. A foreclosure process is, however, not triggered right away. For example, untapped HECM loan balances are used to pay outstanding amounts or refinancing options are evaluated. 
include questions eliciting, for example, bequest motives, risk aversion, debt aversion, and home attachment.

The first five questions of the questionnaire assess general attitudes towards conventional and reverse mortgages and ask about familiarity with reverse mortgages. Next, three questions assess general financial literacy (Lusardi and Mitchell, 2011a) and 13 questions assess HECM knowledge (described in detail in Section 4.3.2). Respondents are then asked whether they have any personal experience with reverse mortgages, and to specify the minimal payout ratio (i.e., the fraction of the home value paid out as a lump sum) required to determine if a reverse mortgage is a good deal. Next, respondents are randomly assigned to two experimental conditions. Approximately half $(51.3 \%)$ of the respondents proceed with the questionnaire, while the other half $(48.7 \%)$ is first shown an explanation of HECMs and their features, that is, knowledge about product features is provided (see Section 4.4.4). Then, this group proceeds with the questionnaire as well.

Afterwards, the intention to use a reverse mortgage is elicited by the question: "In general, how likely is it that you will be taking out a reverse mortgage (HECM)?" (scored on a Likert scale from 1 to 7 , with $1=$ not likely at all to $7=$ very likely). Perceived complexity is elicited by asking agreement to the following statement: "Reverse mortgages (HECMs) are complex products." (scored on a Likert scale from 1 to 7 , with $1=$ totally disagree to $7=$ totally agree). In the questionnaire's final part, demographic information and potential demand factors based on previous literature on reverse mortgage demand are elicited. For example, we obtain information about age, household income, household savings, bequest motives, subjective life expectancy, subjective health, debt aversion, and home attachment. Table 4.1 contains variable definitions, survey questions, and corresponding summary statistics. In section 4.4.3.3 we compare our respondent characteristics with respondents in the Survey of Consumer Finances.

A total of 575 fully completed questionnaires were obtained from SurveyMonkey. Eighteen respondents were removed from the sample because matching demographic information provided directly by SurveyMonkey (gender and highest education level) was not available. Finally, we have 557 complete questionnaires for analysis. 
Table 4.1 Variable Definitions

\begin{tabular}{|c|c|c|c|c|}
\hline Variable & mean & sd & med & Definition \\
\hline RM known & 0.97 & 0.16 & & Indicator variable taking the value 1 if respondent already heard about reverse mortgages; 0 otherwise \\
\hline RM experience & 0.02 & 0.13 & & Indicator variable taking the value 1 if participant has prior experience with reverse mortgages; 0 otherwise \\
\hline RM knowledge & 5.87 & 2.62 & 6 & $\begin{array}{l}\text { Aggregate reverse mortgage-specific knowledge score composed of } 13 \text { items: } 0=\text { no question correct } \ldots 13=\text { all } \\
\text { thirteen questions correct (details on the survey questions are given in Table } 2 \text { ) }\end{array}$ \\
\hline Intention to use & 1.60 & 1.25 & 1 & $\begin{array}{l}\text { Intention to use a reverse mortgage based on responses to the following question: "In general, how likely is it that you } \\
\text { will be taking out a reverse mortgage (HECM)?" } 1 \text { = not likely at all . . } 7 \text { = very likely }\end{array}$ \\
\hline RM good deal & 3.18 & 1.35 & 4 & Agrement to the statement: "A reverse mortgage is generally a good deal.": $1=$ totally disagree $\ldots 7=$ totally agree \\
\hline HECM penetration & 0.03 & 0.02 & 0.03 & Market penetration of HECM loans, based on ZIP code \\
\hline Others known w. RM & 0.18 & 0.38 & & Indicator variable taking the value 1 for respondent knowing other people who have a reverse mortgage; 0 otherwise \\
\hline Required payout & 79.99 & 34.21 & 80 & Required payout (in $\%$ of home value) from a reverse mortgage to rate it as a good deal \\
\hline Prob. loan underwater & 44.21 & 34.05 & 50 & $\begin{array}{l}\text { Probability that loan balance exceeds home value based on responses to the following question: "How likely is it that } \\
\text { the reverse mortgage loan balance over time becomes larger than the home value? Indicate a number ranging from } 0 \\
\text { to } 100 \text {, where } 0 \text { means "impossible" and } 100 \text { means "for sure"." }\end{array}$ \\
\hline Complex & 5.39 & 1.61 & 6 & $\begin{array}{l}\text { Self-assessed product complexity based on responses to the following statement: "Reverse mortgages are complex } \\
\text { products." } 1=\text { totally disagree } \ldots 7=\text { totally agree }\end{array}$ \\
\hline Conv. mortgage & 0.58 & 0.49 & & Indicator variable taking the value 1 for having a mortgage on home; 0 otherwise \\
\hline Gender & 0.49 & 0.50 & & Gender: $0=$ female, $1=$ male \\
\hline Age & 64.84 & 5.86 & 64 & Age of respondent in years as of November 2013 \\
\hline Marital status & 0.75 & 0.43 & & Indicator variable taking the value of 1 for respondent being married; 0 otherwise \\
\hline Retirement & 0.54 & 0.50 & & Indicator variable taking the value of 1 for respondent being already retired; 0 otherwise \\
\hline Higher education & 0.74 & 0.44 & & $\begin{array}{l}\text { Indicator variable taking the value of } 1 \text { for respondent reporting highest education being "associate or bachelor } \\
\text { degree" or "graduate degree"; } 0 \text { for respondent reporting highest eduaction being "less than high school degree", "high } \\
\text { school degree", or "some college". }\end{array}$ \\
\hline White & 0.92 & 0.26 & & Indicator variable taking value of 1 for respondent being white; 0 otherwise \\
\hline Children & 0.79 & 0.41 & & Indicator variable taking the value 1 if respondent has children; 0 otherwise \\
\hline Bequest motive & 4.92 & 1.96 & 5 & $\begin{array}{l}\text { Self-expressed bequest motive based on responses to the following statement: "I would like to leave an inheritance." } 1 \\
=\text { certainly not } \ldots 7=\text { certainly yes }\end{array}$ \\
\hline Financial literacy & 2.60 & 0.71 & 3 & $\begin{array}{l}\text { Aggregate financial literacy score: } 0=\text { no question correct } \ldots .3=\text { all three questions correct (Lusardi and Mitchell, } \\
\text { 2008) }\end{array}$ \\
\hline Planning skill & 4.94 & 1.39 & 5 & $\begin{array}{l}\text { Self-assessed financial planning skills based on responses to the following question: "In general, how would you } \\
\text { assess your understanding of financial planning?" } 1 \text { = very poor } \ldots 7 \text { = very good (HRS) }\end{array}$ \\
\hline
\end{tabular}


Table 4.1 Variable Definitions - continued

\begin{tabular}{|c|c|c|c|c|}
\hline Variable & mean & $\mathrm{sd}$ & med & Definition \\
\hline Risk aversion & 6.25 & 2.19 & 6 & $\begin{array}{l}\text { Risk aversion based on responses to the following question: "Are you generally a person who is willing to take risk?"1 } \\
=\text { unwilling to take risk ... } 10 \text { = willing to take risk (Dohmen et al., 2011) }\end{array}$ \\
\hline Debt aversion & 5.06 & 1.85 & 5 & $\begin{array}{l}\text { Debt aversion based on agreement to the following statement: "Being in debt is never a good thing." } 1=\text { disagree } \ldots 7 \\
=\text { totally agree }\end{array}$ \\
\hline Broker trust & 3.24 & 1.46 & 3 & $\begin{array}{l}\text { Trust in mortgage brokers based on agreement to the following statement: "Mortgage brokers are people that } \\
\text { generally can be trusted." } 1=\text { totally disagree } \ldots 7=\text { totally agree }\end{array}$ \\
\hline Health & 2.26 & 0.93 & 2 & Self-perceived health: $1=$ excellent $\ldots .5=$ poor $(H R S, 2011)$ \\
\hline Subj. life expectancy & 0.82 & 0.25 & & $\begin{array}{l}\text { Subjective life expectancy based on responses to the following question: "What chance do you think there is that you } \\
\text { will live another } 10 \text { years or more? Please indicate the chance on a sclae of } 0 \text { to } 100 \text {, where } 0 \text { means "no chance at } \\
\text { all" and } 100 \text { means "absolutely certain"." }\end{array}$ \\
\hline Obj. life expectancy & 0.75 & 0.15 & 0.80 & 10-year life expectancy (based on Lee-Carter stochastic mortality model) \\
\hline Health insurance & 0.82 & 0.38 & & Indicator variable taking the value 1 for respondent having health insurance; 0 otherwise \\
\hline Long-term care insurance & 0.28 & 0.45 & & Indicator variable taking the value 1 for respondent having long-term care insurance; 0 otherwise \\
\hline Home value & 680 & 4,000 & 250 & Current home value (in \$ '000) \\
\hline Past home value growth & 2.84 & 1.07 & 3 & $\begin{array}{l}\text { Subjective past development of home value based on responses to the satatement: "Over the last } 5 \text { years do you think } \\
\text { the value of your home..." } 1=\text { increased a lot (greater than 20\%), } 2=\text { increased moderately (between } 5 \% \text { and 20\%), } \\
3=\text { remained rather stable (between } 5 \% \text { and }-5 \% \text { ), } 4=\text { decreased moderately (between }-5 \% \text { and }-20 \% \text { ), } 5= \\
\text { decrease a lot (greater than }-20 \% \text { ) }\end{array}$ \\
\hline $\begin{array}{l}\text { Expected home value } \\
\text { growth }\end{array}$ & 2.38 & 0.70 & 2 & $\begin{array}{l}\text { Subjective future development of home value based on responses to the statement: "Over the next five years do you } \\
\text { think the value of your home will..." } 1=\text { increase a lot (greater than 20\%), } 2=\text { increase moderately (between } 5 \% \text { and } \\
20 \% \text { ), } 3=\text { remain rather stable (between } 5 \% \text { and }-5 \% \text { ), } 4=\text { decrease moderately (between }-5 \% \text { and }-20 \% \text { ), } 5= \\
\text { decrease a lot (greater than }-20 \% \text { ) }\end{array}$ \\
\hline House price fluctuations & 5.48 & 1.42 & 6 & Agreement to statement "House prices can fluctuate a lot": $1=$ totally disagree $\ldots .7=$ totally agree \\
\hline Stay home 7+ & 0.71 & 0.45 & & $\begin{array}{l}\text { Indicator variable taking the value } 1 \text { if respondent plans to stay in current home for at least seven more years; } 0 \\
\text { otherwise (FIT) }\end{array}$ \\
\hline Home attachment & 17.72 & 12.29 & 15 & $\begin{array}{l}\text { Home attachment based on responses to the following question: "How many years have you lived in your current } \\
\text { home? (Enter the closest round number. If you have live in your current home less than a year, please enter 1.)" }\end{array}$ \\
\hline Household savings & 103.68 & 60.46 & 150 & $\begin{array}{l}\text { Total value of household savings (in } \$ \text { '000) elicited with the question: "Excluding home value, what is the total value } \\
\text { of your household savings? (including for example checking accounts, savings accounts, stocks, mutual funds, } \\
\text { retirement accounts)" with answer choices being: "less than } \$ 1,500 " \text { ", "between } \$ 1,500 \text { and } \$ 10,000 " \text { ", "between } \\
\$ 10,000 \text { and } \$ 35,000 " \text { ", "between } \$ 35,000 \text { and } \$ 100,000 " \text {, and "more than } \$ 100,000 " \text {. As savings measure, interval mid- } \\
\text { points are used. The upper bound of savings is set to be equal to } \$ 150,000 \text {. }\end{array}$ \\
\hline
\end{tabular}




\begin{tabular}{|c|c|c|c|c|}
\hline Variable & mean & sd & med & Definition \\
\hline Sufficient savings & 4.07 & 2.00 & 4 & Consent with "I have enough savings": $1=$ certainly not $\ldots 7=$ certainly yes \\
\hline Household income & 59.82 & 21.96 & 75 & $\begin{array}{l}\text { Average yearly household income (in } \$ \text { '000) elicited with the question: "What is your approximate average household } \\
\text { income per year?" with answer choices being: "under } \$ 10,000 " \text { ", "between } \$ 10,000 \text { and } \$ 20,000 \text { ", "between } \$ 20,000 \\
\text { and } \$ 35,000 " \text { ", "between } \$ 35,000 \text { and } \$ 500,000 " \text { ", and "over } \$ 500,000 " \text {. As income measure, interval mid-points are } \\
\text { used. The upper bound of income is set to be equal to } \$ 75,000 \text {. }\end{array}$ \\
\hline Sufficient pension & 4.69 & 1.95 & 5 & Consent with "I have/expect to have sufficient pension income": $1=$ certainly not $\ldots 7=$ certainly yes \\
\hline $\mathrm{N}$ & 557 & & & \\
\hline
\end{tabular}

Note: This table presents variable names, summary statistics, and definitions for the survey data. References for survey question wording which is based on existing literature or surveys are given in parentheses. RM abbreviates "Reverse Mortgage", HECM is "Home Equity Conversion Mortgage", HRS is "Health and Retirement Study", and FIT is "Financial Interview Tool." Home value is winsorized at the top $2 \%$ level. 
Table 4.2 Reverse Mortgage Knowledge

\begin{tabular}{|c|c|c|c|c|c|c|c|c|c|}
\hline \multirow[b]{3}{*}{ Variable } & \multirow[b]{3}{*}{ Feature } & \multirow[b]{3}{*}{ Survey Question } & \multirow[b]{3}{*}{ Correct Answer } & \multicolumn{3}{|c|}{ Percent } & \multicolumn{3}{|c|}{ Continuous Response } \\
\hline & & & & & & Don't & & & \\
\hline & & & & Correct & Wrong & Know & Mean & Median & Std \\
\hline rmk1 & unlock equity & $\begin{array}{l}\text { A reverse mortgage allows you to withdraw wealth invested in } \\
\text { your home. }\end{array}$ & true & 82.59 & 6.64 & 10.77 & & & \\
\hline rmk2 & loan character & $\begin{array}{l}\text { A reverse mortgage helps you be debt-free if used to repay an } \\
\text { existing mortgage. }\end{array}$ & false & 43.63 & 28.55 & 27.83 & & & \\
\hline $\mathrm{rmk} 3$ & prerequisites & $\begin{array}{l}\text { For getting a reverse mortgage, your credit history and income will } \\
\text { be checked. }\end{array}$ & false & 19.93 & 50.99 & 29.08 & & & \\
\hline $\mathrm{rmk} 4$ & loan balance & $\begin{array}{l}\text { Over time, the loan balance of a reverse mortgage... [shrinks/stays } \\
\text { constant/grows] }\end{array}$ & grows & 46.68 & 26.39 & 26.93 & & & \\
\hline $\operatorname{rmk} 5$ & life-long living right & $\begin{array}{l}\text { Even when the reverse mortgage loan balance becomes larger than } \\
\text { the home value, you do not have to move out. }\end{array}$ & true & 56.01 & 8.26 & 35.73 & & & \\
\hline rmk6 & age requirement & $\begin{array}{l}\text { To be eligible for a reverse mortgage (HECM), how old do you } \\
\text { have to be at least? }\end{array}$ & $60-65$ years (62 years) & $\begin{array}{c}71.10 \\
(27.11)\end{array}$ & $\begin{array}{c}28.90 \\
(72.89)\end{array}$ & $\mathrm{n} / \mathrm{a}$ & 58.62 & 62.00 & 11.99 \\
\hline rmk7 & interest payments & $\begin{array}{l}\text { When do you have to make interest payments on a reverse } \\
\text { mortgage? [every month/once a year/when the loan is paid } \\
\text { back/never] }\end{array}$ & $\begin{array}{l}\text { when the loan is paid } \\
\text { back/never }\end{array}$ & 51.16 & 11.49 & 37.34 & & & \\
\hline rmk8 & non-recourse loan & $\begin{array}{l}\text { If the reverse mortgage loan balance is larger than the house value, } \\
\text { the lender can force you to pay the loan off with other assets. }\end{array}$ & false & 33.93 & 15.26 & 50.81 & & & \\
\hline rmk9 & home protection & $\begin{array}{l}\text { If you are unable to make your interest pay-ments on the reverse } \\
\text { mortgage loan, a foreclosure process can be started on your home. }\end{array}$ & false & 33.75 & 20.11 & 46.14 & & & \\
\hline rmk10 & interest rates & $\begin{array}{l}\text { When interest rates are higher, one gets less money when taking } \\
\text { out a reverse mortgage. }\end{array}$ & true & 28.37 & 19.57 & 52.06 & & & \\
\hline rmk11 & costs & $\begin{array}{l}\text { What percentage of home value are the likely costs for getting a } \\
\text { reverse mortgage? }[0.5 \% / 1 \% / 3 \% / \ldots / 15 \%]\end{array}$ & $3 \%-7 \% \quad(5 \%)$ & $\begin{array}{r}19.82 \\
(8.73)\end{array}$ & $\begin{array}{c}15.82 \\
(26.91)\end{array}$ & 64.36 & 5.45 & 5.00 & 4.30 \\
\hline rmk12 & obligations & $\begin{array}{l}\text { If you have a reverse mortgage, for which items do you still have to } \\
\text { pay yourself? [property taxes/homeowner insurance/repair and } \\
\text { maintenance/none of these] }\end{array}$ & $\begin{array}{l}\text { property taxes; homeowner } \\
\text { insurance; repair and } \\
\text { maintenance costs }\end{array}$ & 73.61 & 10.95 & 15.44 & & & \\
\hline rmk13 & payout & $\begin{array}{l}\text { How much of a home's value would a reverse mortgage (HECM) } \\
\text { currently pay out as a lump sum to a } 62 \text {-year old borrower? } \\
{[5 \% / 10 \% / \ldots / 130 \%]}\end{array}$ & $40 \%-70 \%$ & 30.70 & 69.30 & $\mathrm{n} / \mathrm{a}$ & 58.48 & 60.00 & 31.41 \\
\hline
\end{tabular}

Note: This table presents the 13 questions used to construct the reverse mortgage knowledge score. Content in square brackets depicts the choices available to respondents; values in parentheses display alternative percentages correct/wrong if the narrower answer range is counted being correct. The variables' ordering resembles the original sequence in the survey. 


\subsubsection{Eliciting Product Knowledge}

To measure product knowledge we use 13 questions. The questions are designed to assess knowledge about the main characteristics of reverse mortgages. We developed the questions by building on the literature that hints at a general misunderstanding among elderly homeowners of debt contracts and reverse mortgages (Leviton, 2002; Lusardi and Tufano, 2009; Reed, 2009; CFPB, 2012; Stark et al., 2014) as well on the FIT (Financial Interview Tool) reverse mortgage counseling questionnaire. Based on responses to the 13 questions, we construct a reverse mortgage knowledge score. Each correctly answered question scores one point. Thus, after totaling the score for the 13 questions, the knowledge score ranges between 0 and 13, where 13 means perfect understanding of revere mortgage features (all results reported subsequently are robust to constructing the knowledge score alternatively based on a factor analysis (Appendix A4.1) or item response theory (Appendix A4.2)). The wording of the individual questions and descriptive statistics on the percentage of correct answers is given in Table 4.2. Questions are labeled rmk' $\mathrm{X}$ ', as an acronym for "reverse mortgage knowledge", question number " $\mathrm{X}$ ".

In Table 4.2, the questions rmk6 (minimum age requirement) and rmk11 (maximum percentage of home value that a reverse mortgage would pay out as a lump-sum) contain a baseline and an alternative specification, which differ in how the intervals are set to count answers to the questions as being correct. Responses to these two questions may vary depending on whether respondents perceive the questions as being asked about HECMs in particular or reverse mortgages in general. We cannot rule out that respondents know about other reverse mortgages products. For the baseline specification used throughout the paper, we treat all answers as correct if they would fit reverse mortgages in general. Our alternative specification (given in parentheses) is restricted to those answers that are correct specifically for HECMs. At the time the survey was distributed, no income or credit score checks were required to qualify for a HECM. The loan was entirely secured by the home serving as collateral. The HECM program has been restructured to prevent borrowers from defaulting on the loan by being unable to pay property taxes and insurance (see, e.g., HUD, 2014; Moulton, Haurin, and Shi, 2015). As of 2015, lenders must perform credit and income checks on potential borrowers. Because some of the survey respondents may have been aware of these proposed changes in 2013, we ran the 
regressions in Sections 4.4.1 and 4.4.2 leaving out the question about prerequisites of reverse mortgages (rmk3). Results obtained were in line with the main specification. The same holds for using the alternative classification of correct responses. ${ }^{13}$

\subsubsection{Survey Data Quality and Additional Data Sources}

SurveyMonkey samples from a representative pool of respondents. To check for representativeness of survey responses, we compare the survey information on income, savings, age, home value, education, race, bequest motives, and conventional mortgage debt with data from the 2013 wave of the Survey of Consumer Finances (SCF). Comparison with the SCF in Table 3 shows that our sample is fairly representative for U.S. homeowners aged 58+ on some but not all dimensions. Dimensions on which we observe some differences are included among the control variables in the regression analyses in Section 4.

Compared to the SCF statistics, respondents in our sample are better educated, and have slightly higher income and wealth. Average home value, however, is substantially larger in our sample $(\$ 680,000)$ than in the SCF $(\$ 270,000)$. A comparison with the sample median home value $(\$ 250,000)$ shows that the high average home value in our sample is driven by outliers (e.g., one respondent reporting a home value of $\$ 80$ million) potentially caused by typos (respondents were ask to enter a number for the home value while for income and savings answer brackets were given). In order to account for such outliers, we winsorize the home value variable at the top 2 percentile. The winsorized variable, which is used in later analysis, has a mean of $\$ 337,000$. This variable is highly correlated $(\rho=0.400, p$-value $=0.000)$ with five digit ZIP code level median home value from 2012 ACS (American Community Survey) data, whereas the correlation of the raw home value with ACS data is low $(\rho=0.083$, $p$-value $=0.052)$.

To further check the quality of our survey data and to generate additional control variables for the regressions in Section 4.4, we match the survey data based on respondents' five digit ZIP codes with HECM reverse mortgage origination data from HUD (U.S. Department of Housing and Urban Development) and ACS data. The HUD HECM origination data contains complete mortgage level origination data for the U.S. through November 2011.

\footnotetext{
${ }^{13}$ Results are available on request.
} 
Table 4.3 Comparison of Survey Respondents' Characteristics with the Survey of Consumer Finances

\begin{tabular}{|c|c|c|c|c|}
\hline & & & This Survey & SCF \\
\hline \multirow[t]{2}{*}{ Age } & mean & & 64.84 & 69.91 \\
\hline & median & & 64 & 68 \\
\hline \multirow[t]{5}{*}{ Health } & excellent & $\%$ & 19.57 & 18.97 \\
\hline & very good & $\%$ & 46.50 & \\
\hline & good & $\%$ & 24.96 & 46.60 \\
\hline & fair & $\%$ & 6.64 & 25.90 \\
\hline & poor & $\%$ & 2.33 & 8.52 \\
\hline \multirow[t]{4}{*}{ Race } & white & $\%$ & 92.46 & 83.66 \\
\hline & black/ afr.-am. & $\%$ & 1.08 & 9.85 \\
\hline & hispanic/latino & $\%$ & 0.90 & 3.90 \\
\hline & other & $\%$ & 1.26 & 2.58 \\
\hline \multirow[t]{4}{*}{ Education } & $<$ high school & $\%$ & 0.54 & 12.00 \\
\hline & high school & $\%$ & 6.46 & 33.83 \\
\hline & some college & $\%$ & 19.21 & 15.80 \\
\hline & college degree & $\%$ & 73.79 & 38.37 \\
\hline \multirow[t]{4}{*}{ Bequest motive } & not important & $\%$ & 23.52 & 19.72 \\
\hline & somewhat imp. & $\%$ & 16.16 & 31.90 \\
\hline & important & $\%$ & 28.73 & 27.11 \\
\hline & very important & $\%$ & 31.60 & 21.27 \\
\hline \multirow[t]{5}{*}{ Household income } & $<10 \mathrm{k}$ & $\%$ & 2.33 & 2.97 \\
\hline & $10-20 \mathrm{k}$ & $\%$ & 4.49 & 14.45 \\
\hline & $20-35 \mathrm{k}$ & $\%$ & 11.67 & 34.52 \\
\hline & $35-50 \mathrm{k}$ & $\%$ & 16.34 & 17.17 \\
\hline & $>50 \mathrm{k}$ & $\%$ & 65.17 & 48.30 \\
\hline \multirow[t]{5}{*}{ Household savings } & $<1.5 \mathrm{k}$ & $\%$ & 9.16 & 13.83 \\
\hline & $1.5-10 \mathrm{k}$ & $\%$ & 6.82 & 13.47 \\
\hline & $10-35 \mathrm{k}$ & $\%$ & 7.90 & 13.63 \\
\hline & $35-100 k$ & $\%$ & 15.44 & 13.67 \\
\hline & $>100 \mathrm{k}$ & $\%$ & 60.68 & 45.40 \\
\hline \multirow[t]{3}{*}{ Home value ('000) } & mean & & 680 & 270 \\
\hline & mean (winsorize & & 337 & \\
\hline & median & & 250 & 170 \\
\hline Conv. Mortgage & yes & $\%$ & 59.07 & 43.21 \\
\hline $\bar{N}$ & & & 557 & 1,852 \\
\hline
\end{tabular}

Note: This table compares summary statistics of the current survey with the 2013 wave of Survey of Consumer Finances (SCF). Statistics from SCF are for the subset of respondents that match our survey criteria, that is, homeowners aged 58+. Savings in the SCF correspond to the variable financial assets, home value to the value of the primary residence. Home value from our survey is reported twice: once based on the raw data and once winsorized at the top $2 \%$ level. 
We first use the HUD data to calculate the number of reverse mortgages outstanding per ZIP code as of November 2011. Then, from the ACS data we use the matching 2011 wave to gather information on the number of households per ZIP code that are eligible for a reverse mortgage. The ACS contains ZIP code level information on the number of households aged $65+$ as well as the fraction of homeowners aged 65+. Multiplying these numbers gives a close proxy for the number of households per ZIP code that are eligible for a reverse mortgage (a perfect proxy would include homeowners households aged 62+). Finally, by dividing the number of reverse mortgages outstanding (HUD) by the number of homeowners eligible for a reverse mortgage (ACS) we generate a ZIP code level reverse mortgage penetration variable (HECM penetration). ZIP codes are heterogeneous with regard to HECM penetration as the variable ranges between $0 \%$ and $17 \%$. Mean (median) HECM penetration is $3 \%(2.5 \%)$, with a standard deviation of $2 \%$. To check for the quality of our survey data, we relate this variable to the survey variable indicating whether a respondent knows somebody else having a reverse mortgage. This survey indicator variable is positively $(\rho=0.158, p$-value $=0.000)$ correlated with the objective penetration variable. That is, respondents are more likely to report knowing a reverse mortgagor if they live near relatively more reverse mortgage borrowers.

In addition, we use MSA (Metropolitan Statistical Area) level data from the Federal Housing Finance Agency on home price growth in the five year period preceding our survey. We match that data to our respondents based on the respondents' ZIP codes and the corresponding MSA data. Next, we compare this objective home price growth data with the subjective five year past home price growth reported by respondents. As the subjective home price growth is reported in brackets (see Table 4.1), we recode the objective data into the same brackets. Both variables are positively and significantly correlated. The Spearman correlation coefficient between both measures is 0.212 ( $\mathrm{p}$-value $=0.001$ ), which is rather high considering that the match of the objective with the subjective data is not perfect as the objective data is only available on the MSA level.

Similarly, the survey-based subjective probabilities to survive another ten years are close to their objective counterparts (calculated based on gender and age-specific U.S. data from the Human Mortality Database and a Lee-Carter Model mortality projection). On average, respondents overestimate their objective probability to survive by 6.5 percentage points (compare Table 4.1), 
which is in line with studies on subjective life expectancies of the elderly (e.g., Hamermesh, 1985; Hurd, Rohwedder and Winter, 2009). ${ }^{14}$

\subsection{Results}

\subsubsection{What Do Elderly Homeowners Know about Reverse Mortgages?}

Table 4.1 contains descriptive statistics on the characteristics of respondents in our sample (reverse mortgage knowledge per question is given in Table 4.2). Of all respondents, 58\% have a conventional mortgage on their home; 97\% indicate that they have heard about reverse mortgages; $18 \%$ of the respondents know at least one other person that has a reverse mortgage. Ten respondents, about $2 \%$ of the sample, have practical experience with reverse mortgages, which is in line with actual take-up rates (Shan, 2011). The mean response for perceived complexity of reverse mortgages is 5.4 (on a 7-point scale with 7 indicating highest complexity). That is, respondents rate reverse mortgages to be fairly complex.

Respondents' average score for self-assessed financial planning skills is 4.94 out of 7 points, and 2.60 points (out of 3 ) for financial literacy. The fraction of correctly answered financial literacy questions is in line with the pattern documented in Lusardi and Mitchell (2011b). In our sample, $87.43 \%, 90.48 \%$, and $81.69 \%$ of respondents were able to correctly answer questions regarding interest compounding, inflation, and diversification, respectively. The percentage of correctly answered questions in our sample is higher than the sample used by Lusardi and Mitchell (2011b), that is, $67.1 \%, 75.2 \%$, and $52.3 \%$. However, the fraction of white and well- educated respondents in our sample also is higher than in Lusardi and Mitchell (2011b), who also report results split by race and education. White individuals answer the questions on interest compounding, inflation, and risk diversification correctly at rates of $72.3 \%, 78.5 \%$, and $55.2 \%$, respectively. For individuals with higher levels of education (who attended college or more), the

\footnotetext{
${ }^{14}$ A potential problem with online surveys is that respondents might look up the information being asked for on the internet. To address this potential issue, we include in the regression explaining knowledge (see Section 4.4.2) survey completion time as a covariate (detailed results available on request). The coefficient for survey completion time (in seconds) is not significant and virtually equal to zero (0.0003). Thus, it is unlikely that some respondents perform better on the knowledge questions because of looking up information on the internet. Moreover, there may be an offsetting effect conceivable in that quicker respondents might be more knowledgeable.
}

82 
percentage of correctly answered questions is $81.2 \%, 85.1 \%$, and $70.2 \%$. Thus, our sample's responses are in line with results for individuals that have similar characteristics.

Next, we present details on the variables rmk1-13 that constitute reverse mortgage product knowledge. These are the 13 items we subsequently use to create the reverse mortgage knowledge score.

Three questions are answered correctly by most respondents (Table 4.2). Rmk1 checks respondents' understanding of the most basic feature of reverse mortgages, the ability to liquidate housing wealth (83\% correct). Rmk6 asks for the minimum age requirement (62 years) to be eligible for a HECM mortgage. This question is correctly answered by $71 \%$ (applying the less strict answer range of 60-65 years) or 27\% (applying only age 62 as the correct answer). Rmk12 asks about the costs the borrower is still responsible for, that is, property taxes, homeowner insurance, and repair and maintenance costs (74\% correct).

Four questions are answered correctly by roughly half of the survey respondents. Forty-four percent of all respondents know that if they use the proceeds to repay a conventional mortgage, they will not be debt free by taking on a reverse mortgage. Rmk4, which determines whether respondents are aware that the loan balance grows over time due to accrued interest being added to the loan balance, has $47 \%$ correct answers. Fifty-six percent of the respondents indicate correctly that a reverse mortgage grants a life-long right for the borrower to remain in the home even if the loan balance exceeds the home value (rmk5). The probability perceived for this event to happen is on average 44\% (compare Table 4.3) which is higher than the historical probability of 10\% (Hong and Lee, 2012) for reverse mortgage loans being assigned to the Federal Housing Administration (not all of these loans are necessarily underwater). ${ }^{15}$ That no regular interest payments have to be made on a reverse mortgage loan is correctly indicated by $51 \%$ of our sample's respondents ( $\mathrm{rmk} 7)$.

Based on the percentage of correct answers, the remaining reverse mortgage knowledge questions turn out to be the most difficult ones. Roughly one third or less of our respondents correctly answer questions rmk3, 8, 9, 10, 11, and 13.

\footnotetext{
${ }^{15}$ Of all loans (origination years 1989 to 2011) in the HUD HECM origination data (see Section 4.3.3), 1.4\% are flagged as having been underwater when the mortgage was terminated. Looking only at loans originated before 2000 (and thus having had a longer time to become underwater) 3.3\% of loans are flagged of having been underwater.
} 
Rmk3 asks about prerequisites for a reverse mortgage loan and is correctly answered by $20 \%$ of respondents. Here, we identify whether survey respondents know that there are no credit history checks and income requirements, since the loan is backed exclusively by the home as collateral. To determine whether respondents are aware of the protection reverse mortgages offer from over indebtedness (non-recourse nature of the loan), we have them answer a true or false question about whether a lender can force a borrower to repay the loan with other assets than the home if the loan balance exceeds home value (rmk8). Unlike conventional mortgages, interest on a reverse mortgage is added to the loan balance and the borrower is not obliged to regularly pay interest. Hence, there can be no foreclosure process because of inability to make interest payments. ${ }^{16}$ We elicit whether respondents are aware of this fact in item rmk9. Both rmk9 and rmk8 are answered correctly by only one third ( $34 \%$ for each) of respondents.

Slightly more than a quarter $(28 \%)$ of the respondents understand that a higher loan interest rate results in lower total borrowing amount (rmk10). Rmk11 captures awareness about the costs borne by opting for a reverse mortgage, which are approximately $5 \%$ of home value (see Section 4.2). Only $20 \%$ of all respondents answer this question correctly if the correct answer range for costs is set to $3-7 \%$.

Rmk13 asks respondents to estimate the approximate payout ratio (as a percentage of home value) applicable to a 62-year old reverse mortgage borrower. At the time of the survey, this payout ratio was around $50 \%$ based on quotes from an online reverse mortgage calculator. ${ }^{17}$ The mean (median) response for this question is $58 \%$ (60\%). However, only $31 \%$ of respondents, using a range from $40-70 \%$ for correct answers, answer this question correctly. ${ }^{18}$ Interestingly, the mean response to a question about the payout ratio that respondents would require to rate a reverse mortgage a good deal is $80 \%$ (compare Table 4.1). That is, the average "desired" payout ratio exceeds the payout ratio offered by the market. In particular, $26 \%$ of respondents indicate a

\footnotetext{
${ }^{16}$ There can be a foreclosure process because of inability to pay taxes or insurance premiums, but the survey question explicitly mentioned only interest payments.

${ }^{17}$ http://www.reversemortgage.org/About/ReverseMortgageCalculator.aspx

${ }^{18}$ We use a range that is $-10 \%$ to $+20 \%$ around the correct payout ratio. We use a higher upper end of the range as the payout ratio increases strongly with age (Shan, 2011). Many borrowers in the sample are older than 62 and might have answered this question reflecting more their own situation.
} 
higher desired payout ratio, than what they believe (rmk13) a reverse mortgage would actually pay.

Next, we aggregate the responses to the 13 product knowledge questions into the reverse mortgage knowledge score (0 points for each incorrect and "don't know" response, 1 point for each correct answer). The resulting mean knowledge score is 5.91 ; the $25 \%(50 \% ; 75 \%)$ quartile is $4(6 ; 8)$. Figure 4.1 , showing the distribution of the reverse mortgage knowledge score, highlights that there is considerable heterogeneity in respondents' reverse mortgage product knowledge.

Figure 4.1 Distribution of the Reverse Mortgage Product Knowledge Score

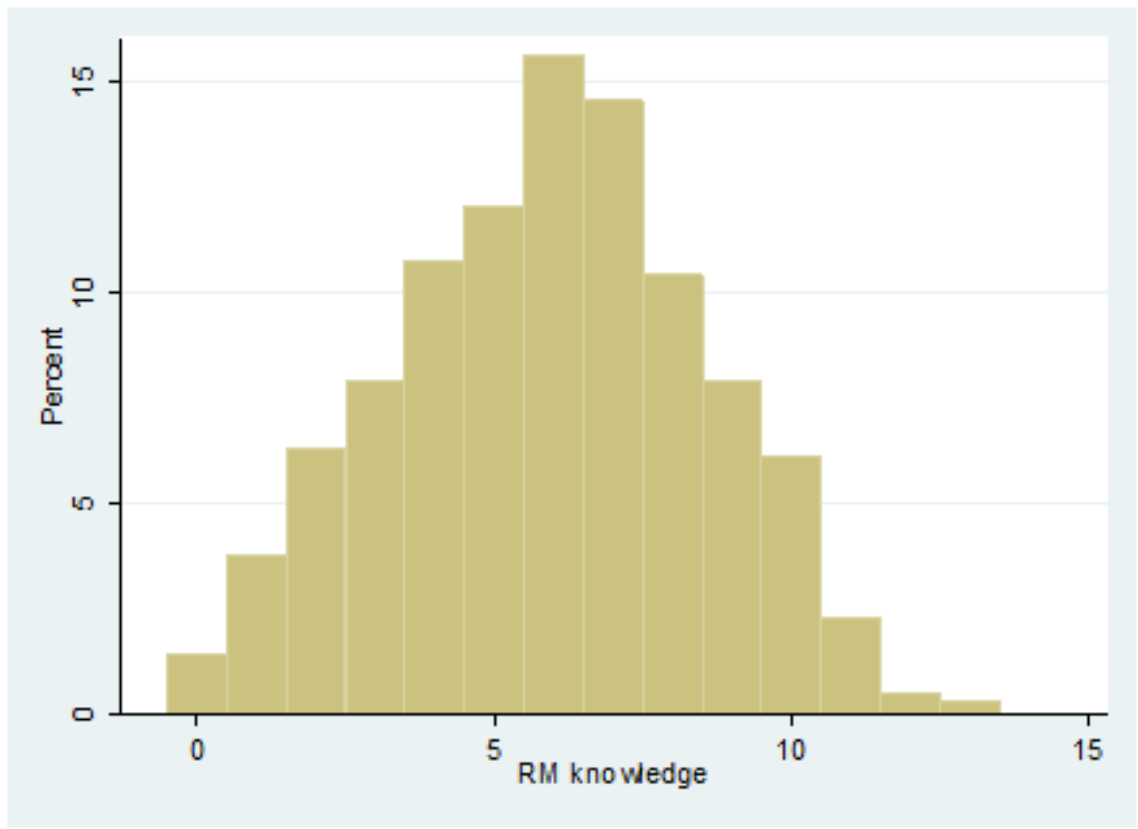

Note: This figure shows the distribution of the 13 item reverse mortgage product knowledge score.

For the main analyses we use this reverse mortgage knowledge score. Analyses based on extracting a single factor from the knowledge score, differentiating between whether an item was answered correctly or incorrectly or "don't know" vs. another answer, yield results in line with the main results (see Appendix A4.1). Likewise, modelling heterogeneity in question difficulty explicitly based on item response theory yields results in line with the main results (see Appendix A4.2). 


\subsubsection{Reverse Mortgage Product Knowledge and Respondent Characteristics}

In this section, we relate reverse mortgage product knowledge to respondent characteristics. We first regress the 13-item knowledge score on a set of basic demographic characteristics (age, being retired, gender, education, race, marital status, having children, income, savings, home value) and a set of variables potentially related to financial sophistication and experience with reverse mortgage products (financial literacy, financial planning skills, number of people known with a reverse mortgage, personal experience with reverse mortgages, ZIP code-specific HECM penetration). Next, in a second regression model, we add a set of variables based on previous empirical and theoretical literature that might also play a role in respondents' perceptions of reverse mortgages (see, e.g., Davidoff, 2009; Nakajima and Telyukova, 2017; Cocco and Lopes, 2014; Fornero et al., 2016; Hanewald, Post, and Sherris, 2016). In addition, we include the survey item eliciting the perceived complexity of reverse mortgages products. Regression results are given in Table 4.4 .

With respect to demographics (Table 4.4, model 1), older, male (potentially proxying the household's financial planner), and white respondents have a better understanding of reverse mortgages. General financial literacy and self-assessed financial planning skill are positively and significantly related to knowledge.

When adding the additional set of variables to the regression model (Table 4.4, model 2) we find that having long-term care insurance is negatively related to knowledge. Having insurance potentially decreases the necessity to rely on home equity to fund future medical expenses and care costs. However, the theoretically expected relationship is complex and ambiguous (Davidoff, 2009). Higher trust in mortgage brokers is negatively related to knowledge indicating that greater reliance on a broker's expertise reduces incentives to acquire own knowledge. The negative and significant coefficient for risk aversion is potentially in line with the theoretical predictions of Eeckhoudt and Godfroid (2000). That is, the value of acquiring information can fall with risk aversion if a decision maker in advance had expected a high likelihood not to take action (and thus the information is likely not to be valuable). Age is no longer (marginally) significant in the second model specification. Less knowledge is marginally significantly associated with respondents rating the product to be more complex. 
Table 4.4 Explaining Reverse Mortgage Product Knowledge

\begin{tabular}{|c|c|c|}
\hline & $\begin{array}{c}\text { RM knowledge } \\
\text { (1) }\end{array}$ & $\begin{array}{c}\text { RM knowledge } \\
\text { (2) }\end{array}$ \\
\hline Age & $\begin{array}{l}0.037^{*} \\
(0.021)\end{array}$ & $\begin{array}{c}0.022 \\
(0.022)\end{array}$ \\
\hline Retirement & $\begin{array}{c}0.033 \\
(0.242)\end{array}$ & $\begin{array}{l}-0.076 \\
(0.250)\end{array}$ \\
\hline Gender & $\begin{array}{c}0.696^{* * * *} \\
(0.216)\end{array}$ & $\begin{array}{c}0.564^{* *} * \\
(0.223)\end{array}$ \\
\hline Higher Education & $\begin{array}{c}0.217 \\
(0.248)\end{array}$ & $\begin{array}{c}0.234 \\
(0.250)\end{array}$ \\
\hline White & $\begin{array}{r}0.996 * * \\
(0.401)\end{array}$ & $\begin{array}{l}0.894 * * \\
(0.398)\end{array}$ \\
\hline Marital status & $\begin{array}{c}0.053 \\
(0.267)\end{array}$ & $\begin{array}{l}-0.028 \\
(0.265)\end{array}$ \\
\hline Children & $\begin{array}{c}0.224 \\
(0.263)\end{array}$ & $\begin{array}{c}0.323 \\
(0.273)\end{array}$ \\
\hline Ln(household income) & $\begin{array}{l}-0.061 \\
(0.222)\end{array}$ & $\begin{array}{c}0.102 \\
(0.228)\end{array}$ \\
\hline Ln(household savings) & $\begin{array}{c}0.075 \\
(0.080)\end{array}$ & $\begin{array}{c}0.060 \\
(0.087)\end{array}$ \\
\hline Ln(homevalue) & $\begin{array}{c}0.027 \\
(0.195)\end{array}$ & $\begin{array}{l}-0.058 \\
(0.201)\end{array}$ \\
\hline Financial literacy & $\begin{array}{c}0.780 * * * \\
(0.165)\end{array}$ & $\begin{array}{c}0.690 * * * \\
(0.168)\end{array}$ \\
\hline Planning skill & $\begin{array}{c}0.305^{* * * *} \\
(0.082)\end{array}$ & $\begin{array}{c}0.283 * * * \\
(0.085)\end{array}$ \\
\hline Conv. mortgage & $\begin{array}{c}0.041 \\
(0.225)\end{array}$ & $\begin{array}{c}0.085 \\
(0.231)\end{array}$ \\
\hline RM experience & $\begin{array}{l}1.906 * * \\
(0.802)\end{array}$ & $\begin{array}{l}1.958^{* *} \\
(0.797)\end{array}$ \\
\hline Others known w. RM & $\begin{array}{l}0.532 * \\
(0.273)\end{array}$ & $\begin{array}{l}0.551 * * \\
(0.273)\end{array}$ \\
\hline HECM penetration & $\begin{array}{c}5.176 \\
(5.088)\end{array}$ & $\begin{array}{c}4.456 \\
(5.148)\end{array}$ \\
\hline Stay home 7+ & & $\begin{array}{c}0.135 \\
(0.238)\end{array}$ \\
\hline Subj. life expectancy & & $\begin{array}{l}-0.857^{*} \\
(0.483)\end{array}$ \\
\hline Health & & $\begin{array}{c}0.027 \\
(0.127)\end{array}$ \\
\hline Health insurance & & $\begin{array}{l}-0.370 \\
(0.279)\end{array}$ \\
\hline Long-term care insurance & & $\begin{array}{c}-0.644 * * * \\
(0.238)\end{array}$ \\
\hline
\end{tabular}


Table 4.4 Explaining Reverse Mortgage Product Knowledge - continued

\begin{tabular}{|c|c|c|}
\hline Sufficient savings & & $\begin{array}{l}0.117 \\
(0.077)\end{array}$ \\
\hline Sufficient pension & & $\begin{array}{l}-0.026 \\
(0.072)\end{array}$ \\
\hline Broker trust & & $\begin{array}{c}-0.243 * * * \\
(0.073)\end{array}$ \\
\hline Bequest motive & & $\begin{array}{c}0.037 \\
(0.056)\end{array}$ \\
\hline Risk aversion & & $\begin{array}{c}-0.133^{* *} * \\
(0.052)\end{array}$ \\
\hline Debt aversion & & $\begin{array}{c}0.043 \\
(0.059)\end{array}$ \\
\hline Past home value growth & & $\begin{array}{c}0.153 \\
(0.108)\end{array}$ \\
\hline Expected home value growth & & $\begin{array}{l}-0.216 \\
(0.178)\end{array}$ \\
\hline Home attachment & & $\begin{array}{l}0.008 \\
(0.009)\end{array}$ \\
\hline House price fluctuations & & $\begin{array}{c}0.001 \\
(0.076)\end{array}$ \\
\hline Complex & & $\begin{array}{l}-0.110^{*} \\
(0.065)\end{array}$ \\
\hline Constant & $\begin{array}{l}-2.199 \\
(2.530)\end{array}$ & $\begin{array}{l}0.206 \\
(2.913)\end{array}$ \\
\hline $\begin{array}{l}\text { Observations } \\
\text { Adj. } \mathrm{R}^{2}\end{array}$ & $\begin{array}{c}557 \\
0.196\end{array}$ & $\begin{array}{c}557 \\
0.247\end{array}$ \\
\hline
\end{tabular}

Note: This table presents the results from OLS regressions of the 13 item reverse mortgage product knowledge score on respondent characteristics. Variables are defined in Table 4.1. Standard errors are given in parentheses. *, **, and *** denote statistical significance at the $10 \%, 5 \%$, and $1 \%$ levels, respectively.

Having personal experience with the product and knowing others with a reverse mortgage is positively and significantly related to product knowledge. ${ }^{19}$ These results hold even though we control for ZIP code-specific HECM penetration and thus unobserved location-specific factors related to reverse mortgage knowledge. Hence, peer effects seem to play an important role for knowledge about reverse mortgages.

\footnotetext{
${ }^{19}$ An alternative specification, in which we exclude the ten respondents with personal reverse mortgage experience from the sample yields similar results in terms of coefficient magnitudes and significance (detailed results available on request).
} 
Generally, regression results indicate a striking tendency: Those respondents that would benefit most from reverse mortgages and thus should have more incentives to acquire knowledge about the product do not have better knowledge about the product than other respondents. For example, neither having lower income, higher home values, lower savings, existing mortgage debt, nor having (no) children are associated with greater product knowledge.

The regression in model 2 includes two variables for both savings and income: the dollar measures for both income and savings, as well as subjective evaluations of each measure (sufficient savings, sufficient pension income). The insignificance of the coefficients for the subjective measures might be caused by multicollinearity between the objective and subjective measures. When using only the subjective measures, the model yields a positive and marginally significant coefficient of 0.136 ( $\mathrm{p}$-value $=0.065)$ for the subjective evaluation for savings. Respondents who evaluate their savings to be sufficient know more about reverse mortgages. Once again, this indicates that respondents who have better financial planning skills and are better prepared for retirement have better product knowledge. ${ }^{20}$ This is contrary to the notion that those individuals who are more in need of the benefits that may be derived from a reverse mortgage might have a greater incentive to acquire the knowledge necessary to become consumers of the product.

Overall, product knowledge is explained by financial sophistication, being well-prepared for retirement, individual experience with the product as well as knowing peers having the product, but not by financial needs to obtain a reverse mortgage.

\subsubsection{Reverse Mortgage Knowledge and Intention to use a Reverse Mortgage}

Next, we analyze respondents' intention to use a reverse mortgage. In general, the intention is low, which is in line with actual demand numbers. The mean of intention to use a reverse mortgage is 1.6 (range $=1$ to 7 , where $1=$ "not likely at all" to $7=$ "very likely"). We regress

\footnotetext{
${ }^{20}$ These findings are potentially consistent with the evidence in Meier and Sprenger (2013) and Lusardi, Michaud, and Mitchell (2017). These authors show, that individuals who put a greater weight on future consumption (i.e., discount the future less or have a need to transfer financial resources over time) acquire more financial literacy as the future benefits from this investment are valued more and returns on financial investments might be improved. We do not assess subjective discount factors or a preference for saving, but being better prepared for retirement may proxy for putting greater emphasis on future consumption.
} 
respondents' intention to use a reverse mortgage on the reverse mortgage knowledge score and additional variables. ${ }^{21} \mathrm{We}$ employ the same independent variables used previously to explain reverse mortgage product knowledge (compare Table 4.4, models 1 and 2), with one exception. We exclude the variable indicating personal experience with reverse mortgages (currently having one or having had one in the past) from the regression model and the corresponding 10 respondents from the sample. Table 4.5 (models 1 and 2) contains the regression results.

\subsubsection{Knowledge and Financial Literacy}

We find a significant positive relation between knowledge and the intention to use a reverse mortgage. Better understanding of reverse mortgages is related to higher intention to use a (HECM) reverse mortgage. General financial literacy, however, is marginally significantly and negatively related to the intention to use a reverse mortgage (model 2). The latter result resembles the Italian survey evidence from Fornero et al. (2016), and the U.S. evidence in Duca and Kumar (2014) for standard home equity conversion loans. Note however, that the channel through which financial literacy operates in our case is not clear. Duca and Kumar (2014) conjecture that less financially literate households underestimate the downside risks from borrowing against one's home and for that reason borrow more (or even too much). For reverse mortgages, however, there is virtually no risk for the homeowner, as they have a lifelong living right and the loan is nonrecourse. Potentially, homeowners' widespread misconception about the protective features of reverse mortgages may make the more financial literate shy away from the product as well. Alternatively, the financial literacy variable may be related to various aspects regarding being financially prepared for retirement, not fully controlled for by the measures for income and savings. Thus, as more financially sophisticated households have potentially better planned for retirement, there is less need for them to extract home equity.

\footnotetext{
${ }^{21}$ Employing an ordered logit or probit regression to account for the fact that the dependent variable can only take discrete values between one and seven yields results in line with the OLS specification. Moreover, we employ logit and probit regressions (dependent variable $=0$ if intention to use $=1$ and 1 if intention to use is $>1$ ) to check robustness of results with respect to the skewed distribution of the intention to use variable (around $70 \%$ of respondents select the lowest value of 1 on the scale). Again, results are in line with the OLS specification. Detailed results for the four models are available on request.
}

90 
Table 4.5 Explaining the Intention to Use a Reverse Mortgage

\begin{tabular}{|c|c|c|c|}
\hline & $\begin{array}{c}\text { Intention to } \\
\text { Use } \\
\text { (1) }\end{array}$ & $\begin{array}{c}\text { Intention to } \\
\text { Use } \\
\text { (2) }\end{array}$ & $\begin{array}{c}\text { Intention to } \\
\text { Use } \\
\text { (3) }\end{array}$ \\
\hline RM knowledge & $\begin{array}{c}0.047 * * \\
(0.019)\end{array}$ & $\begin{array}{c}0.047 * * \\
(0.019)\end{array}$ & $\begin{array}{c}0.047 * * \\
(0.019)\end{array}$ \\
\hline Age & $\begin{array}{l}-0.010 \\
(0.009)\end{array}$ & $\begin{array}{l}-0.008 \\
(0.009)\end{array}$ & $\begin{array}{l}-0.008 \\
(0.009)\end{array}$ \\
\hline Retirement & $\begin{array}{l}-0.105 \\
(0.106)\end{array}$ & $\begin{array}{l}-0.022 \\
(0.109)\end{array}$ & $\begin{array}{l}-0.018 \\
(0.110)\end{array}$ \\
\hline Gender & $\begin{array}{c}0.100 \\
(0.096)\end{array}$ & $\begin{array}{c}0.032 \\
(0.099)\end{array}$ & $\begin{array}{c}0.034 \\
(0.099)\end{array}$ \\
\hline Higher Education & $\begin{array}{l}-0.007 \\
(0.109)\end{array}$ & $\begin{array}{c}0.036 \\
(0.110)\end{array}$ & $\begin{array}{c}0.035 \\
(0.110)\end{array}$ \\
\hline White & $\begin{array}{l}-0.259 \\
(0.175)\end{array}$ & $\begin{array}{l}-0.265 \\
(0.174)\end{array}$ & $\begin{array}{c}-0.264 \\
(0.175)\end{array}$ \\
\hline Marital status & $\begin{array}{c}0.072 \\
(0.118)\end{array}$ & $\begin{array}{c}0.063 \\
(0.117)\end{array}$ & $\begin{array}{c}0.063 \\
(0.117)\end{array}$ \\
\hline Children & $\begin{array}{c}-0.171 \\
(0.116)\end{array}$ & $\begin{array}{l}-0.133 \\
(0.121)\end{array}$ & $\begin{array}{l}-0.133 \\
(0.121)\end{array}$ \\
\hline Ln(household income) & $\begin{array}{l}-0.179 * \\
(0.097)\end{array}$ & $\begin{array}{l}-0.168 * \\
(0.100)\end{array}$ & $\begin{array}{c}-0.166^{*} \\
(0.100)\end{array}$ \\
\hline Ln(household savings) & $\begin{array}{c}0.030 \\
(0.035)\end{array}$ & $\begin{array}{c}0.077 * * \\
(0.038)\end{array}$ & $\begin{array}{c}0.077 * * \\
(0.038)\end{array}$ \\
\hline Ln(homevalue) & $\begin{array}{l}-0.137 \\
(0.085)\end{array}$ & $\begin{array}{c}-0.103 \\
(0.088)\end{array}$ & $\begin{array}{c}-0.102 \\
(0.088)\end{array}$ \\
\hline Financial literacy & $\begin{array}{l}-0.105 \\
(0.075)\end{array}$ & $\begin{array}{l}-0.144 * \\
(0.076)\end{array}$ & $\begin{array}{c}-0.145^{*} \\
(0.076)\end{array}$ \\
\hline Planning skill & $\begin{array}{l}-0.026 \\
(0.037)\end{array}$ & $\begin{array}{l}-0.011 \\
(0.038)\end{array}$ & $\begin{array}{l}-0.011 \\
(0.038)\end{array}$ \\
\hline Conv. mortgage & $\begin{array}{c}0.286 * * * \\
(0.099)\end{array}$ & $\begin{array}{c}0.260 * * \\
(0.101)\end{array}$ & $\begin{array}{c}0.261 * * \\
(0.102)\end{array}$ \\
\hline Others known w. RM & $\begin{array}{c}0.316 * * * \\
(0.121)\end{array}$ & $\begin{array}{c}0.286 * * \\
(0.121)\end{array}$ & $\begin{array}{c}0.285 * * \\
(0.121)\end{array}$ \\
\hline HECM penetration & $\begin{array}{c}0.341 \\
(2.244)\end{array}$ & $\begin{array}{c}0.047 \\
(2.272)\end{array}$ & $\begin{array}{c}0.011 \\
(2.277)\end{array}$ \\
\hline Stay home 7+ & & $\begin{array}{c}0.023 \\
(0.104)\end{array}$ & $\begin{array}{c}0.020 \\
(0.105)\end{array}$ \\
\hline Subj. life expectancy & & $\begin{array}{c}0.055 \\
(0.212)\end{array}$ & $\begin{array}{c}0.060 \\
(0.212)\end{array}$ \\
\hline Health & & $\begin{array}{c}0.075 \\
(0.056)\end{array}$ & $\begin{array}{c}0.075 \\
(0.056)\end{array}$ \\
\hline Health insurance & & $\begin{array}{l}0.211 * \\
(0.123)\end{array}$ & $\begin{array}{l}0.212^{*} \\
(0.123)\end{array}$ \\
\hline Long-term care insurance & & $\begin{array}{l}-0.040 \\
(0.105)\end{array}$ & $\begin{array}{l}-0.039 \\
(0.105)\end{array}$ \\
\hline Sufficient savings & & $\begin{array}{c}-0.072 * * \\
(0.034)\end{array}$ & $\begin{array}{c}-0.072 * * \\
(0.034)\end{array}$ \\
\hline
\end{tabular}


Table 4.5 Explaining the Intention to Use a Reverse Mortgage - continued

\begin{tabular}{|c|c|c|c|}
\hline \multicolumn{2}{|l|}{ Sufficient pension } & $\begin{array}{l}-0.028 \\
(0.032)\end{array}$ & $\begin{array}{l}-0.028 \\
(0.032)\end{array}$ \\
\hline Broker trust & & $\begin{array}{l}0.054^{*} \\
(0.032)\end{array}$ & $\begin{array}{c}0.053 \\
(0.032)\end{array}$ \\
\hline Bequest motive & & $\begin{array}{c}-0.049 * * \\
(0.025)\end{array}$ & $\begin{array}{c}-0.049 * * \\
(0.025)\end{array}$ \\
\hline Risk aversion & & $\begin{array}{c}-0.060 * * * \\
(0.023)\end{array}$ & $\begin{array}{c}-0.060 * * * \\
(0.023)\end{array}$ \\
\hline Debt aversion & & $\begin{array}{l}0.050^{*} \\
(0.026)\end{array}$ & $\begin{array}{l}0.050^{*} \\
(0.026)\end{array}$ \\
\hline Past home value growth & & $\begin{array}{c}0.013 \\
(0.048)\end{array}$ & $\begin{array}{c}0.013 \\
(0.048)\end{array}$ \\
\hline Expected home value growth & & $\begin{array}{l}-0.071 \\
(0.078)\end{array}$ & $\begin{array}{l}-0.073 \\
(0.079)\end{array}$ \\
\hline Home attachment & & $\begin{array}{c}0.001 \\
(0.004)\end{array}$ & $\begin{array}{c}0.001 \\
(0.004)\end{array}$ \\
\hline House price fluctuations & & $\begin{array}{l}-0.005 \\
(0.033)\end{array}$ & $\begin{array}{l}-0.004 \\
(0.033)\end{array}$ \\
\hline Complex & & $\begin{array}{l}-0.035 \\
(0.029)\end{array}$ & $\begin{array}{l}-0.035 \\
(0.029)\end{array}$ \\
\hline Treatment group & & & $\begin{array}{c}0.028 \\
(0.091)\end{array}$ \\
\hline Constant & $\begin{array}{c}4.204 * * * \\
(1.109)\end{array}$ & $\begin{array}{c}3.891 * * * \\
(1.272)\end{array}$ & $\begin{array}{c}3.874 * * * \\
(1.274)\end{array}$ \\
\hline Observations & 547 & 547 & 547 \\
\hline Adj. $R^{2}$ & 0.076 & 0.134 & 0.134 \\
\hline
\end{tabular}

Note: This table presents the results from OLS regressions of the intention to use a reverse mortgage survey variable on the 13 item reverse mortgage product knowledge score and respondent characteristics. Variables are defined in Table 4.1. Standard errors are given in parentheses. *, **, and *** denote statistical significance at the $10 \%, 5 \%$, and $1 \%$ levels, respectively.

\subsubsection{Peer Effects}

Knowing other people who have a reverse mortgage is positively related to the intention to use a reverse mortgage. The coefficient for this variable is significant in all models, even when we control for ZIP code specific HECM penetration. Hence, the variable is picking up peer effects and not unobserved location specific factors related to reverse mortgage demand. This finding relates to the literature on peer effects in financial and retirement decision making. For example, Duflo and Saez $(2002,2003)$ find that enrollment in a pension plan, as well as investment decisions are impacted by peer effects. Hong, Kubik, and Stein (2004) and Brown et al. (2008) 92 
find that an individual's stock market participation increases through word-of-mouth communication and social interaction. Chalmers, Johnson, and Reuter (2014) find that retirement timing decisions are influenced by having coworkers in a similar decision situation. In our case, both familiarity with the product through personal knowledge, and knowing other people who have a reverse mortgage increase the intention to use a reverse mortgage. In fact, both of these variables, are amongst the regressors that have the largest explanatory power for the intention to use a reverse mortgage based on a decomposition of the $\mathrm{R}^{2}$ (Owen values) of the regression model (2). Knowing other people explains $11.60 \%$, personal knowledge $9.72 \%$ of the $\mathrm{R}^{2}$. Two other important variables are having a conventional mortgage (13.29\%) and sufficient savings (11.13\%). Note that peer effects increase the intention to use a reverse mortgage in two ways. First, peer effects serve to increase objective familiarity and general product knowledge (see Section 4.4.2). Second, as we control for knowledge in the regressions shown in Table 4.5, it is apparent that peer effects also increase perceived familiarity of the product.

Finding evidence for peer effects further supports the interpretation that (lack of) knowledge about reverse mortgages drives the (low) demand. Peer effects emerge especially in decision environments characterized by complexity, uncertainty about decision outcomes, little individual experience and knowledge, long-term tradeoffs, and delayed and noisy feedback. In such environments an individual is more likely to follow the behavior of peers by inferring good and appropriate decisions (e.g., Park and Lessig 1977; Mitchell and McGoldrick 1996; Steinberg and Monahan 2007).

\subsubsection{Further Factors}

A stronger bequest motive reduces the intention to use a reverse mortgage (model 2). That is, as taking out a reverse mortgage (and consuming the proceeds) lowers the bequest, respondents with higher bequest motives are reluctant to opt for a reverse mortgage.

Total household savings have no significant relationship with the intention to use a reverse mortgage in model 1 , but contrary to expectations, there is a positive and significant relationship in model 2. Model 2 includes, however, also the subjective savings measure. The coefficient for the variable indicating having sufficient savings is negatively and significantly related to the intention to use a reverse mortgage. That is, respondents who rate their savings to be insufficient, 
have a higher intention to use a reverse mortgage. The dollar amount of household savings may thus not be a good indicator of respondents' consumption needs. For example, low savings may not be a problem per se if consumption needs are adapted to those savings and savings are rated to be sufficient.

In line with theoretical models (e.g., Hanewald, Post, and Sherris, 2016), respondent income is negatively related to the intention to use a reverse mortgage. Having existing conventional mortgage debt is positively related to the intention to use a reverse mortgage. This finding is at odds with the predictions of Hanewald, Post, and Sherris (2016). In their life cycle model, existing debt reduces the welfare gains from reverse mortgages, as a fraction of the reverse mortgage proceeds cannot be consumed but needs to be used to retire the existing debt. Our findings are, however, in line with the empirical evidence in CFPB (2012) and Moulton et al. (2014). Compared to other households, reverse mortgage borrowers are more likely to have existing conventional mortgage debt in the first place and conditional on having debt, their debt comprises a larger fraction of home value.

Trust in mortgage brokers is positively related to the intention to use a reverse mortgage (model 2). A reverse mortgage is a difficult product to understand and there have been reports of reverse mortgage scams (see, e.g., Carswell, et. al., 2013; Stark et al., 2014). Consumers who trust the party offering the product are more likely to decide to use it. The effect of risk aversion, however, is opposite to theoretical predictions from life cycle models (e.g., Hanewald, Post, and Sherris, 2016). Being more risk averse reduces the intention to use a reverse mortgage. This effect may be driven by the general misconception of the product (see Section 4.4.2). Instead of viewing the product as reducing risks (e.g. outliving financial resources, exposure to home prices), our results indicate that respondents often believe the opposite. Respondents in our sample, for example, believe that if they have a reverse mortgage, they may be forced to move out of the home. Another interpretation of the negative coefficient on risk aversion is that this variable picks up respondents' uncertainty of whether the product in general is beneficial for them. Reverse mortgages are complex products and respondents need to evaluate long-term tradeoffs to make an informed decision. For example, respondents may be uncertain about future consumption needs and may find it difficult to evaluate how a reverse mortgage might change future consumption opportunities. This interpretation of the risk aversion variable is consistent with the findings on trust. Both variables are closely (and negatively) related to decision making in risky situations. 94 
While trust helps to overcome the uncertainty of a risky situation (the choice in favor of a poorly understood product), risk aversion has the opposite effect (see, e.g., Johnson and Grayson, 2005).

Contrary to results from the Italian survey by Fornero et al. (2016), model 2 shows that debt aversion is positively related to the intention to use a reverse mortgage. This finding is in line with our respondents' product misperception that reverse mortgages will help them become debt free. Having health insurance increases the intention to use a reverse mortgage as being insured can reduce the need to keep the (complete) home's value as a buffer against large unexpected expenses (see, e.g., Davidoff, 2009).

Other factors, which according to theoretical models should be related to reverse mortgage demand, such as experienced and expected home price growth, subjective life expectancy, having long-term care insurance or home attachment do not significantly relate to the intention to use a reverse mortgage.

\subsubsection{Robustness}

Due to the cross-sectional nature of our data, we cannot establish causality. The question is whether reverse mortgage product knowledge drives the intention to use a reverse mortgage or whether the relationship is the other way around. Looking jointly at the results from Section 4.4.2 and 4.4.3 provides evidence consistent with the notion that product knowledge drives the intention to use a reverse mortgage. The analyses in Section 4.4.3 show that respondents with insufficient savings have a higher intention to use reverse mortgages. But, the analyses in Section 4.4.2 reveal that those respondents have less knowledge. If the relation between knowledge and the intention to use a reverse mortgage is the other way around, we would expect to observe an opposite effect: Respondents with a higher intention to use the product (e.g., because of their insufficient savings) should have greater knowledge.

\subsubsection{Summary}

Overall, several results about the intention to use a reverse mortgage emerge. First, respondents with more knowledge about reverse mortgages generally express a higher intention to use a reverse mortgage. This group of respondents is more likely to make a decision based on information. Second, respondents seem to be influenced by peers having a reverse mortgage. 
Third, respondents for whom a reverse mortgage is more appropriate (e.g., having lower income, insufficient savings) express a higher intention to use a reverse mortgage. This group of respondents, however, does not have strong product knowledge. Thus, potentially the target group for reverse mortgages is not making a well-informed decision, and may insufficiently evaluate alternative options for their retirement financial planning. These findings relate to the literature examining the low demand for annuities. Brown et al. (2011) find that product complexity, misunderstanding of the product, and inability to value the product, explain why annuities are rarely used.

\subsubsection{The Impact of Information Transfer on the Intention to Use a Reverse Mortgage}

In this section we test whether respondents differ in their intention to use a reverse mortgage after they had the opportunity to learn about reverse mortgage product features. Half of the respondents were assigned to the treatment group that received information, the other half served as the control group. The treatment group was asked to read a short and rather simple ${ }^{22}$ product description, which explains the most important features of HECM reverse mortgages. The following text was shown:

Please read the following information carefully. If you have finished, please click 'next'. A Home Equity Conversion Mortgage (HECM) allows seniors to access their home equity without any requirement to meet income or credit qualifications. Similar to a "conventional" mortgage, it is a loan which uses the house as a security. The homeowner, who borrows money against his home, has the choice between a onetime payment (lump sum), a line of credit, which can be used any time, a supplement to monthly retirement income (annuity), or any combination of these. Over time, interest charges are added to the loan amount, thus the loan amount rises. Repayment of the loan is required if the homeowner sells the home, moves out, or dies. When those events occur, the home can be sold to pay back the loan. HECM borrowers are protected against the possibility that their home may fall in value. If the home is worth less than the loan

\footnotetext{
${ }^{22}$ The description has a Flesch-Kincaid grade level of 10.5. A Flesch-Kincaid grade level statistic of 10.5 indicates that the text requires the level of education of grade 10 to 11 based on U.S. education (e.g., Oakland and Lane, 2004).
} 
amount due, the borrower is not obliged to pay the bank more than the value of the home to satisfy the loan. As long as the loan is in place, the borrower remains the owner of the house, including all duties that come along with homeownership, such as obligation to pay property taxes and insurances. If the homeowner still repays an existing mortgage, a reverse mortgage can only be taken if the funds received from it are used to repay the existing mortgage.

Survey respondents in the treated group seem to have read the text. On average they spent three minutes and 20 seconds on this survey page.

Results in Table 4.5, model 3 show that the intention to use a reverse mortgage is not significantly different between the treatment and control group. The difference in means for the intention to use a reverse mortgage between the treated and control group is 0.028 and not statistically significant ( $\mathrm{p}$-value $=0.755$ ). In addition, we find no significant heterogeneous treatment effects based on analyzing subsamples split along several dimensions (e.g., product knowledge, gender, financial literacy, being retired or not, knowing others with a reverse mortgage or not, education, and time spent reading the text): ${ }^{23}$

Educating potential borrowers about the product does not increase the intention to use a reverse mortgage. The effect of education might be different in personal interviews, as done with the counseling sessions for HECM loans. However, homeowners who attend counseling sessions must first have a sufficient amount of interest in, and knowledge about, the product.

Providing homeowners with a relatively simple description of HECM, which is a complex product, does not have an effect on their intention to use a reverse mortgage. This result relates to the literature in two ways. First, it is in line with the meta-analysis of Fernandes, Lynch, and Netemeyer (2014) who claim that interventions to improve general financial literacy have often (but not always) little explanatory power for subsequent behaviors. Second, Wong-Parodi, Bruine de Bruin, and Canfield (2013) find in the domain of energy conservation brochure materials, that helping to educate via simplification does work for straightforward information material, but not for complex material.

\footnotetext{
${ }^{23}$ detailed results available on request
} 


\subsection{Conclusion}

We find that an important factor relating to low reverse mortgage demand is potential borrowers' insufficient knowledge, or product-specific literacy.

Our results are based on a survey of U.S. homeowners aged 58 and older. Our survey elicits information about our respondents' knowledge about HECM mortgages and the intention to use a reverse mortgage. Almost all of the respondents in our sample (who are, on average, better educated and wealthier than the general U.S. population), claim that they have heard of reverse mortgages. However, on average, knowledge is low among eligible homeowners. Around three quarters of respondents understand that the purpose of a reverse mortgage is to unlock home equity, know the minimum age requirement, and are aware that they need to continue to pay taxes and homeowner insurance as part of the duties of a reverse mortgage consumer. Around half of respondents do know that a reverse mortgage is actually a loan, the loan balance grows over time, no regular interest payments have to be made, and that a reverse mortgage grants a life-long right to remain in the home without repaying any of the loan. Only one third of respondents know that a lender cannot force them to leave the home when the loan balance becomes larger than the home value, are aware of the relationship between interest rates and maximum loan amounts, and have realistic expectations about maximum payout amounts.

Respondents who are financially sophisticated, have personal experience with reverse mortgages, and/or know other people with reverse mortgages have superior product knowledge. However, those respondents that would theoretically benefit most from reverse mortgages (e.g., those having lower income, higher home values, lower savings) do not have better knowledge about the product.

Our results show that reverse mortgage product knowledge is positively related to the intention to use a reverse mortgage. On average, knowledge among respondents is fairly low, implying that potential factors for low product demand are limited knowledge and misconceptions of the product. Peer influence (knowing other people with a reverse mortgage) is a strong predictor of the intention to use a reverse mortgage. Homeowners who theoretically could benefit most are indeed more likely to use a reverse mortgage. But these homeowners lack product knowledge and thus may insufficiently evaluate alternative options to finance retirement consumption. Not 98 
assessing alternative options properly is especially relevant as reverse mortgages are expensive and include substantial fees (see Lucas, 2015 as well as Section 4.2), and thus may turn out to be more costly than alternatives.

Our results support the growing body of evidence that the functioning and growth of reverse mortgage market is hindered by multiple factors. There are no easy or obvious fixes when trying to sell an inherently complex and potentially expensive product to poorer and older households that have limited financial literacy and product knowledge.

We find that providing potential consumers with a brief text explaining key reverse mortgage product features had no impact on the intention to use a reverse mortgage. One way to interpret this finding is that an avenue to make the product more appealing to homeowners is not to educate them better, but to reduce the complexity inherent in the product itself. We also find some evidence that indicates that respondents may be uncertain about whether or not a reverse mortgage would be beneficial to them. This contributes to a lower intention to use reverse mortgages and also indicates that reduced product complexity might increase product consumption. It could also be that the use of a simple explanatory text is not a powerful enough tool when compared with, for example, providing visualizations. Campbell (2016) suggests that bundling reverse mortgages with attractive and easier to understand products (like long-term care insurance) might make the package more appealing. We leave testing these approaches to future research. 



\section{Summary}

Household financial decision making is complex, and the complexity of choice and financial products is ever more increasing (see e.g. Vohs et al., 2008; Remund, 2010). Our technologydriven and internationally connected world provides a plethora of information virtually available for everyone within just a few mouse clicks or a single online search command. This additional information might be valuable and helpful to enrich household decision making. From a traditional economic point of view, each additional piece of information will bring a decisionmaker one step closer towards an optimal decision. In reality, however, all the information cannot be absorbed and processed by a household. Individuals that comprise households have limited cognitive abilities and a certain, limited, attention span (cf. Hauser and Wernerfelt, 1990; Agnew and Szykman, 2005). An ever increasing choice set can result in information overload, suboptimal decision making or even lead to the decision "not to choose" (Shafir and Tversky, 1992; Dhar, 1997). Instead of making a decision, thus committing to a certain outcome, households might shy away from decision making entirely (e.g. Thompson, Hamilton, and Rust, 2005). This effect can be exacerbated with complexity of choice (cf. Scheibehenne, Greifeneder, and Todd, 2010). If the household would make a decision, it needs to face the consequences and might feel regret. Postponing or deferring a decision results in not feeling responsible, since no action was taken. In the context of household savings, no explicit decision on "how" or "how much" to save can still lead to "accidental" or residual savings at the end of the month

In Chapter 2 we observe the outcome of households' accumulated decision making regarding savings and analyze their savings behavior. Since households are diverse, we take a structured approach to identify how psychological characteristics influence savings behavior. Policymakers are mainly focused on financial literacy programs to improve financial decision making. Our findings show that policymakers need to also incorporate psychological characteristics of households in order to design effective financial literacy programs. Additionally, in a related 
vein, policymakers need to acknowledge the inherent latent heterogeneity across households. A "one size fits all" approach is unlikely to be effective, and instead, programs should be tailored based on households' heterogeneity (cf. Eberhardt et al., 2016). Taking such heterogeneity into consideration and actively incorporating it into policy programs will most likely increase the programs' effectiveness. Psychological characteristics have different relationships and impact on savings behavior. A focus on self-control would be a promising avenue towards improved savings behavior, but only for a certain segment of households, not for the entire population. For "the striving", who are a particularly vulnerable segment of the population, with rather low savings and income, a focus on a positive savings attitude is a more promising way, instead of focusing on self-control.

Since latent heterogeneity is not directly observable based on demographic variables, it is important for future research and policymakers alike to adopt a structured way to approach segmentation of data. Our Finite Mixture Partial Least Squares (FIMIX-PLS) approach used in Chapter 2 has the advantage of being free from potential investigator bias. For certain research questions it might not be suitable, as it is not designed to test a priori hypotheses due to its datadriven approach. We aim to advocate taking heterogeneity explicitly into account, and encourage other researchers to analyze in more depth the complexity between psychological characteristics and decision making (outcomes).

The data we utilized on household savings reflects the outcome of multiple decisions over time. Those decisions are (partially) made based on beliefs. As such, each and every household decision, be it consciously or subconsciously, reflects to some extent the decision maker's beliefs. In Chapter 3, we focus on investment decisions and monitor beliefs, as proxied by return expectations and risk perception. Past research has identified both as significant determinants of belief formation, which in itself influences decision making outcomes. We focus on the impact different default information horizons have on the magnitude of individual investor belief updating. The fewer individuals update their beliefs, the less likely they are to issue or execute trades. Since overtrading is a common behavior of individual investors, which is a major source of wealth destruction, we conjecture that less trading activity is beneficial for most households. As such, lower belief updates are also beneficial for investors, and if the choice of a certain default has the potential to impact belief updating, this might be an easily adoptable policy intervention. Using an experimental approach, we show that on average, the default does not have 102 
an impact on the strength of belief updating. However, we show that when the data is partitioned into those experiment participants who decide to stay with the default information horizon presented to them versus those who decide to actively opt out of their default, we find important differences. A longer information horizon reduces belief updating magnitude for individuals who stay in the default condition. However, the opposite result emerges for individuals who opt out of the default. Thus, contrary to some general recommendations that longer information horizons are always beneficial, our findings would support such notion only in case the individual is not presented with the decision to opt out. In such case, the longer information horizon has a mitigating effect and reduces belief updates. While this holds true in case individuals cannot opt out of their default condition, as we just explained, the situation needs to be more carefully examined when it comes to situations where individuals can indeed opt out of the default.

Additional analyses show that financial literacy is positively related to individuals' tendency to opt out of the default. A long default information horizon might thus be seen as effective for individuals with low financial literacy. Our findings raise awareness for the importance of personal characteristics. Such characteristics need to be taken into account, especially when making policy decisions about, for example, what default to present to individual investors. Chapter 3 shows that relying on average effects might not necessarily be beneficial, and an insignificant effect might be due to two contrary and offsetting effects.

Chapter 4 studies reverse mortgage decision making. Reverse mortgages are a specialized product only available to elderly homeowners, and are barely known outside of the U.S. (even though they exist in most European countries, too). Theoretically appealing and welfare enhancing for a certain target group, actual demand is lacking far behind theoretical predictions. We survey elderly U.S. homeowners and assess in detail their knowledge about the most common reverse mortgage product in the U.S. Based on that data, we are able to determine intention to use a reverse mortgage. We relate this to product knowledge and several socioeconomic household characteristics which are conjectured to be influencing factors for reverse mortgage demand. We find that almost all of our sample respondents are aware of the existence of reverse mortgages and have heard of them. However, actual knowledge about the product is limited. Reverse mortgage are highly complex products, and a decision to take on a reverse mortgage is a long-lasting and serious commitment. As such, a lack of product knowledge and misunderstanding of crucial characteristics can be seen as a determinant of low demand for 
reverse mortgages. For example, only one third of our surveyed respondents understand the safety feature a reverse mortgage provides, in that it is a non-recourse loan and the lender cannot force the borrower to move out of his home, even if the accrued loan balance exceeds the home value.

We find that households with higher financial literacy and exposure to reverse mortgages - either through direct experience or by knowing others who have a reverse mortgage - have higher product knowledge. The main target group of reverse mortgages, the so-called "cash poor, home rich", do not exhibit higher knowledge about the product terms. Product knowledge is, however, positively related to the intention to use reverse mortgage products. Chapter 4 has shown that those households who could theoretically benefit most from reverse mortgage usage are actually more likely to use them. Their low product knowledge, however, may hinder them from reaching a well-informed decision and might lead to insufficient evaluation of available options and alternatives. Financial literacy programs are unlikely to work for such complex products like reverse mortgages. To achieve a higher demand, it might be needed to decrease the product's complexity in and by itself.

Overall, the three essays presented in this thesis enhance our understanding of household financial decision making. The findings enrich existing theories of economic decision making and show the importance of further connecting different research disciplines to gain a better understanding of an increasingly important aspect of people's lives, managing their financial affairs. Generalizing to broader contexts, they serve as a foundation on which future research can build. 


\section{Research Impact}

The findings outlined in the previous chapters contribute to current academic knowledge and provide implications for policymakers, too.

In Chapter 2, we analyze UK household survey data with regard to saving decisions and relate those, among others, to psychological factors. Our Finite Mixture Partial Least Squares (FIMIXPLS) models combine segmentation and regression analyses simultaneously. We show that psychological factors are important determinants of households' saving decisions. As such, any policy changes or interventions which are targeted at savings behavior or affect such decision making, even implicitly, by, for example, changing tax exemptions of private pension savings, should incorporate psychological factors to create a more holistic viewpoint and make informed decisions. Otherwise, policy interventions might not have the desired, or even an opposing, effect.

Not only do we show the importance of psychological factors which influence saving decisions, but due to our methodology, we are able to show that considerable heterogeneity exists among households with regard to psychological variables. That is, different factors are found as determinants of behavior for one segment versus another. Additionally, the direction of effects might differ: Whereas one factor might be positively related to savings rate for one segment, this factor might have a negative relationship with savings rate for another segment. Hence, a careful examination of latent heterogeneity in any given dataset becomes important, as otherwise such relationships might not be uncovered, or due to their opposing effects, offset each other and thus would not be identifiable in an aggregate view.

While we apply a structured and methodology-driven approach to identify latent heterogeneity among households, other research tends to segment at the researcher's own discretion. While such a priori segmentation offers the benefit of simplicity, it bears the risk of not achieving a proper 
segmentation. Segments might not be identifiable alongside one or two observable household characteristics, such as age or income. A more data-driven segmentation methodology as we employ takes out the "human factor" and manages to achieve an optimized segmentation. For policymakers, a well-done segmentation allows them to better tailor their actions and programs to the household segments, which will increase the effectiveness of such policy changes or interventions. Our findings are based on household savings data, but the findings and implications regarding heterogeneity can be used broader and could be generalized to different contexts, as well.

Another example why aggregate data might not be conclusive for researchers or policymakers is given in Chapter 3. We show that differences in belief updating can arise due to framing effects. Employing lab and online experiments, we examine the effect default frames for presenting past return information have on belief updating. Over the course of the experiment, subjects get to randomly see either daily, monthly or yearly returns as the default. The other two information horizons are available with a single mouse click and subjects could opt out easily and at no costs.

Lower belief updates are considered beneficial for the subject, as it leads to less trading activity, which for the average individual investor corresponds to higher returns. On average, across all subjects, we do not find a significant effect of the default presentation formatting, and differences between the groups are almost non-existent. When we split the groups, however, into subjects who decided to stay in their default presentation format, and those who "opt out" and click to view return information on horizons other than their default, we find opposing effects: While subjects who stay in their randomly assigned default horizon display a reduction in belief updates for longer default information horizons, subjects who opt out of the default exhibit reduced belief updating when viewing shorter information horizons by default.

Providing subjects the opportunity to opt out of the default thus creates opposing recommendations for policymakers when deciding on what default to use to display information. While longer aggregation periods are preferred for households who tend to stick with the default, shorter periods are more beneficial for those households who are more likely to request additional information. This is important information which can strongly influence a policy intervention's effectiveness designed to reduce (excess) trading activity by means of implementing or changing the default presentation format. Additionally, our experiments serve as another example of how 
aggregate information is not necessarily informative. While a mere focus on aggregate data might lead to the conclusion that default formatting has no effect, it would be harmful and misleading to disregard the influence a default has on - in our case - belief updating. We prove the impact and consequences a default can have on decision makers, as it influences beliefs, which in turn impacts the ultimate actions of the decision maker.

Chapter 4 uses a survey to enhance understanding of reverse mortgage decision making. In particular, it focuses on determining influencing factors that impact elderly U.S. households when deciding in favor of, or against, a reverse mortgage contract. In our research, we develop a comprehensive measure of reverse mortgage knowledge. Applying this measure, we show that knowledge of reverse mortgage contract terms is limited across the target group.

Important features of reverse mortgages are misunderstood by a large fraction of the households surveyed. For example, the protective non-recourse feature inherent in reverse mortgage products is not understood by two-thirds of our survey participants. Reverse mortgages are designed in a way that homeowners are protected against the loan balance exceeding home value over time. In case of the HECM, the most widespread reverse mortgage product in the U.S., this longevity risk is covered by a governmentally-backed insurance fund, so that even the reverse mortgage lender does not bear that risk. This feature, designed to protect the homeowners, might be misunderstood and not perceived as providing additional safety.

Taking into account that one's home is the single-most valuable asset for the average household, and additionally regarding elderly homeowners' attachment to their home, it can be understood why such misperception of this key feature lets reverse mortgages appear in a less favorable light than they would otherwise be. This is only one example, and Chapter 4 provides a detailed overview of product terms and features which are not sufficiently well comprehended by households eligible for the product.

The main target group for reverse mortgages, the "house-rich, cash-poor" households, expresses greater intent to use a reverse mortgage. This target group does not display higher product knowledge. Product knowledge is, however, positively related to the intention to use a reverse mortgage. Thus, demand could theoretically be increased via better understanding of the products in general. Taking into account the high level of complexity inherent in reverse mortgage products, standard literacy programs might have little effect. Policy makers might be more 
successful in increasing demand for the products if they focus on a redesign of contract terms and reduce the product's inherent complexity. This way, households and individuals with lower literacy levels could better understand the product and reverse mortgages might be more widely accepted by the main target group, thereby increasing households' welfare and allowing for a better refined decision making.

Why do households spend so little time on key financial decisions? How can they actually make sound decisions if they do not invest the time to do so? How can their decision making be improved or how can they be nudged to take more time for important financial decisions?

There is no single answer to those questions, but the essays presented in the previous chapters have shown that many factors should be taken into account when attempting to improve household decision making, such as controlling for heterogeneity, psychological factors, financial literacy, and even taking into account the context of a certain situation.

Government policy retrenchment in household finance issues can lead to a focus on simplified and more average-driven interventions. Common policy programs focus on financial literacy to improve household decision making. While some programs, for example in high schools, have positive effects, others have been questioned for their effectiveness (cf. Mitchell and Lusardi, 2015; Lusardi, Michaud, Mitchell, 2017). Even though an increase in financial literacy has its merits, one problem is that basic literacy might not help for decision making in complex situations. An example for this has been pointed out in Chapter 4, in the form of reverse mortgages. Policy interventions should take the complexity and context of a certain situation more into account and employ a better tailored approach towards households, which takes latent heterogeneity in account, as well.

Taking all together, the research presented in this thesis has some specific implications for a variety of topics in the area of household finance. The findings can also be generalized to other contexts and thus, have broader implications, which go beyond the focus of this thesis. 


\section{References}

Aber, J. L., Jones, S., and Cohen, J. (2000). The Impact of Poverty on the Mental Health and Development of Very Young Children. In: C. H. Zeanah Jr. (Ed.), Handbook of Infant Mental Health (2nd ed., pp. 113-128). New York, NY: Guilford Press.

Agnew, J. R., and Szykman, L. R. (2005). Asset allocation and information overload: The influence of information display, asset choice, and investor experience. Journal of Behavioral Finance, 6(2): 57-70.

Alessie, R., and Lusardi, A. (1997). Saving and Income Smoothing: Evidence from Panel Data. European Economic Review, 41(7): 1251-1279.

Ando, A., and Modigliani, F. (1963). The "life cycle" hypothesis of saving: Aggregate implications and tests. American Economic Review, 53(1): 55-84.

Antonides, G., de Groot, I. M., van Raaij, W. F. (2011). Mental Budgeting and the Management of Household Finance. Journal of Economic Psychology, 32(4): 546-555.

Artle, R., and Varaiya, P. (1978). Life Cycle Consumption and Homeownership. Journal of Economic Theory, 18: 38-58.

Arya, S., Eckel, C., and Wichman, C. (2013). Anatomy of the Credit Score. Journal of Economic Behavior and Organization, 95(November): 175-185.

Ashraf, N., Karlan, D., and Yin, W. (2006). Tying Odysseus to the Mast: Evidence From a Commitment Savings Product in the Philippines. Quarterly Journal of Economics, 121(2): 635-672. 
Aspara, J., Chakravarti, A. and Hoffmann, A. O. I. (2015). Focal versus Background Goals in Consumer Financial Decision-Making: Trading Off Financial Returns for Self-Expression? European Journal of Marketing, 49(7/8): 1114-1138.

Aspara, J., and Tikkanen, H. (2010). Consumers' Stock Preferences Beyond Expected Financial Returns. International Journal of Bank Marketing, 28(3): 193-221.

Aspara, J., and Tikkanen, H. (2011). Individuals' Affect-Based Motivations to Invest in Stocks: Beyond Expected Financial Returns and Risks. Journal of Behavioral Finance, 12(2): 78-89.

Barber, B. M. and T. Odean (2000). Trading is Hazardous to Your Wealth: the Common Stock Investment Performance of Individual Investors. Journal of Finance, 55(2): 773-806.

Barrick, M. R., Stewart, G. L., and Piotrowski, M. (2002). Personality and Job Performance: Test of the Mediating Effects of Motivation among Sales Representatives. Journal of Applied Psychology, 87(1): 43-51.

Bazley, W. J., Cronqvist, H., and Mormann, M. (2016). In the Red: How Color Affects Investors and Financial Markets. Working Paper (Yale University).

Bearden, W. O., Netemeyer, R. G., and Haws, K. L. (2011). Handbook of Marketing Scales: Multi-Item Measures for Marketing and Consumer Behavior Research. $3^{\text {rd }}$ ed., SAGE Publications.

Benartzi, S., and Thaler, R. H. (1995). Myopic Loss Aversion and the Equity Premium Puzzle. Quarterly Journal of Economics, 110(1): 73-92.

Bernerth, J. B., Taylor, S. G., Walker, H. J., and Whitman, D. S. (2012). An Empirical Investigation of Dispositional Antecedents and Performance-Related Outcomes of Credit Scores. Journal of Applied Psychology, 97(2): 469-478.

Bernheim, B. D., Ray, D., and Yeltekin, S. (2015). Poverty and Self-Control. Econometrica, 83(5): 1877-1911.

Bertrand, M., Mullainathan, S., and Shafir, E. (2006). Behavioral Economics and Marketing in Aid of Decision Making Among the Poor. Journal of Public Policy and Marketing, 25(1): 823. 
Beshears, J., Choi, J. J., Laibson, D., and Madrian, B. C. (2017). Does Aggregated Returns

Disclosure Increase Portfolio Risk-Taking? Review of Financial Studies, 30(6): 1971-2005.

Brice, J., Buck, N., and Prentice-Lane, E. (2002). British Household Panel Survey User Manual Volume A: Introduction, Technical Report, and Appendices. Colchester: University of Essex.

Brockner, J., and Higgins, E. T. (2001). Regulatory Focus Theory: Implications for the Study of Emotions at Work. Organizational Behavior and Human Decision Processes, 86(1): 35-66.

Brown, J., Farrell, A., and Weisbenner, S. (2016), Decision-Making Approaches and the Propensity to Default: Evidence and Implications. Journal of Financial Economics, 121(3): 477-495.

Brown, J. R., Ivcović, Z., Smith, P. A., and Weisbenner, S. (2008). Neighbors Matter: Causal Community Effects and Stock Market Participation. The Journal of Finance, 63: 1509-1531.

Brown, J. R., Kapteyn A., Luttmer, E. F. P., and Mitchell, O. (2012). Do Consumers Know How to Value Annuities? Complexity as a Barrier to Annuitization. Working Paper, Santa Monica, CA: RAND Corporation.

Brown, S., and Taylor, K. (2014). Household Finances and the 'Big Five' Personality Traits. Journal of Economic Psychology, 45: 197-212.

Bruhin, A., Fehr-Duda, H., and Epper, T. (2010). Risk and Rationality: Uncovering Heterogeneity in Probability Distortion. Econometrica, 78: 1375-1412.

Buhrmester, M., Kwang, T., and Gosling, S. D. (2011). Amazon's Mechanical Turk: A New Source of Inexpensive, Yet High-Quality, Data? Perspectives on Psychological Science, 6(1): 3-5.

Campbell, J. Y. (2016). Restoring Rational Choice: The Challenge of Consumer Financial Regulation. NBER Working Paper No. 22025.

Canova, L., Manganelli Rattazzi, A. M., and Webley, P. (2005). The Hierarchical Structure of Saving Motives. Journal of Economic Psychology, 26(1): 21-34. 
Carswell, A.T., Seay, M.C., and Polanowski, M. (2013). Reverse mortgage fraud against seniors: Recognition and education of a burgeoning problem. Journal of Housing for the Elderly, 27: 146-160.

Carver, C. S., and Scheier, M. F. (1999). Optimism. In: C. R. Snyder (Ed.), Coping. The Psychology of What Works (pp. 182-204). New York: Oxford University Press.

Case, B., and Schnare, A. B. (1994). Preliminary Evaluation of the HECM Reverse Mortgage Program. Journal of the American Real Estate and Urban Economics Association, 22(2): 301346.

Casler, K., Bickel, L., and Hackett, E. (2013). Separate but equal? A comparison of participants and data gathered via Amazon's MTurk, social media, and face-to-face behavioral testing. Computers in Human Behavior, 29(6): 2156-2160.

CFPB (2012). Report to Congress on Reverse Mortgages. Consumer Financial Protection Bureau, June 2012, Iowa, U.S.

CFPB (2015). A closer look at reverse mortgage advertisements and consumer risks. Consumer Financial Protection Bureau, June 2015, Washington, D.C., U.S.

Chalmers, J., Johnson, W. T., and Reuter, J. (2014). The effect of pension design on employer costs and employee retirement choices: Evidence from Oregon. Journal of Public Economics, 116: 17-34.

Charness, G. and Gneezy, U. (2010). Portfolio Choice and Risk Attitudes: An Experiment. Economic Inquiry, 48(1): 133-146.

Chin, W. W. (2000). Frequently Asked Questions - Partial Least Squares \& PLS-Graph. Online available at http://disc-nt.cba.uh.edu/chin/plsfaq.htm , last accessed 20/02/2017.

Chin, W. W., and Dibbern, J. (2010). A Permutation Based Procedure for Multi-Group PLS Analysis: Results of Tests of Differences on Simulated Data and a Cross Cultural Analysis of the Sourcing of Information System Services between Germany and the USA. In Vinzi, V. E., Chin, W. W., Henseler, J. and Wang, H. (eds.) Handbook of Partial Least Squares, pp. 171193. Berlin, Heidelberg: Springer Germany. 
Cho, S. H., Loibl, C., and Geistfeld, L. (2014). Motivation for Emergency and Retirement Saving: An Examination of Regulatory Focus Theory. International Journal of Consumer Studies, 38(6): 701-711.

Cobb-Clark, D. A., and Schurer, S. (2012). The Stability of Big-Five Personality Traits. Economics Letters, 115(1): 11-15.

Cobb-Clark, D.A., Kassenboehmer, S.C. and M. Sinning (2016). Locus of Control and Savings. Journal of Banking and Finance, 73(December): 113-130.

Cocco, J., and Lopes, P. (2014). Reverse Mortgage Design. Working Paper, London Business School.

Costa-Font, J., Gil, J., and Mascarilla, O. (2010). Housing Wealth and Housing Decisions in Old Age: Sale and Reversion. Housing Studies, 25: 375-395.

Cronbach, L. J. (1951). Coefficient Alpha and the Internal Structure of Tests. Psychometrika, 16(3): 297-334.

Davidoff, T. (2009). Housing, Health, and Annuities. Journal of Risk and Insurance, 76: 31-52.

Davidoff, T. (2010a). Financing Retirement with Stochastic Mortality and Endogenous Sale of a Home. Working Paper, University of British Columbia.

Davidoff, T. (2010b). Home equity commitment and long-term care insurance demand. Journal of Public Economics, 94: 44-49.

Davidoff, T. (2010c). Interest Accumulation in Retirement Home Equity Products. Working Paper, University of British Columbia.

Davidoff, T. (2015). Can "High Costs" Justify Weak Demand for the Home Equity Conversion Mortgage? Review of Financial Studies, 28: 2364-2398.

Davidoff, T., Gerhard, P., and Post, T. (2017). Reverse Mortages: What Homeowners (Don't) Know and How it Matters. Journal of Economic Behavior and Organization, 133: 151-171.

Davidoff, T. and Wetzel, J. (2014). Do Reverse Mortgage Borrowers Use Credit Ruthlessly? Working Paper, University of British Columbia. 
Davies, E., and Lea, S. E. (1995). Student Attitudes to Student Debt. Journal of Economic Psychology, 16(4): 663-679.

DeVaney, S. A., Anong, S. T., and Yang, Y. (2007). Asset Ownership by Black and White Families. Journal of Financial Counseling and Planning, 18(1): 33-45.

Dhar, R. (1997). Consumer preference for a no-choice option. Journal of Consumer Research, 24(2): 215-231.

Dholakia, U., Tam, L., Yoon, S., and Wong, N. (2016). The Ant and the Grasshopper: Understanding Personal Saving Orientation of Consumers. Journal of Consumer Research, 43(1): 134-155.

Dillingh, R., Prast, H., Rossi, M., and Urzi Brancati, C. (2013). The psychology and economics of reverse mortgage attitudes: evidence from the Netherlands. Working Paper.

Dohmen, T., Falk, A., Huffman, D., Sunde, U., Schupp, J., and Wagner, G. G. (2011). Individual Risk Attitudes: Measurement, Determinants, and Behavioral Consequences. Journal of the European Economic Association, 9(3): 522-550.

Dominitz, J. and Manski, C. F. (2011). Measuring and Interpreting Expectations of Equity Returns. Journal of Applied Econometrics, 26(3): 352-370.

Donnellan, M. B., and Lucas, R. E. (2008). Age Differences in the Big Five across the Life Span: Evidence from Two National Samples. Psychology and Aging 23(3): 558-566.

Donnelly, G., Iyer, R., and Howell, R. T. (2012). The Big Five Personality Traits, Material Values, and Financial Well-Being of Self-Described Money Managers. Journal of Economic Psychology, 33(6): 1129-1142.

Duca, J. V. and Kumar, A. (2014). Financial literacy and mortgage equity withdrawals. Journal of Urban Economics, 80: 62-75.

Duflo, E., and Saez, E. (2002). Participation and investment decisions in a retirement plan: the influence of colleagues' choices. Journal of Public Economics, 85: 121-148. 
Duflo, E., and Saez, E. (2003). The Role of Information and Social Interactions in Retirement Plan Decisions: Evidence from a Randomized Experiment. Quarterly Journal of Economics, 118: 815-842.

Eberhardt, W., Brüggen, E., Post, T., and Hoet, C. (2016). Segmentation of pension plan participation: Identifying dimensions of heterogeneity. Design Paper 47, Netspar Industry Paper Series.

Eeckhoudt, L., and Godfroid, P. (2000). Risk Aversion and the Value of Information. Journal of Economic Education, 31: 382-388.

Epley, N., and Gilovich, T. (2006). The Anchoring-and-Underadjustment Heuristic. Psychological Science, 17(4): 311-318.

Fazio, R. H. (1986). How do attitudes guide behavior? In Sorrentino, R. M. and Higgins, E. T. (Eds). Handbook of Motivation and Cognition: Foundations of Social Behavior, pp. 204-243, New York: Guilford Press.

Federal Reserve Board (2016). Report on the Economic Well-Being of U.S. Households in 2015. Online available at: https://www.federalreserve.gov/2015-report-economic-well-being-ushouseholds-201605.pdf, last accessed 19/03/2017.

Fellner, G., and Sutter, M. (2009). Causes, Consequences, and Cures of Myopic Loss Aversion An Experimental Investigation. The Economic Journal, 119(537): 900-916.

Fernandes, D., Lynch Jr, J. G., and Netemeyer, R. G. (2014). Financial Literacy, Financial Education, and Downstream Financial Behaviors. Management Science, 60(8): 1861-1883.

Financial Conduct Authority (2014). Consumer Credit and Consumers in Vulnerable Circumstances. Online available at: https://www.fca.org.uk/publications/research/consumercredit-and-consumers-vulnerable-circumstances, last accessed 27/01/2017.

Findley, T. S., and Caliendo, F. N. (2015). Time Inconsistency and Retirement Choice. Economics Letters, 129: 4-8. 
Fischhoff, B., Slovic, P., Lichtenstein, S., Read, S., Combs, B. (1978). How Safe is Safe Enough? A Psychometric Study of Attitudes Towards Technological Risks and Benefits. Policy Sciences, 9: 127-152.

Forkmann, S., Henneberg, S. C., Naudé, P., and Mitrega, M. (2016). Supplier Relationship Management Capability: A Qualification and Extension. Industrial Marketing Management, 57(August): 185-200.

Fornero, E., Rossi, M., and Urzi Brancati, M. C. (2016). Explaining why, right or wrong, (Italian) Households do not like reverse mortgages. Journal of Pension Economics and Finance, 15: 180-202.

Ganzach, Y. (2000). Judging Risk and Return of Financial Assets. Organizational Behavior and Human Decision Processes, 83(2): 353-370.

Geers, A. L., Wellman, J. A., Seligman, L. D., Wuyek, L. A., and Neff, L. A. (2010). Dispositional Optimism, Goals, and Engagement in Health Treatment Programs. Journal of Behavioral Medicine, 33: 123-134.

Gerhard, P., Gladstone, J. J., and Hoffmann, A. O. I. (2018). Psychological characteristics and household savings behavior: The importance of accounting for latent heterogeneity. Journal of Economic Behavior and Organization, 148: 66-82.

Gerhard, P., Hoffmann, A. O. I., and Post, T. (2017). Past Performance Framing and Investors' Belief Updating: Is Seeing Long-Term Returns Always Associated with Smaller Belief Updates? Journal of Behavioral and Experimental Finance, 15: 38-51.

Gneezy, U., and Potters, J. (1997). An Experiment on Risk Taking and Evaluation Periods. Quarterly Journal of Economics, 112(2): 631-645.

Greenwood, R., and Shleifer, A. (2014). Expectations of Returns and Expected Returns. Review of Financial Studies, 27(3): 714-746.

Gugerty, M. K. (2007). You Can't Save Alone: Commitment in Rotating Savings and Credit Associations in Kenya. Economic Development and Cultural Change, 55(2): 251-282. 
Guiso, L., Sapienza, P. and Zingales, L. (2013). The Determinants of Attitudes toward Strategic Default on Mortgages. Journal of Finance, 68: 1473-1515.

Hair, J. F., Black, W. C., Babin, B. J., and Anderson, R. E. (2009). Multivariate Data Analysis ( $7^{\text {th }}$ edition). New York: Pearson Higher Education.

Hamermesh, D. S. (1985). Expectations, life expectancy, and economic behavior. Quarterly Journal of Economics, 100: 389-408.

Hanewald, K., Post, T., and Sherris, M. (2016). Portfolio Choice in Retirement - What is the Optimal Home Equity Release Product? Journal of Risk and Insurance, 83: 421-446.

Hauser, J. R., and Wernerfelt, B. (1990). An evaluation cost model of consideration sets. Journal of Consumer Research, 16(4): 393-408.

Haushofer, J., and Fehr, E. (2014). On the Psychology of Poverty. Science, 344 (6186): 862-67.

Hoffmann, A. O. I. and T. L. J. Broekhuizen (2009). Susceptibility to and Impact of Interpersonal Influence in an Investment Context. Journal of the Academy of Marketing Science, 37(4): 488503.

Hoffmann, A. O. I., and Post, T. (2016). How Does Investor Confidence Lead to Trading? Linking Investor Return Experiences, Confidence, and Investment Beliefs. Journal of Behavioral and Experimental Finance, 12(December): 65-78.

Hoffmann, A. O. I., Post, T., and Pennings, J. M. E. (2013). Individual Investor Perceptions and Behavior during the Financial Crisis. Journal of Banking and Finance, 37(1): 60-74.

Hogg, M., and Vaughan, G. (2005). Social Psychology (4th edition). London: Prentice-Hall.

Hong, H., J. D. Kubik, and Stein, J. C. (2004). Social Interaction and Stock-Market Participation, Journal of Finance, 59(1): 137-163.

Hong, C. H. T. and and Lee, G. H. (2012). Understanding Ginnie Mae Reverse Mortgage HREMICs: Its Programs and Cashflow Analysis, Encyclopedia of Finance, 691-704.

Horioka, C. Y., and Watanabe, W. (1997). Why Do People Save? A Micro-Analysis of Motives for Household Saving in Japan. Economic Journal, 107(442): 537-552. 
HUD (2014). Mortgagee Letter 2014-22. U.S. Department of Housing and Urban Development, November 2014, Washington, DC, U.S.

Hurd, M. D., Rohwedder, S., and Winter, J. (2009). Subjective Probabilities of Survival: An International Comparison. Unpublished manuscript.

Johnson, D. and Grayson, K. (2005). Cognitive and affective trust in service relationships. Journal of Business Research, 58: 500-507.

Judge, T. A., Livingston, B. A., and Hurst, C. (2012). Do Nice Guys - and Gals - Really Finish Last? The Joint Effects of Sex and Agreeableness on Income. Journal of Personality and Social Psychology, 102(2): 390-407.

Kast, F., Meier, S., and Pomeranz, D. (2012). Under-Savers Anonymous: Evidence on Self-Help Groups and Peer Pressure as a Savings Commitment Device. NBER Working Paper No. 18417, Online available at http://www.nber.org/papers/w18417, last accessed 21/02/2017.

Klapper, L., Lusardi, A., and van Oudheusden, P. (2014). Financial Literacy Around the World. Insights From The Standard \& Poor's Ratings Services Global Financial Literacy Survey. Online available at https://responsiblefinanceforum.org/wp-content/uploads/2015/12/2015Finlit_paper_17_F3_SINGLES.pdf, last accessed 22/02/2017.

Kotov, R., Gamez, W., Schmidt, F., and Watson, D. (2010). Linking "Big” Personality Traits to Anxiety, Depressive, and Substance Use Disorders: A Meta-Analysis. Psychological Bulletin, 136(5): 768-821.

Kühberger, A. (1998). The Influence of Framing on Risky Decisions: A Meta-analysis. Organizational Behavior and Human Decision Processes, 75(1): 23-55.

Lai, P. H., Lyons, K. D., Gudergan, S. P., and Grimstad, S. (2017). Understanding the Psychological Impact of Unconventional Gas Developments in Affected Communities. Energy Policy, 101(February): 492-501.

Laibson, D. (1997). Golden Eggs and Hyperbolic Discounting. Quarterly Journal of Economics, 112(2): 443-477. 
Lee, A. Y., Aaker, J. L., and Gardner, W. L. (2000). The Pleasures and Pains of Distinct SelfConstruals: The Role of Interdependence in Regulatory Focus. Journal of Personality and Social Psychology, 78(6): 1122-1134.

Lee, S., Hanna, S., and Siregar, M. (1997). Children's College as a Saving Goal. Journal of Financial Counseling and Planning, 8(1): 33-36.

Leviton, R. (2002). Reverse Mortgage Decision-Making. Journal of Aging and Social Policy, 13: $1-16$.

Li, Y., Baldassi, M., Johnson, E. J. and Weber, E. U. (2013). Complementary cognitive abilities: Economic decision making and aging. Psychology and Aging, 28: 595-613.

Li, Y., Gao, J., Enkavi, A. Z., Zaval, L., Weber, E. U. and Johnson, E. J. (2015). Sound credit scores and financial decisions despite cognitive aging. Proceedings of the National Academy of Sciences, 112: 65-69.

Linardi, S., and Tanaka, T. (2013). Competition as a Savings Incentive: A Field Experiment at a Homeless Shelter. Journal of Economic Behavior and Organization, 95(November): 240-251.

Livingstone, S. M., and Lunt, P. K. (1992). Predicting Personal Debt and Debt Repayment: Psychological, Social and Economic Determinants. Journal of Economic Psychology, 13(1): 111-134.

Loibl, C., Kraybill, D. S., and DeMay, S. W. (2011). Accounting for the Role of Habit in Regular Saving. Journal of Economic Psychology, 32(4): 581-592.

Loibl, C., Summers, B., McNair, S., Bruine de Bruin, W. (2016). Pension Freedom Day in the United Kingdom: Liberation or Irresponsibility? Working Paper (The Ohio State University).

Looney, C. A., and Hardin, A. M. (2009). Decision Support for Retirement Portfolio Management: Overcoming Myopic Loss Aversion via Technology Design. Management Science, 55(10): 1688-1703.

Lucas, D. (2015). Hacking Reverse Mortgages. Working Paper. 
Lunt, P. K., and Livingstone, S. M. (1991). Psychological, Social and Economic Determinants of Saving: Comparing Recurrent and Total Savings. Journal of Economic Psychology, 12(4): 621-641.

Lusardi, A., Michaud, P. and Mitchell, O. S. (2017). Optimal Financial Knowledge and Wealth Inequality. Journal of Political Economy, 125(2): 431-477.

Lusardi, A. and Mitchell, O. S. (2007a). Baby Boomer Retirement Security: The Roles of Planning, Financial Literacy, and Housing Wealth. Journal of Monetary Economics, 54(1): 205-224.

Lusardi, A. and Mitchell, O. S. (2007b). Financial Literacy and Retirement Preparedness: Evidence and Implications for Financial Education. Business Economics, 42(1): 35-44.

Lusardi, A. and Mitchell, O. S. (2011a). Financial Literacy Around the World: An Overview. Journal of Pension Economics and Finance, 10(4): 497-508.

Lusardi, A., and Mitchell, O. S. (2011b). Financial literacy and planning: Implications for retirement wellbeing. NBER Working Paper No. 17078.

Lusardi, A. and Tufano, P. (2009). Debt Literacy, Financial Experiences, and Overindebtedness. NBER Working Paper No. 14808.

Lynch, J. G., Netemeyer, R. G., Spiller, S. A., and Zammit, A. (2010). A Generalizable Scale of Propensity to Plan: The Long and the Short of Planning for Time and for Money. Journal of Consumer Research, 37(1): 108-128.

Lynch, J. G., and Wood, W. (2006). Special issue editors' statement: Helping consumers help themselves. Journal of Public Policy and Marketing, 25(1): 1-7.

Lucas, R. E., and Donnellan, M. B. (2011). Personality Development across The Life Span: Longitudinal Analyses With A National Sample From Germany. Journal of Personality and Social Psychology, 101(4): 847-861.

Lusardi, A. (2008). Household saving behavior: The role of financial literacy, information, and financial education programs. NBER Working Paper No. 13824, Online available at http://www.nber.org/papers/w13824, last accessed 22/02/2017. 
Lusardi, A. (2009). Overcoming the Saving Slump: How to Increase the Effectiveness of Financial Education and Savings Programs. Chicago, IL: The University of Chicago Press.

Lusardi, A., Michaud, P. C., and Mitchell, O. S. (2018). Assessing the Impact of Financial Education Programs: A Quantitative Model. Working Paper, Online available at https://repository.upenn.edu/prc_papers/19/, last accessed 14/04/2019.

Lusardi, A., and Mitchell, O. (2007). Financial Literacy and Retirement Preparedness: Evidence and Implications for Financial Education. Business Economics, 42(1): 35-44.

Mani, A., Mullainathan, S. Shafir, E. and Zhao, J. (2013). Poverty Impedes Cognitive Function. Science, 341(6149): 976-980.

Matthews, L. M., Sarstedt, M., Hair, J. F., and Ringle, C. M. (2016). Identifying and Treating Unobserved Heterogeneity with FIMIX-PLS. European Business Review, 28(2): 208-224.

Mayer, C. J., and Simons, K. V. (1994a). A New Look at Reverse Mortgages: Potential Market and Institutional Constraints. New England Economic Review, Mar/Apr 94: 15-26.

Mayer, C. J., and Simons, K. V. (1994b). Reverse Mortgages and the Liquidity of Housing Wealth. Journal of the American Real Estate and Urban Economics Association, 22: 235-255.

McCrae, R. R., and John, O. P. (1992). An Introduction to the Five-Factor Model and Its Applications. Journal of Personality, 60(2): 175-215.

Meier, S., and Sprenger, C. D. (2013). Discounting financial literacy: Time preferences and participation in financial education programs. Journal of Economic Behavior and Organization, 95: 159-174.

MetLife report (2012). Changing Attitudes, Changing Motives: The MetLife Study of How Aging Homeowners Use Reverse Mortgages.

Mitchell, O. S. and Lusardi, A. (2015). Financial literacy and economic outcomes: Evidence and policy implications. Journal of retirement, 3(1): 107-114. 
Mitchell, V. W. and McGoldrick. P. J. (1996). Consumers' Risk-Reduction Strategies: A Review and Synthesis, International Review of Retail, Distribution and Consumer Research, 6(1): 133.

Mosca, I., and McCrory, C. (2016). Personality and Wealth Accumulation among Older Couples: Do Dispositional Characteristics Pay Dividends? Journal of Economic Psychology, 56(October): 1-19.

Moulton, S., Haurin, D., Shi, W., and Eriksen, M. (2014). Who Gets a Reverse Mortgage? Identifying Household Level Determinants of Reverse Mortgage Choice and the Influence of Counseling. Working Paper, Ohio State University.

Moulton, S., Haurin, D., and Shi, W. (2015). An Analysis of Default Risk in the Home Equity Conversion Mortgage (HECM) Program. Journal of Urban Economics, 90: 17-34.

Mühlbauer, K. (2013). Die 111 wichtigsten Fragen der Vermögensanlage: Klare Antworten zu Geld, Börse und Altersvorsorge. 1. ed. Munich: Finanzbuchverlag.

Mullainathan, S., and Shafir, E. (2013). Scarcity: Why Having Too Little Means so Much. New York: Henry Holt and Company.

Munnell, A. H., and Sass, S. (2014). The Government's Redesigned Reverse Mortgage Program. Center for Retirement Research at Boston College, Issues in Brief 12-20.

Munnell, A. H., Webb, A., and Golub-Sass, F. (2012). The National Retirement Risk Index: An Update. Center for Retirement Research at Boston College, Issues in Brief 14-1.

Nakajima, M., and Telyukova, I. A. (2017). Reverse Mortgage Loans: A Quantitative Analysis. Journal of Finance, 72(2): 911-950.

Nyhus, E. K., and Webley, P. (2001). The Role of Personality in Household Saving and Borrowing Behaviour. European Journal of Personality, 15(S1): 85-103.

Oakland, T., and Lane, H. B. (2004). Language, Reading, and Readability Formulas: Implications for Developing and Adapting Tests. International Journal of Testing, 4: 239-252. 
Oechssler, J., Roider, A., and Schmitz, P. W. (2009). Cognitive Abilities and Behavioral Biases. Journal of Economic Behavior and Organization, 72(1): 147-152.

Ong, R. (2009). House Price Appreciation Among Elderly Home Owners in Australia. Centre for Research in Applied Economics, Curtin University of Technology, Australia.

Oppenheimer, D. M., Meyvis, T., and Davidenko, N. (2009). Instructional manipulation checks: Detecting satisficing to increase statistical power. Journal of Experimental Social Psychology, 45(4): 867-872.

Otto, A. (2013). Saving in Childhood and Adolescence: Insights from Developmental Psychology. Economics of Education Review, 33: 8-18.

Paolacci, G., Chandler, J., and Ipeirotis, P. G. (2010). Running experiments on Amazon Mechanical Turk. Judgment and Decision Making, 5(5): 411-419.

Park, C. W. and Lessig, V. P. (1977). Students And Housewives: Differences in Susceptibility to Reference Group Influence. Journal of Consumer Research, 4: 102-110.

Petkoska, J., and Earl, J. K. (2009). Understanding the Influence of Demographic and Psychological Variables on Retirement Planning. Psychology and Aging, 24(1): 245-251.

Puri, M., and Robinson, D. T. (2007). Optimism and Economic Choice. Journal of Financial Economics, 86(1): 71-99.

Rasmussen, D. W., Megbolugbe, I. F., and Morgan, B. A. (1995). Using the 1990 Public Use Microdata Sample to Estimate Potential Demand for Reverse Mortgage Products. Journal of Housing Research, 6: 1-23.

Raver, C. C. (2004). Placing Emotional Self-Regulation in Sociocultural and Socioeconomic Contexts. Child Development, 75: 346-353.

Reed, R. (2009). The Increasing Use of Reverse Mortgages by Older Households. Working Paper, Deakin University.

Remund, D. L. (2010). Financial literacy explicated: The case for a clearer definition in an increasingly complex economy. Journal of Consumer Affairs, 44(2): 276-295. 
Ringle, C. M., Sarstedt, M., and Mooi, E. A. (2010). Response-Based Segmentation using Finite Mixture Partial Least Squares: Theoretical Foundations and an Application to American Customer Satisfaction Index Data. In Stahlbock, R. et al. (eds.) Data Mining, pp. 19-49. New York, Dordrecht: Springer US.

Roberts, B. W., and Robins, R. W. (2000). Broad Dispositions, Broad Aspirations: The Intersection of Personality Traits and Major Life Goals. Personality and Social Psychology Bulletin, 26(10): 1284-1296.

Sarstedt, M., and Ringle, C. M. (2010). Treating Unobserved Heterogeneity in PLS path Modeling: A Comparison of FIMIX-PLS with Different Data Analysis Strategies. Journal of Applied Statistics, 37(8): 1299-1318.

Sarstedt, M., Becker, J.-M., Ringle, C. M., and Schwaiger, M. (2011). Uncovering and Treating Unobserved Heterogeneity with FIMIX-PLS: Which Model Selection Criterion Provides an Appropriate Number of Segments? Schmalenbach Business Review, 63(January): 34-62.

Scheibehenne, B., Greifeneder, R., and Todd, P. M. (2010). Can there ever be too many options? A meta-analytic review of choice overload. Journal of Consumer Research, 37(3): 409-425.

Scheier, M. F., Carver, C. S., and Bridges, M. W. (1994). Distinguishing Optimism From Neuroticism (and Trait Anxiety, Self-Mastery, and Self-Esteem): A Reevaluation of the Life Orientation Test. Journal of Personality and Social Psychology, 67(6): 1063-1078.

Schulz, R., Bookwala, J., Knapp, J. E., Scheier, M., Williamson, G. M. (1996). Pessimism, Age, and Cancer Mortality. Psychology and Aging, 11: 304-309.

Shafir, E., and Tversky, A. (1992). Thinking through uncertainty: Nonconsequential reasoning and choice. Cognitive Psychology, 24(4): 449-474.

Shan, H. (2011). Reversing the Trend: The Recent Expansion of the Reverse Mortgage Market. Real Estate Economics, 39: 743-768.

Shaton, M. (2015). The Display of Information and Household Investment Behavior. Working Paper (University of Chicago). 
Shefrin, H. (2001). Editorial Comment: Do Investors Expect Higher Returns From Safer Stocks Than From Riskier Stocks? Journal of Behavioral Finance, 2(4): 176-181.

Sherris, M., and Sun, D. (2010). Risk Based Capital and Pricing for Reverse Mortgages Revisited. Research Paper No. 2010ACTL04, UNSW Australian School of Business, Sydney, NSW.

Stango, V. and Zinman, J. (2009). Exponential Growth Bias and Household Finance. Journal of Finance, 64(6): 2807-2849.

Stark, D. P., Choplin, J. M., Mikels, J. A., and McDonnell, A. S. (2014). Complex Decision Making and Cognitive Aging Call for Enhanced Protection of Seniors Contemplating Reverse Mortgages. Arizona State Law Journal, 46: 299-364.

StataCorp. (2015). Stata Item Response Theory Reference Manual Release 14. Stata Press.

Steinberg, L. and Monahan, K. C. (2007). Age Differences in Resistance to Peer Influence. Developmental Psychology, 43: 1531-1543.

Tangney, J. P., Baumeister, R. F., and Boone, A. L. (2004). High Self-Control Predicts Good Adjustment, Less Pathology, Better Grades, and Interpersonal Success. Journal of Personality, 72(2): 271-322.

Thaler, R., and Benartzi, S. (2004). Save More Tomorrow ${ }^{\mathrm{TM}}$ : Using Behavioral Economics to Increase Employee Saving. Journal of Political Economy, 112(S1): S164-S187.

Thaler, R. H., and Shefrin, H. M. (1981). An Economic Theory of Self-Control. Journal of Political Economy, 89(2): 392-406.

Thaler, R. H., and Sunstein, C. R. (2003). Libertarian Paternalism. American Economic Review, 93(2): 175-179.

Thompson, D. V., Hamilton, R. W., and Rust, R. T. (2005). Feature fatigue: When product capabilities become too much of a good thing. Journal of marketing research, 42(4): 431-442.

Tversky, A., and Kahneman, D. (1974). Judgment under Uncertainty: Heuristics and Biases. Science, 185(4157): 1124-1131. 
Tversky, A., and Kahneman, D. (1981). The Framing of Decisions and the Psychology of Choice. Science, 211(4481): 453-458.

Valette-Florence, P., Guizani, H., and Merunka, D. (2011). The Impact of Brand Personality and Sales Promotions on Brand Equity. Journal of Business Research, 64(1): 24-28.

Vanden Abeele, P., 1988. Economic Agents' Expectations in a Psychological Perspective. In:

W.F. van Raaij, G.M. van Veldoven and K.-E. Warneryd (eds.), Handbook of Economic Psychology. Dordrecht: Kluwer. pp. 478-515.

Van Rooij, M., A. Lusardi, Alessie, R. (2011). Financial Literacy and Stock Market Participation. Journal of Financial Economics, 101(2): 449-472.

Van Rooij, M., and Teppa, F. (2014). Personal Traits and Individual Choices: Taking Action in Economic and Non-Economic Decisions. Journal of Economic Behavior and Organization, 100: $33-43$.

Vohs, K. D., Baumeister, R. F., and Schmeichel, B. J. (2012). Motivation, Personal Beliefs, and Limited Resources all Contribute to Self-Control. Journal of Experimental Social Psychology, 48(4): 943-947.

Vohs, K. D., Baumeister, R. F., Schmeichel, B. J., Twenge, J. M., Nelson, N. M., and Tice, D. M. (2008). Making choices impairs subsequent self-control: a limited-resource account of decision making, self-regulation, and active initiative. Journal of Personality and Social Psychology, 94(5): 883-898.

Wärneryd, K.-E. (1999). The Role of Macroeconomic Psychology. Applied Psychology, 48(3): 273-296.

Watson, J. J. (2003). The Relationship of Materialism to Spending Tendencies, Saving, and Debt. Journal of Economic Psychology, 24(6): 723-739.

Wedel, M. and Kamakura, W. (2000). Market Segmentation: Conceptual and Methodological Foundations. London: Kluwer, 2nd edition. 
Wong-Parodi, G., Bruine de Bruin, W. and Canfield, C. (2013). Effects of simplifying outreach materials for energy conservation programs that target low-income consumers. Energy Policy. 62: $1157-1164$.

Xiao, J. J., and Fan, J. X. (2002). A Comparison of Saving Motives of Urban Chinese and American Workers. Family and Consumer Sciences Research Journal, 30(4): 463-495.

Xiao, J. J., and Noring, F. E. (1994). Perceived Saving Motives and Hierarchical Financial Needs. Financial Counseling and Planning, 5(1): 25-44.

Yogo, M. (2016). Portfolio Choice in Retirement: Health Risk and the Demand for Annuities, Housing, and Risky Assets. Journal of Monetary Economics, 80: 17-34.

Zhou, R., and Pham, M. T. (2004). Promotion and Prevention across Mental Accounts: When Financial Products Dictate Consumers' Investment Goals. Journal of Consumer Research, 31(1): 125-135. 

Appendix 
Appendix Table A2.1 Classification of saving motives as promotion and prevention

\begin{tabular}{|c|c|c|c|c|c|}
\hline & $\begin{array}{l}\text { Promotional } \\
\text { (aiming to gain } \\
\text { positive) } \\
\text { (1) }\end{array}$ & $\begin{array}{c}\text { Neither } \\
\text { (2) }\end{array}$ & $\begin{array}{c}\text { Prevention } \\
\text { (aiming to avoid } \\
\text { negative) } \\
\text { (3) }\end{array}$ & (4) & $\begin{array}{c}\text { p-value (one- } \\
\text { sample z-test) } \\
\text { (5) }\end{array}$ \\
\hline For unexpected expenditures (a rainy day) & 13 & 9 & 75 & 97 & $0.000 * * *$ \\
\hline To pay for bills (e.g., gas, electricity, etc) & 20 & 19 & 58 & 97 & $0.000 * * *$ \\
\hline For a deposit to buy a property & 87 & 8 & 1 & 96 & $0.000 * * *$ \\
\hline For a planned purchase in the future (e.g., car, fridge, etc) & 83 & 7 & 7 & 97 & $0.000 * * *$ \\
\hline $\begin{array}{l}\text { For planned maintenance costs in the future (e.g., car repairs, } \\
\text { home renovation, etc) }\end{array}$ & 16 & 10 & 71 & 97 & $0.000 * * *$ \\
\hline For holidays or other leisure expenditures & 88 & 7 & 2 & 97 & $0.000 * * *$ \\
\hline $\begin{array}{l}\text { To provide income in retirement (please note we are not } \\
\text { referring to pension saving) }\end{array}$ & 59 & 9 & 29 & 97 & $0.001 * * *$ \\
\hline Because it's a good investment in the long-term & 68 & 20 & 9 & 97 & $0.000 * * *$ \\
\hline $\begin{array}{l}\text { Because of a recent/upcoming event (e.g., marriage, birth of } \\
\text { a child) }\end{array}$ & 64 & 12 & 21 & 97 & $0.000 * * *$ \\
\hline For a family-member's future (e.g., a child trust fund) & 69 & 12 & 16 & 97 & $0.000 * * *$ \\
\hline In order to repay a loan & 27 & 16 & 54 & 97 & $0.002 * * *$ \\
\hline
\end{tabular}

Note: This table provides an overview of all saving motives and how they belong to the self-regulation systems promotion and prevention. Ninety-seven individuals recruited on Amazon's Mechanical Turk classified 11 possible saving motives according to their fit to either promotion, prevention, or neither of those categories. The first column displays the saving motive as stated in the survey. The following three columns ((1)-(3)) summarize the amount of times a certain saving motive was classified as belonging to a certain category. $\mathrm{N}$ is is the total number of respondents who classified the saving motives. Column (5) contains information about the p-value of a one-sample z-test to indicate statistically significant differences between columns (1) and (3). '***' indicates significance at the 1\%-level. Bold numbers display how a given saving motive is ultimately categorized for usage in our analyses. 


\section{Appendix A2.2 FIMIX-PLS pseudocode}

Below are the pseudocode and screenshots of the FIMIX-PLS procedure that was followed in this paper.

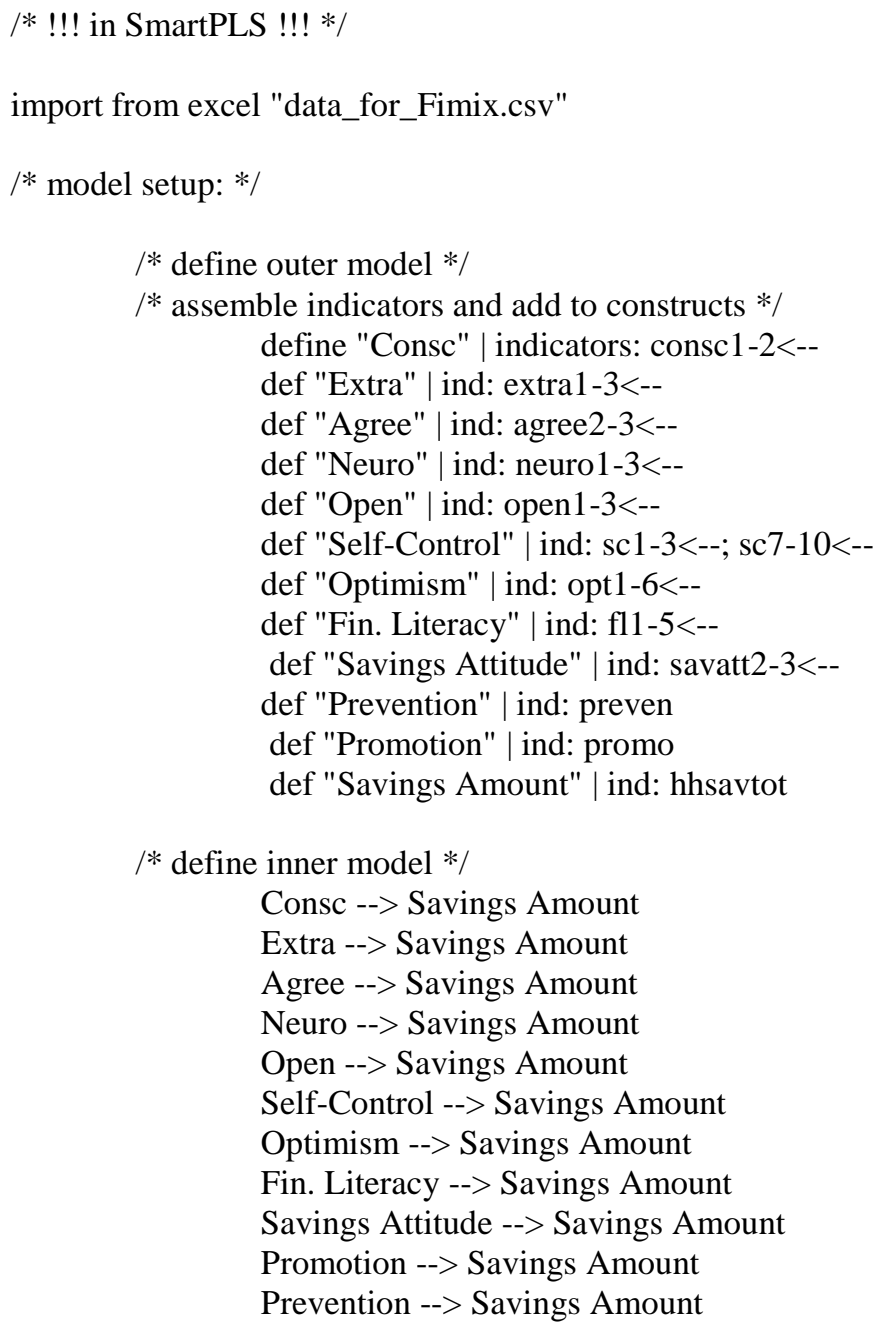

/* Fimix procedure */

$/ *$ determine number of segments */

loop over values $\mathrm{q}=2-7$ \{

Calculate Fimix segmentation (' q's'segments; 10000 Max iterations;

10 stop criterion; 10 repetitions)

export to excel "smartpls_output.xlsx": Segment Assignment; R Square; Fit Indices;

Path Coefficients | append

loop over values $\mathrm{p}=1-2$ \{

import from excel "data_segment_'p'.csv"

Calculate PLS Algorithm

export to excel "smartpls_output.xlsx": Path Coefficients | append

Calculate Bootstrapping

export to excel "smartpls_output.xlsx": Path Coefficients | append

\} 


\section{Appendix Figure A2.2.1 Model in SmartPLS}

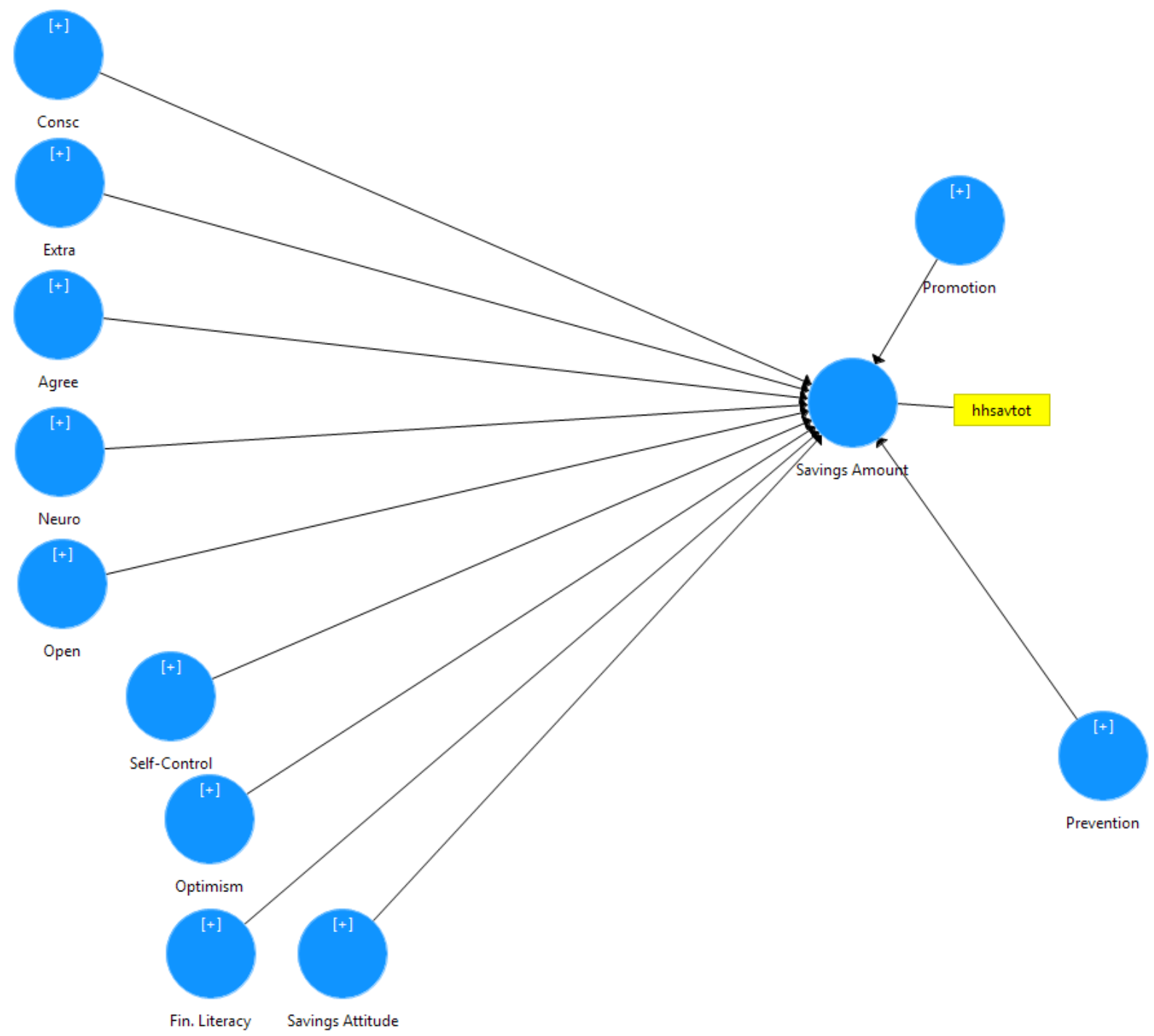

Note: In the terminology of Ringle et al. (2010), this figure represents the "inner model". The PLS path analysis predominantly focuses on estimating and analyzing the relationships between the latent variables in the inner model (Ringle et al., 2010). Indicators of latent constructs (i.e., specific survey questions), which represent the "outer model", are not shown in this figure. 


\section{Appendix Figure A2.2.2 FIMIX-options in SmartPLS}

Finite Mixture (FIMIX) Segmentation

Finite mixture partial least squares (FIMIX-PLS) segmentation is a method to uncover unobserved heterogeneity in the inner (structural) model. It captures heterogeneity by estimating the probabilities of segment memberships for each observation and simultaneously estimates the path coefficients for all segments.

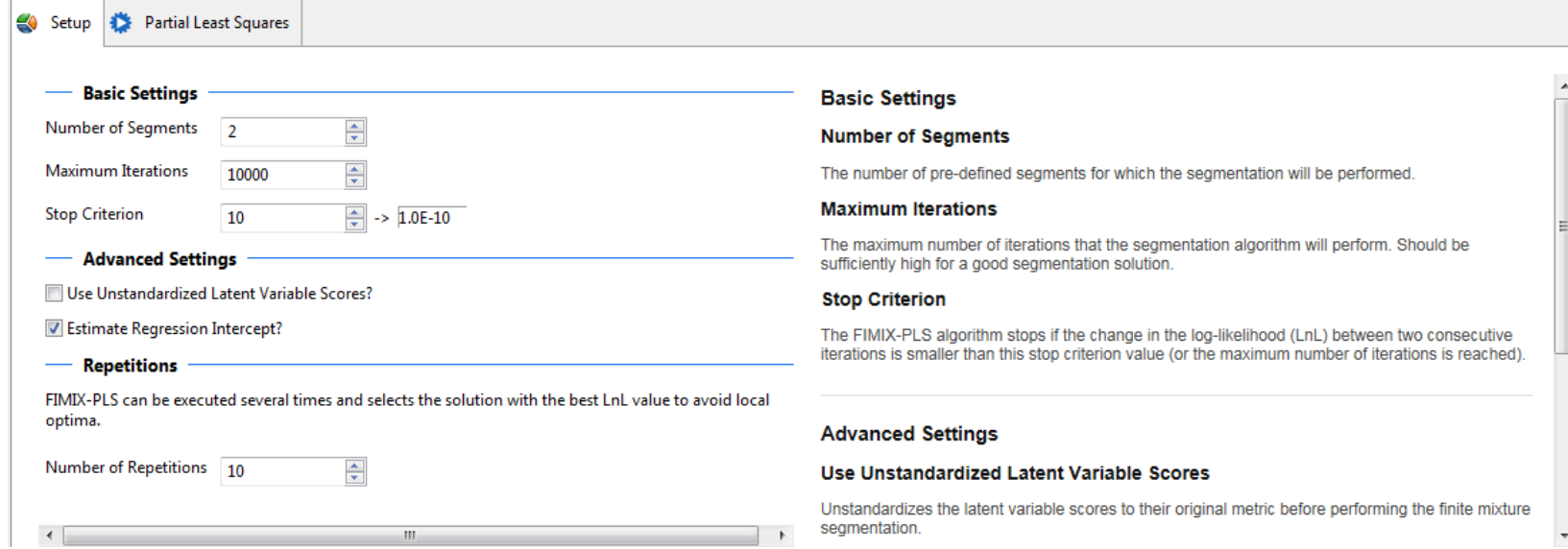




\section{Appendix Figure A2.2.3 SmartPLS algorithm options}

\section{Partial Least Squares Algorithm}

The PLS path modeling method was developed by Wold (1982). In essence, the PLS algorithm is a sequence of regressions in terms of weight vectors. The weight vectors obtained at convergence satisfy fixed point equations (see Dijkstra, 2010, for a general analysis of these equations).

— Setup ii Weighting
— Basic Settings
Weighting Scheme $\bigcirc$ Centroid $\bigcirc$ Factor $\odot$ Path
Maximum Iterations:
Stop Criterion $\left(10^{\wedge}-\mathrm{X}\right): 7$
- Advanced Settings

Initial Weights $\square$ Use Lohmoeller Settings

or configure individual initial weights

Basic Settings

Weighting Scheme

PLS-SEM allows the user to apply three structural model weighting schemes:

(1) centroid weighting scheme,

(3) path weighting scheme (default).

While the results differ little for the alternative weighting schemes, path weighting is the recommended approach. This weighting scheme provides the highest $\mathrm{R}^{2}$ value for endogenous latent variables and is generally applicable for all kinds of PLS path model specifications and estimations. Moreover, when the path model includes higher-order constructs (often called secondorder models), researchers should usually not use the centroid weighting scheme.

Maximum Iterations

This parameter represents the maximum number of iterations that will be used for calculating the PLS results. This number should be sufficiently large (e.g., 300 iterations). When checking the PLSSEM result, one must make sure that the algorithm did not stop because the maximum number of iterations was reached but due to the stop criterion. Note: The selection of 0 for the maximum number of iterations allows you to obtain results of the sum scores approach. 


\section{Appendix Figure A2.2.4 Bootstrapping options in SmartPLS}

Bootstrapping

Bootstrapping is a nonparametric procedure that allows testing the statistical significance of various PLS-SEM results such path coefficients, Cronbach's alpha, HTMT, and $\mathrm{R}^{2}$ values.

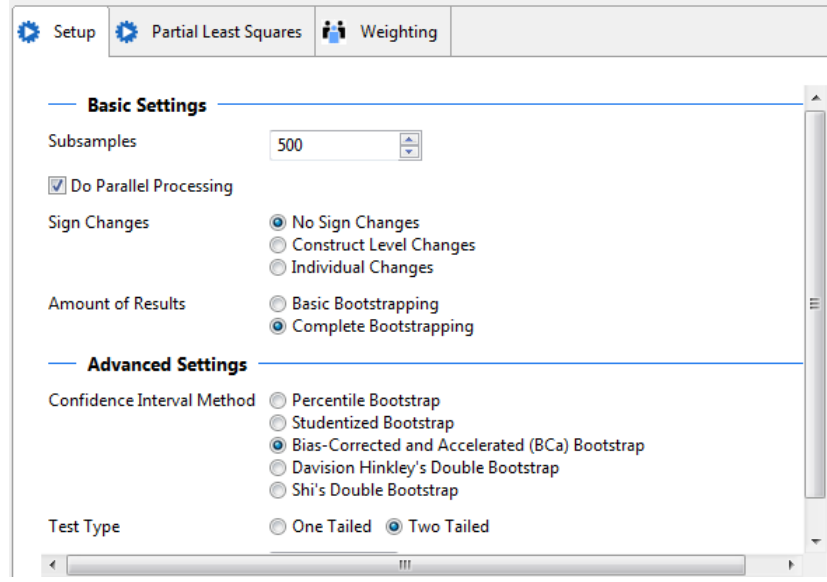

Basic Settings
Subsamples
In bootstrapping, subsamples are created with observations randomly drawn (with replacement)
from the original set of data. To ensure stability of results, the number of subsamples should be
large. For an initial assessment, one may use a smaller number of bootstrap subsamples (e.g.,
500 ). For the final results preparation, however, one should use a large number of bootstrap
subsamples (e.g., 5,000 ).
Note: Larger numbers of bootstrap subsamples increase the computation time.
Do Parallel Processing
This option runs the bootstrapping routine on multiple processors (if your computer device offers
more than one core). Using parallel computing will reduce computation time.
Sign Changes
Sets the method for dealing with sign changes during the bootstrap iterations. The following options
are available:
(1) No Sign Changes (default)
Sign changes in the resamples will be ignored and the results are taken as they are.
This is the most conservative estimation option and the recommended choice when
running the bootstrapping routine. 


\section{Appendix A2.3 Probabilities of segment membership}

The graph below shows the distribution of segment membership probabilities. We reached a twosegment solution and employ an $85 \%$ probability cutoff level for individuals to be classified as belonging to a particular segment. This is a very conservative cutoff level and considerably higher than the $50 \%$ cutoff level as used by Matthews et al. (2016). Figure A3.1 indicates that the great majority of households can be unambiguously classified as belonging to one of the two segments. In particular, $95.54 \%$ of the 3,382 households exceed the $85 \%$ probability threshold, leaving a final sample of 3,231 households for analysis.

Appendix Figure A2.3.1 Total household savings - segment membership probabilities

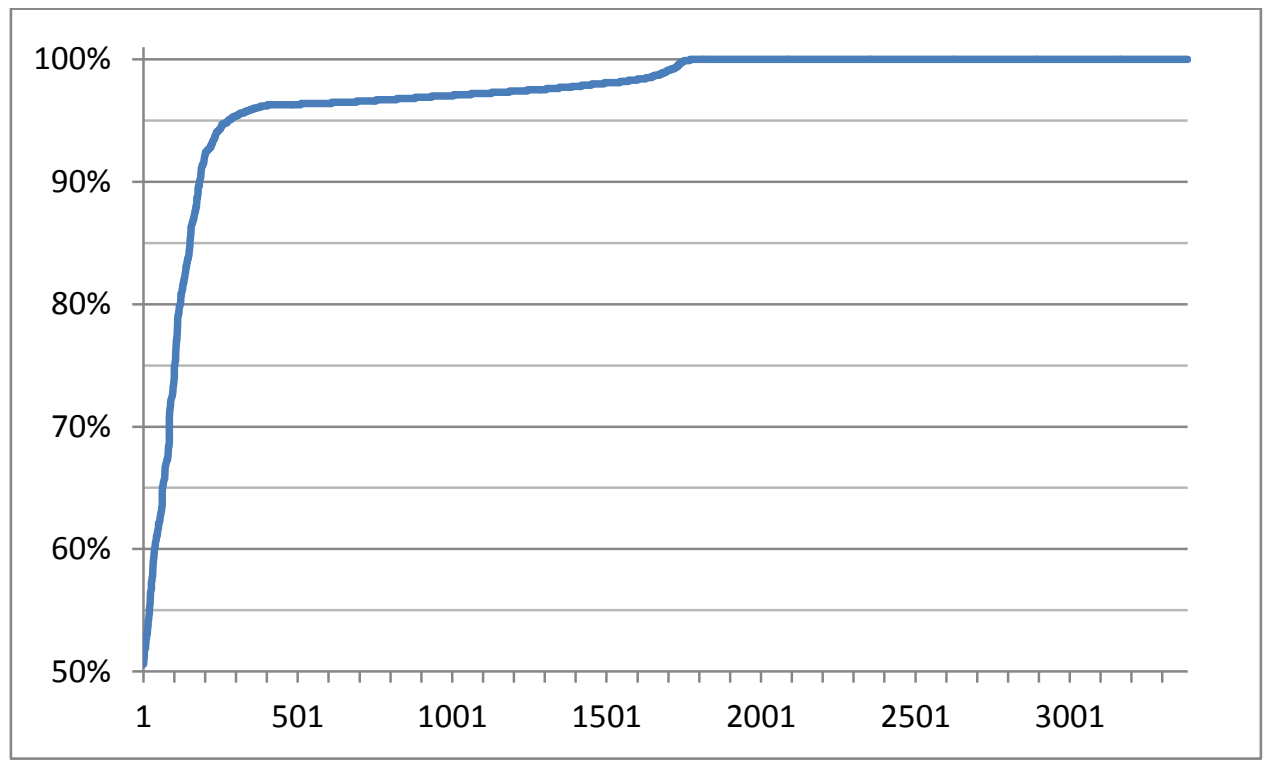

Note: This figure presents the highest segment membership probabilities for each of all the 3,382 households in our total sample. The graph is based on the two-segment solution for total household savings based on FIMIX-PLS results. 


\section{Appendix A4.1 Factor Analysis of the Reverse Mortgage Knowledge Index}

The reverse mortgage knowledge score as used for our analyses is a composite score which has the advantage of being intuitively interpretable as the final knowledge score for each individual ranges between 0 and 13. Hence, when using the score in regression analyses, any changes can be immediately attributed to changes in this score. However, the way the composite score is created has a drawback: correctly answered questions increase the score by one, whereas incorrectly answered questions and "don't know" answers both translate into zero points for a particular question.

Don't know answers can be taken explicitly take into account, as they might indicate a good selfperception of survey respondents. Furthermore, there is substantial variation amongst knowledge items regarding the percentage of respondents answering questions with "don't know". The percentage of "don't know" answers varies from as low as $11 \%$ for rmk1 to almost $65 \%$ for rmk11 (see Table 4.2 for details). A way to explicitly take into account "don't know" responses is to obtain Bartlett factor scores and to use them as weights to construct a reverse mortgage literacy index, similarly to the procedure used by van Rooij et al. (2011) in an analysis of stock market literacy.

We create one dummy variables to indicate for each item whether a respondent answered a knowledge question correct (1) or incorrect (0) and a second dummy variable indicating if a response was "don't know" (1) or not (0). Exceptions are items rmk6 and rmk13, which due to the nature of those questions did not contain "don't know" answers as possible choices. Excluding those two items, factor analysis using iterated principal factoring allows to extract a single factor for reverse mortgage knowledge. As all items used to identify knowledge are tailored towards reverse mortgage knowledge, theoretical reasoning suggests a single factor to be extracted. Inspection of the corresponding Scree plot shows a large kink after factor 1, also pointing towards a single factor to be extracted. Furthermore, the first factor explains $74.5 \%$ of variance in the individual responses, which also supports the notion of a single factor. Factor loadings for this single-factor solution are presented in Table 4.6. 
Appendix Table A4.6 Factor Loadings of the Reverse Mortgage Knowledge Index

\begin{tabular}{|c|c|c|c|}
\hline Variable & Survey Question & & Factor Loadings \\
\hline \multirow[t]{2}{*}{ rmk1 } & \multirow[t]{2}{*}{ A reverse mortgage allows you to withdraw wealth invested in your home. } & Correct & 0.4317 \\
\hline & & Don't know & -0.5209 \\
\hline \multirow[t]{2}{*}{ rmk2 } & \multirow[t]{2}{*}{ A reverse mortgage helps you be debt-free if used to repay an existing mortgage. } & Correct & 0.5476 \\
\hline & & Don't know & -0.5438 \\
\hline \multirow[t]{2}{*}{ rmk3 } & \multirow[t]{2}{*}{ For getting a reverse mortgage, your credit history and income will be checked. } & Correct & 0.2886 \\
\hline & & Don't know & -0.3034 \\
\hline \multirow[t]{2}{*}{ rmk4 } & \multirow[t]{2}{*}{ Over time, the loan balance of a reverse mortgage... [shrinks/stays constant/grows] } & Correct & 0.3262 \\
\hline & & Don't know & -0.5331 \\
\hline \multirow[t]{2}{*}{ rmk5 } & \multirow{2}{*}{$\begin{array}{l}\text { Even when the reverse mortgage loan balance becomes larger than the home value, you } \\
\text { do not have to move out. }\end{array}$} & Correct & 0.5396 \\
\hline & & Don't know & -0.6196 \\
\hline \multirow[t]{2}{*}{ rmk7 } & \multirow{2}{*}{$\begin{array}{l}\text { When do you have to make interest payments on a reverse mortgage? [every } \\
\text { month/once a year/when the loan is paid back/never] }\end{array}$} & Correct & 0.5507 \\
\hline & & Don't know & -0.6357 \\
\hline \multirow[t]{2}{*}{$\mathrm{rmk} 8$} & \multirow{2}{*}{$\begin{array}{l}\text { If the reverse mortgage loan balance is larger than the house value, the lender can force } \\
\text { you to pay the loan off with other assets. }\end{array}$} & Correct & 0.5950 \\
\hline & & Don't know & -0.6834 \\
\hline \multirow[t]{2}{*}{ rmk9 } & \multirow{2}{*}{$\begin{array}{l}\text { If you are unable to make your interest pay-ments on the reverse mortgage loan, a } \\
\text { foreclosure process can be started on your home. }\end{array}$} & Correct & 0.6033 \\
\hline & & Don't know & -0.6495 \\
\hline \multirow[t]{2}{*}{ rmk10 } & \multirow{2}{*}{$\begin{array}{l}\text { When interest rates are higher, one gets less money when taking out a reverse } \\
\text { mortgage. }\end{array}$} & Correct & 0.3518 \\
\hline & & Don't know & -0.5935 \\
\hline \multirow[t]{2}{*}{ rmk11 } & \multirow{2}{*}{$\begin{array}{l}\text { What percentage of home value are the likely costs for getting a reverse mortgage? } \\
{[0.5 \% / 1 \% / 3 \% / \ldots / 15 \%]}\end{array}$} & Correct & 0.3923 \\
\hline & & Don't know & -0.3307 \\
\hline \multirow[t]{2}{*}{ rmk12 } & \multirow{2}{*}{$\begin{array}{l}\text { If you have a reverse mortgage, for which items do you still have to pay yourself? } \\
\text { [property taxes/homeowner insurance/repair and maintenance/none of these/don't } \\
\text { know] }\end{array}$} & Correct & 0.3999 \\
\hline & & Don't know & -0.4719 \\
\hline
\end{tabular}

This table presents factor loadings for 22 items based on 11 questions to assess reverse mortgage knowledge. Factor loadings are obtained using iterated principle factoring.

The resulting Bartlett factor scores are used as weights in an alternative reverse mortgage knowledge index. To analyze robustness of the reverse mortgage knowledge results (as summarized in Table 4.4), we use the Bartlett factor score-based index to replicate the same model specifications explaining reverse mortgage knowledge. Results are presented in Table 4.7, models 1 and 2. A comparison between Table 4.4 and Table 4.7 highlights the robustness of the knowledge questions and their determinants. In both model specifications, all coefficient signs are the same for the composite knowledge score and the factor-based index. Overall, results are robust and leave the interpretation unchanged, no matter which way the reverse mortgage knowledge items are aggregated and weighted. The same holds when including the factorweighted index in the intention to use a reverse mortgage regressions. Thus, both the composite score with its easy interpretation and the more elaborate index using factor weights allow for the same conclusion. 
Appendix Table A4.7 Explaining Reverse Mortgage Product Knowledge using a Factor Weighted Index and IRT scores

\begin{tabular}{|c|c|c|c|c|}
\hline & $\begin{array}{c}\text { Knowledge index } \\
\text { (1) }\end{array}$ & $\begin{array}{c}\text { Knowledge index } \\
(2)\end{array}$ & $\begin{array}{c}\text { IRT score } \\
\text { (3) }\end{array}$ & $\begin{array}{c}\text { IRT score } \\
(4)\end{array}$ \\
\hline Age & $\begin{array}{c}0.017 * * \\
(0.008)\end{array}$ & $\begin{array}{c}0.010 \\
(0.009)\end{array}$ & $\begin{array}{c}0.002 * * \\
(0.001)\end{array}$ & $\begin{array}{c}0.001 \\
(0.001)\end{array}$ \\
\hline Retirement & $\begin{array}{l}-0.050 \\
(0.098)\end{array}$ & $\begin{array}{l}-0.054 \\
(0.102)\end{array}$ & $\begin{array}{c}0.005 \\
(0.009)\end{array}$ & $\begin{array}{c}0.001 \\
(0.010)\end{array}$ \\
\hline Gender & $\begin{array}{c}0.302 * * * \\
(0.087)\end{array}$ & $\begin{array}{c}0.240 * * * \\
(0.090)\end{array}$ & $\begin{array}{c}0.018 * * \\
(0.008)\end{array}$ & $\begin{array}{c}0.014 \\
(0.009)\end{array}$ \\
\hline Higher Education & $\begin{array}{c}0.019 \\
(0.100)\end{array}$ & $\begin{array}{c}0.016 \\
(0.101)\end{array}$ & $\begin{array}{c}0.008 \\
(0.010)\end{array}$ & $\begin{array}{c}0.008 \\
(0.010)\end{array}$ \\
\hline White & $\begin{array}{l}0.371 * * \\
(0.165)\end{array}$ & $\begin{array}{c}0.345^{* *} * \\
(0.163)\end{array}$ & $\begin{array}{c}0.047 * * * \\
(0.015)\end{array}$ & $\begin{array}{c}0.044 * * * \\
(0.015)\end{array}$ \\
\hline Marital status & $\begin{array}{c}0.030 \\
(0.108)\end{array}$ & $\begin{array}{l}-0.008 \\
(0.107)\end{array}$ & $\begin{array}{c}0.005 \\
(0.010)\end{array}$ & $\begin{array}{c}0.002 \\
(0.010)\end{array}$ \\
\hline Children & $\begin{array}{c}0.083 \\
(0.106)\end{array}$ & $\begin{array}{c}0.128 \\
(0.110)\end{array}$ & $\begin{array}{c}0.006 \\
(0.010)\end{array}$ & $\begin{array}{c}0.010 \\
(0.011)\end{array}$ \\
\hline Ln(household income) & $\begin{array}{l}-0.038 \\
(0.090)\end{array}$ & $\begin{array}{c}0.040 \\
(0.093)\end{array}$ & $\begin{array}{l}-0.004 \\
(0.009)\end{array}$ & $\begin{array}{c}0.001 \\
(0.009)\end{array}$ \\
\hline Ln(household savings) & $\begin{array}{c}0.045 \\
(0.033)\end{array}$ & $\begin{array}{c}0.037 \\
(0.035)\end{array}$ & $\begin{array}{c}0.003 \\
(0.003)\end{array}$ & $\begin{array}{c}0.002 \\
(0.003)\end{array}$ \\
\hline Ln(homevalue) & $\begin{array}{c}0.047 \\
(0.079)\end{array}$ & $\begin{array}{l}-0.003 \\
(0.081)\end{array}$ & $\begin{array}{c}0.002 \\
(0.008)\end{array}$ & $\begin{array}{l}-0.001 \\
(0.008)\end{array}$ \\
\hline Financial literacy & $\begin{array}{c}0.296 * * * \\
(0.067)\end{array}$ & $\begin{array}{c}0.260 * * * \\
(0.068)\end{array}$ & $\begin{array}{c}0.035 * * * \\
(0.006)\end{array}$ & $\begin{array}{c}0.033 * * * \\
(0.006)\end{array}$ \\
\hline Planning skill & $\begin{array}{c}0.121 * * * \\
(0.033)\end{array}$ & $\begin{array}{c}0.107 * * * \\
(0.034)\end{array}$ & $\begin{array}{c}0.011 * * * \\
(0.003)\end{array}$ & $\begin{array}{c}0.010 * * * \\
(0.003)\end{array}$ \\
\hline Conv. mortgage & $\begin{array}{c}0.013 \\
(0.091)\end{array}$ & $\begin{array}{c}0.062 \\
(0.094)\end{array}$ & $\begin{array}{c}0.004 \\
(0.009)\end{array}$ & $\begin{array}{c}0.007 \\
(0.009)\end{array}$ \\
\hline RM experience & $\begin{array}{c}0.867 * * * \\
(0.323)\end{array}$ & $\begin{array}{c}0.851 * * * \\
(0.320)\end{array}$ & $\begin{array}{c}0.072 * * \\
(0.031)\end{array}$ & $\begin{array}{c}0.075 * * \\
(0.031)\end{array}$ \\
\hline Others known w. RM & $\begin{array}{c}0.269 * * \\
(0.110)\end{array}$ & $\begin{array}{c}0.271 * * \\
(0.110)\end{array}$ & $\begin{array}{c}0.025 * * \\
(0.011)\end{array}$ & $\begin{array}{c}0.025 * * \\
(0.011)\end{array}$ \\
\hline HECM penetration & $\begin{array}{c}2.016 \\
(2.052)\end{array}$ & $\begin{array}{c}1.775 \\
(2.073)\end{array}$ & $\begin{array}{c}0.132 \\
(0.196)\end{array}$ & $\begin{array}{c}0.115 \\
(0.199)\end{array}$ \\
\hline Stay home $7+$ & & $\begin{array}{c}-0.039 \\
(0.097)\end{array}$ & & $\begin{array}{c}0.001 \\
(0.009)\end{array}$ \\
\hline Subj. life expectancy & & $\begin{array}{l}-0.275 \\
(0.194)\end{array}$ & & $\begin{array}{c}-0.038 * * \\
(0.019)\end{array}$ \\
\hline Health & & $\begin{array}{c}-0.007 \\
(0.051)\end{array}$ & & $\begin{array}{l}-0.002 \\
(0.005)\end{array}$ \\
\hline Health insurance & & $\begin{array}{c}-0.192 * \\
(0.113)\end{array}$ & & $\begin{array}{c}-0.019 * \\
(0.011)\end{array}$ \\
\hline Long-term care insurance & & $\begin{array}{c}-0.239 * * \\
(0.096)\end{array}$ & & $\begin{array}{c}-0.029 * * * \\
(0.009)\end{array}$ \\
\hline
\end{tabular}


Appendix Table A4.7 Explaining Reverse Mortgage Product Knowledge using a Factor Weighted Index and IRT scores - continued

\begin{tabular}{|c|c|c|c|c|}
\hline & & $(0.096)$ & & $(0.009)$ \\
\hline \multirow[t]{2}{*}{ Sufficient savings } & & 0.035 & & 0.002 \\
\hline & & $(0.031)$ & & $(0.003)$ \\
\hline \multirow[t]{2}{*}{ Sufficient pension } & & -0.009 & & 0.003 \\
\hline & & $(0.029)$ & & $(0.003)$ \\
\hline \multirow[t]{2}{*}{ Broker trust } & & $-0.081 * * *$ & & $-0.008 * * *$ \\
\hline & & $(0.029)$ & & $(0.003)$ \\
\hline \multirow[t]{2}{*}{ Bequest motive } & & -0.002 & & 0.000 \\
\hline & & $(0.023)$ & & $(0.002)$ \\
\hline \multirow[t]{2}{*}{ Risk aversion } & & $-0.059 * * *$ & & $-0.004 *$ \\
\hline & & $(0.021)$ & & $(0.002)$ \\
\hline \multirow[t]{2}{*}{ Debt aversion } & & 0.018 & & 0.001 \\
\hline & & $(0.024)$ & & $(0.002)$ \\
\hline \multirow[t]{2}{*}{ Past home value growth } & & 0.023 & & 0.004 \\
\hline & & $(0.044)$ & & $(0.004)$ \\
\hline \multirow[t]{2}{*}{ Expected home value growth } & & -0.094 & & -0.007 \\
\hline & & $(0.072)$ & & $(0.007)$ \\
\hline \multirow[t]{2}{*}{ Home attachment } & & $0.008 * *$ & & 0.000 \\
\hline & & $(0.003)$ & & $(0.000)$ \\
\hline \multirow[t]{2}{*}{ House price fluctuations } & & 0.022 & & 0.001 \\
\hline & & $(0.031)$ & & $(0.003)$ \\
\hline \multirow[t]{2}{*}{ Complex } & & $-0.063^{* *}$ & & -0.003 \\
\hline & & $(0.026)$ & & $(0.003)$ \\
\hline \multirow[t]{2}{*}{ Constant } & $-3.308 * * *$ & $-2.181^{*}$ & $0.522 * * *$ & $0.619 * * *$ \\
\hline & (1.025) & $(1.180)$ & $(0.097)$ & $(0.113)$ \\
\hline Observations & 557 & 557 & 557 & 557 \\
\hline Adj. $R^{2}$ & 0.201 & 0.255 & 0.205 & 0.251 \\
\hline
\end{tabular}

Note: This table presents the results from OLS regressions of the reverse mortgage product knowledge index on respondent characteristics. Knowledge index is constructed using Bartlett factor scores as weights for the 22 individual items (models 1 and 2) or IRT scores for the 13 questions (models 3 and 4). Variables are defined in Table 4.1. Standard errors are given in parentheses. *, **, and *** denote statistical significance at the $10 \%, 5 \%$, and $1 \%$ levels, respectively.Even though it might be possible to question the validity of the single factor solution of the factor analysis, due to low factor loadings of some items, results are robust. A stepwise exclusion of those rather low-loading items, which are rmk3, rmk4, rmk11, and rmk12 and obtaining Bartlett scores for each of the remaining 14 items still leaves the emerging pattern unchanged in terms of coefficient signs and variable significance. ${ }^{24}$ Hence, items with loadings which might be considered too low for inclusion are not confounding the results.

${ }^{24}$ detailed results available upon request 


\section{Appendix A4.2 Modelling Reverse Mortgage Knowledge using Item Response Theory}

A potential drawback of the composite knowledge index is that it weights each item equally. Hence, it does not account for the differences in difficulty between individual items. Questions related to certain aspects of reverse mortgages might be answered by a larger fraction of respondents correctly if it is a generally easier question. To approach the potential concern of varying difficulty between questions, we apply item response theory (IRT) in order to explicitly model the probability to answer a knowledge question correctly. IRT methods are commonly used in developing tests and exams (for an overview of IRT methods see, e.g., StataCorp, 2015). The resulting item characteristic curves (ICC) are given in Figure 4.2.

\section{Appendix Figure A4.2 Item Characteristic Curves for Reverse Mortgage Knowledge Questions}

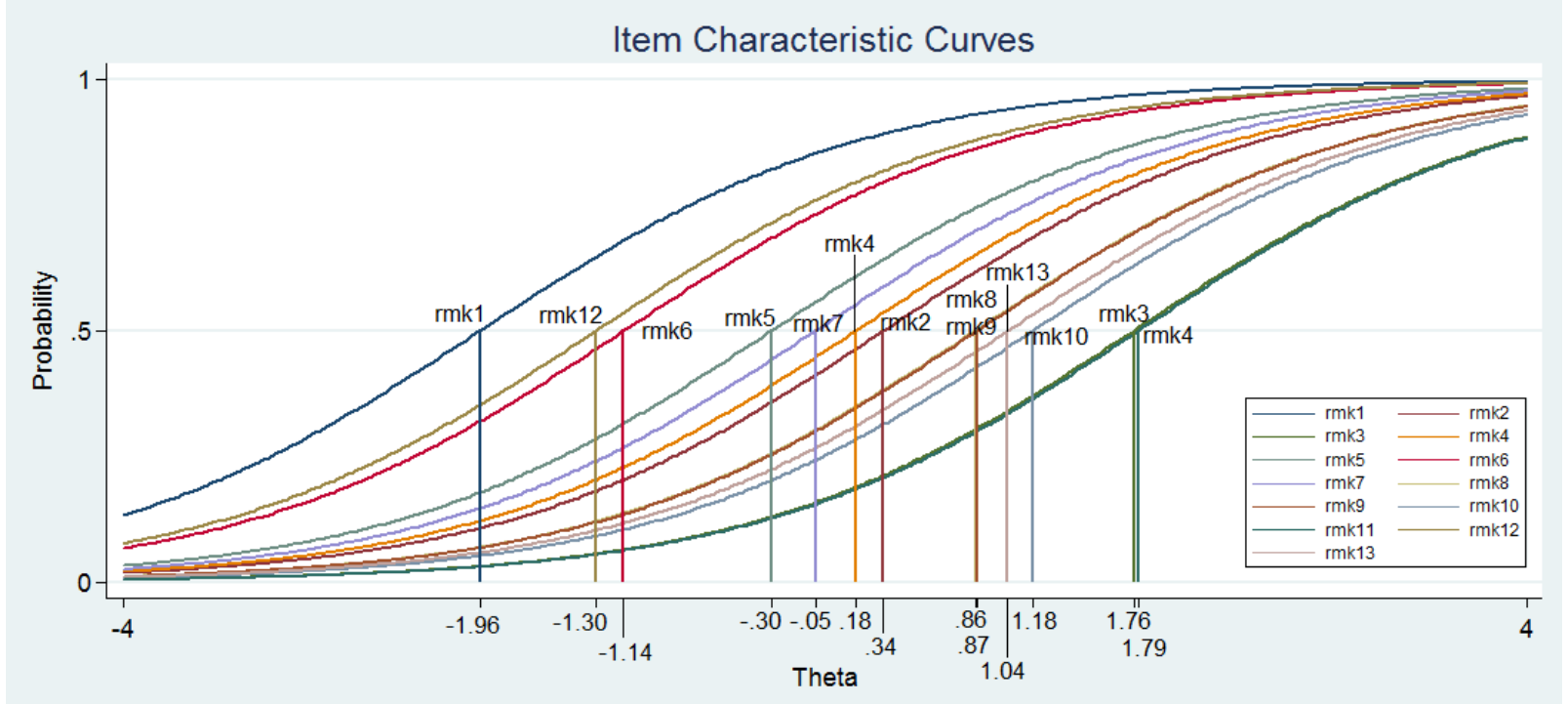

Note: This figure shows item characteristic curves for the 13 questions assessing reverse mortgage knowledge. The curves show the probability to correctly answer any of the 13 questions. Theta expresses the level of skill necessary to answer a question correctly. Difficulty of questions increases with Theta. The question content is given in Table 4.2 .

Figure 4.2 shows the chance that a respondent with a given knowledge level of Theta answers a question correctly. Difficulty increases with Theta, which means that survey items with curves located more towards the right are more difficult to answer than those more to the left. Based on Figure 4.2, questions rmk1, rmk6, and rmk12 are the easiest and require low general knowledge to be answered correctly, whereas questions rmk3 and rmk4 are the most difficult in our array of questions. The wide spread in question difficulty provides the rationale for applying IRT to 
account for heterogeneity in question difficulty. Instead of our composite reverse mortgage knowledge index, we next use the predicted IRT scores as variable indicating reverse mortgage knowledge. Regression results are given in Table 4.7, models 3 and 4. Compared with Table 4.4, coefficient signs and significance do not change. Thus, our baseline results are not confounded by heterogeneity in question difficulty. 


\section{Biography}

Patrick Gerhard was born on April 1, 1987, in Stolberg, Germany. He holds a B.Sc. degree in Business Administration from RWTH Aachen University and a M.Sc. degree in International Business with a specialization in Finance from Maastricht University.

After his graduation in 2012, he joined the Department of Finance at Maastricht University's School of Business and Economics as a Ph.D. candidate under the supervision of Piet Eichholtz, Arvid Hoffmann and Thomas Post. He is a Netspar Junior Fellow and member of the Marketing Finance Research Lab. Patrick taught courses on Behavioral Finance, Managing Takeovers, and Shareholder Value and Market-Based Assets. He supervised several students' for their master theses and was the web administrator for the Marketing Finance Research Lab's.

His research interests include individual investor decision making, behavioral finance and economics, and consumer financial decision making. Parts of this dissertation has been presented at various international conferences and invited seminars, such as the American Economic Association Annual Meeting, the Annual Congress of the European Economic Association, Boulder Summer Conference on Consumer Financial Decision Making, WU Gutmann Center Symposium - Retirement and Asset Management, Netspar International Pension Workshops, TIBER Symposium on Psychology and Economics, Conference of the Experimental Finance Association, Netspar Pension Days, SERVSIG International Research Conference, Maastricht Behavioral Experimental Economics Symposium, Federal Reserve Bank of New York, RWTH Aachen University, Adelaide Business School, Queensland University of Technology, University of Western Australia Business School, and has been published in the Journal of Economic Behavior and Organization and in the Journal of Behavioral and Experimental Finance. 